$$
\begin{gathered}
\text { UNIVERSIDADE DE SÃO PAULO } \\
\text { FFCLRP- DEPARTAMENTO DE PSICOLOGIA } \\
\text { PROGRAMA DE PÓS-GRADUAÇÃO EM PSICOLOGIA }
\end{gathered}
$$

Cognição, atenção, temperamento e comportamento em crianças nascidas pré-termo na fase pré-escolar.

Fabíola Dantas Andréz Nobre Arantes de Carvalho

Ribeirão Preto - SP

2015 
Fabíola Dantas Andréz Nobre Arantes de Carvalho

\section{Cognição, atenção, temperamento e comportamento em crianças nascidas pré-termo na fase pré-escolar.}

Tese apresentada à Faculdade de Filosofia, Ciências e Letras de Ribeirão Preto da Universidade de São Paulo, como parte das exigências para obtenção do título de Doutor em Ciências.

Área de Concentração: Psicologia em Saúde e Desenvolvimento

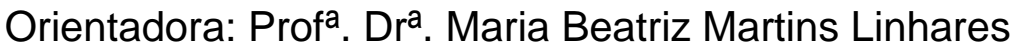

Apoio:

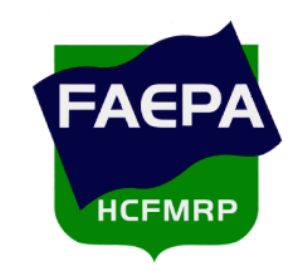

Ribeirão Preto - SP

2015 
Autorizo a reprodução e divulgação total ou parcial deste trabalho, por qualquer meio convencional ou eletrônico, para fins de estudo e pesquisa, desde que citada a fonte.

Nobre, Fabíola Dantas Andréz

Cognição, atenção, temperamento e comportamento em crianças nascidas pré-termo na fase pré-escolar. Ribeirão Preto, 2015.

172 p.: il.; $30 \mathrm{~cm}$

Tese de Doutorado, apresentada à Faculdade Filosofia Ciências e Letras de Ribeirão Preto, USP. Área de Concentração: Psicologia em Saúde e Desenvolvimento.

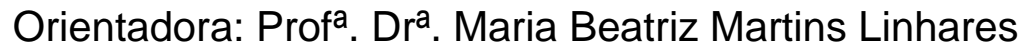

1. Cognição. 2. Atenção. 3. Temperamento. 4. Comportamento.

5. Nascimento pré-termo 
Nome: Nobre, Fabíola Dantas Andréz

Título: Cognição, atenção, temperamento e comportamento em crianças nascidas pré-termo na fase pré-escolar.

Tese apresentada à Faculdade Filosofia, Ciências e Letras de Ribeirão Preto, da Universidade de São Paulo, para obtenção do título de Doutor em Ciências.

Aprovado em

Banca Examinadora

\section{Prof.Dr}

Instiuição Assinatura:

Prof. Dr.

Instituição

Assinatura:

Prof. Dr.

Instituição

Assinatura:

Prof. Dr.

Instituição

Assinatura:

Prof. Dr.

Instituição Assinatura: 


\section{Dedico este trabalho}

Aos meus filhos João Pedro e Isadora que a cada dia me ensinam, me modificam, me fazem ser uma mãe, mulher, profissional melhor. Com vocês aprendi o que é AMAR incondicionalmente, a respeitar os limites de vocês e os meus. Obrigada por me darem força para continuar sempre, em forma de sorrisos e abraços.

Ao meu marido, amigo e companheiro Christian pela compreensão, paciência, incentivo e apoio em todos os momentos. Obrigada por acreditar no meu sonho, e fazer dele o nosso sonho.

Aos meus eternos avos, Pedrinho e Nair (in memorian) que contribuíram imensamente para minha formação, em todos os sentidos da minha existência. A paciência, a tolerância e a persistência são marcas fortes do meu querido avô e a garra, a insistência, a disponibilidade, a força, a fé e a dedicação à família são características fortes da minha avó. Vocês sempre serão meu espelho e meu exemplo, para tudo e em tudo.

Aos meus pais Antônio e Magali, muito obrigada por acreditarem em mim, por me incentivarem na busca do conhecimento, me dando conselhos, me ouvindo nos momentos de conflito e contribuírem para o meu crescimento na vida acadêmica. Acredito que esta vitória também é de vocês.

Aos meus irmãos Yuri e Karina e suas famílias, obrigada por compreenderem e apoiarem as minhas decisões, por me darem força e acreditarem em mim. Sinto a emoção, a força e a torcida que vocês têm pela minha vitória! 


\section{Agradecimento Especial}

\section{À Profa. Dra. Maria Beatriz Martins Linhares,}

Ao longo de toda a minha trajetória, em nenhum momento você me deixou desistir, muito pelo contrário, me incentivou e apoio em todos os momentos. Me amparou, me ensinou, se dedicou a mim e me fez olhar as coisas de uma outra maneira.

A você, só tenho a agradecer!

Obrigada inicialmente por me mostrar o caminho da ciência, por me auxiliar, por acreditar em mim, por me incentivar e por tornar leve os momentos mais estressantes. Nossas conversas durante todo meu processo de aprendizagem foram fundamentais para minha formação e transformação.

Obrigada por dedicar seu tempo e compartilhar seu conhecimento imensurável para minha formação. O seu olhar critico e construtivo me auxiliou a superar os desafios deste trabalho, à você serei eternamente grata. 


\section{AGRADECIMENTO}

Aos que ouviram os meus desabafos; aos que presenciaram e respeitaram o meu silêncio; que compartilharam estes longos anos, de páginas, de livros, artigos; que fizeram meu mundo melhor; que me acompanharam, choraram, riram, sentiram, participaram, aconselharam, dividiram; as suas companhias, os seus sorrisos, as suas palavras e mesmo as ausências foram expressões de carinho. As alegrias de hoje também dedico a vocês, pois seus estímulos e carinhos foram instrumentos para minha vitória.

À Deus, por me amparar, por estar ao meu lado nesta caminhada, dando me forças e me abençoando, com uma família linda e com muitas conquistas.

À querida amiga Cláudia Maria Gaspardo, muito obrigada pela dedicação, compreensão, disponibilidade, paciência e amizade sincera de longa data. Obrigada pelo auxílio nos momentos que mais precisei, por me compreender, respeitar e por me ensinar. Seu conhecimento, suas contribuições são essenciais para minha formação profissional e pessoal.

À "companheira de doutorado" Beatriz Valeri, obrigada por me auxiliar nos momentos mais estressantes, me apoiando, dando-me conforto e segurança de que estamos no caminho certo. Muito obrigada pela parceria e toda colaboração.

Às colaboradas diretas no meu estudo Carolina, Maria Eduarda, Tatiana e Maria Luiza, muito obrigada pela disponibilidade e dedicação nas coletas de dados.

À equipe do LAPREDES, Beatriz, Rafaela, Luciana, Elisa, Doane, Nátali, Martina, Sofia, Francine, Juliana, Rebeca e Renata, muito obrigada pela amizade, paciência, tolerância e dedicação. O companheirismo de vocês me auxiliou na realização desta tese.

Às professoras Sônia Pasian e Flávia Padovani pelas contribuições no Exame Geral de Qualificação. Agradeço pelas ricas sugestões e argumentações. 
Às equipes dos Ambulatórios de prematuros do HCFMRP/USP, obrigada pela imensa colaboração prestada durante a realização de coleta de dados deste estudo, em especial ao Dr. Arthur Lopes por acreditar no trabalho da Psicologia e valoriza-lo. Obrigada pelo conhecimento de cada dia e confiança em meu trabalho.

Às queridas Patrícia, Raquel, Ana Claúdia e Kaynara, colega de trabalho e da vida, obrigada pelo apoio, compreensão e amizade.

Ao Departamento de Puericultura e Pediatria do Hospital das Clínicas de Ribeirão Preto/FMRP-USP, obrigada pelo apoio na realização deste trabalho.

À Fundação de Apoio ao Ensino, Pesquisa e Assistência - FAEPA do HCFMRP/USP, agradeço pelo auxílio financeiro concedido para utilização dos equipamentos na coleta de dados e para participação de evento científico.

À Jaqueline, secretária do Programa de Pós-graduação em Psicologia da FFCLRP/UP, agradeço pela atenção e disponibilidade com que atenderam às minhas solicitações.

Às mães que participaram desta pesquisa, pela confiança ao permitirem a participação de seus filhos neste trabalho e pela colaboração em tornar tudo isso possível.

Aos bebês prematuros, obrigada por me mostrarem o caminho da luz. Vocês são grandes guerreiros, na luta pela vida.

À Nathália, Inês, Elaine, Karina, Carmem e Erika, obrigada pela atenção e auxílio.

Aos meus familiares, amigos e a todas as pessoas que, de alguma forma contribuíram para a realização deste trabalho. Obrigada pelo apoio e orações ao longo desta trajetória, disponibilizando atenção e amizade, meus sinceros agradecimentos. 


\section{RESUMO}

Nobre, F. D. A. (2015). Cognição, atenção, temperamento e comportamento em crianças nascidas pré-termo na fase pré-escolar. Tese (Doutorado). Faculdade Filosofia Ciências e Letras de Ribeirão Preto, Universidade de São Paulo, Ribeirão Preto.

O nascimento pré-termo aumenta o risco para problemas no desenvolvimento. $O$ estudo teve por objetivos: a) examinar as associações entre condições clínicas neonatais e indicadores de cognição, atenção, temperamento e comportamento de crianças nascidas pré-termo; b) comparar esses indicadores em grupos estratificados pelo nível de prematuridade. A amostra foi composta por 50 crianças nascidas pré-termo (idade gestacional média $=31$ semanas [26-35] e com peso ao nascimento médio de $1.190 \mathrm{~g}$ [650-1.500g], de seis anos de idade, participantes de um programa de follow-up em um hospital universitário de nível terciário. As crianças foram avaliadas pela Escala de Inteligência Wechsler para Crianças (WISC-III) e Teste de Atenção por Cancelamento. As mães responderam aos Child Behavior Questionnaire (CBQ), Questionário de Capacidades e Dificuldades (SDQ) e ficha de caracterização. A história clínica foi analisada com base nos prontuários médicos. Foram processadas as análises de regressão linear múltipla e comparação entre grupos ( $t$-Student/Qui-Quadrado); $p \leq 0,05$. Os resultados mostraram que, na avaliação cognitiva pelo WISC-III, a maior parte das crianças apresentou resultados na média ou acima média nos Qls Total $(70 \%)$, Verbal $(76 \%)$ e de Execução $(76 \%)$ e no índice fatorial de Resistência à distração (78\%). No escore total de atenção, $74 \%$ das crianças situaram-se na média ou acima desta. No temperamento, as crianças apresentaram escores moderados entre 4 a 5 , nos três fatores do CBQ (afeto negativo, extroversão e controle com esforço). No comportamento, $56 \%$ das crianças obtiveram classificação normal no total, assim como $96 \%$ em comportamento pró-social e $76 \%$ em relacionamento com colegas. No entanto, houve altas porcentagens de classificações limítrofes/anormais nos sintomas emocionais (64\%), problemas de conduta (56\%) e hiperatividade (50\%). Na comparação entre grupos, às crianças pré-termo extremo/muito pré-termo apresentaram pior desempenho apenas na atenção alternada do que as pré-termo moderado/tardio. $\mathrm{Na}$ análise de predição, foram encontrados os seguintes resultados nos desfechos cognitivos: menor QI-Total foi predito por menor QI-Verbal e escolaridade materna; menor QI Verbal foi predito por menos controle com esforço e atenção e menor escolaridade materna; menor QI-Execução foi predito por menos atenção, menor escolaridade materna e nível socioeconômico. Os problemas de comportamento global foram preditos por mais afeto negativo e extroversão e menor controle com esforço e atenção. A hiperatividade foi predita por mais afeto negativo e menor controle com esforço e atenção. Os problemas de conduta foram preditos por mais afeto negativo, sexo masculino e menor QI-Verbal. Os problemas de relacionamento com os colegas foi predito por mais extroversão, maior escolaridade paterna, menor escolaridade materna e menor QI-Execução. Os sintomas emocionais foram preditos por menor idade gestacional, controle com esforço e nível socioeconômico e mais afeto negativo e extroversão. Apesar da vulnerabilidade das crianças, foram verificados recursos cognitivos e de atenção. Os problemas concentraram-se mais no comportamento, que foi predito por fatores da criança (temperamento, sexo, idade gestacional) e socioeconômicos. 
Palavra-chave: cognição; atenção; temperamento; comportamento; nascimento prétermo 


\begin{abstract}
Nobre, F.D. A. (2015). Cognition, attention, temperament, and behavior in preschool children born preterm. Tese (Doutorado). Faculdade Filosofia Ciências e Letras de Ribeirão Preto, Universidade de São Paulo, Ribeirão Preto.

The preterm birth increases risk for developmental problems. The objectives of the present study were the following: a) to exam the associations between neonatal clinical conditions and cognition, attentional, temperament, and behavior indicators in preschool children born preterm; b) to compare these indicators in groups according to the prematurity level. The sample was composed of 50 children born preterm (mean gestational age $=31$ weeks [26-35]), mean birth weight of 1,190g [650$1,500 \mathrm{~g}]$ ), with six years of age, who participated in a follow-up program in a tertiary teaching hospital. Preterm children were evaluated according to the Wechsler Intelligence Scale for Children (WISC-III) and the Test of Attention by Cancelling. Mothers answered to the Child Behavior Questionnaire (CBQ), Strengths and Difficulties Questionnaire (SDQ), and the Questionnaire of characteristics. Clinical history was reviewed on the medical chart. The multiple linear regression and between group comparison (t-test/Chi-square) analyses were performed; $p \leq 0,05$. The results showed that, in the WISC-III cognition assessment, the majority of the children presented results on average on the following intelligence quotients (QIs) scores: Total (70\%), Verbal (76\%), and Executive (76\%), and in the Resistance to distraction Index subscale (78\%). On the total attentional score $74 \%$ of the children presented mean or above mean scores. Concerning the temperament indicator, children presented moderated scores between 4 and 5 on the three CBQ factors (Negative Affectivity, Surgency, and Effortful Control). On behavior indicators, $56 \%$ of the children obtained total normal classification, as well as $96 \%$ on prosocial behavior and $76 \%$ on peer relationship. However, there were high percentages of boarder/abnormal on emotional symptoms (64\%), conduct problems (56\%), and hyperactivity (50\%). The between groups comparison showed that children born extremely/very preterm presented lower performance only on alternating attention than moderate/late preterm children. The multiple linear regression analysis showed the following cognition outcomes: lower Total-IQ was predicted by lower Verbal IQ and maternal schoolarship; lower Verbal-IQ was predicted by lower Effortful Control and attention, and maternal schoolarship; lower Executive-IQ was predicted by lower attention, maternal scholarship, and socioeconomic status. Global behavior problems were predicted by higher Negative Affectivity, and Surgency, and lower Effortful Control, and Attention. Hyperactivity was predicted by higher Negative Affectivity and lower Effortful Control, and Attention. Conduct problems were predicted by higher Negative Affectivity, male sex, and Verbal-IQ. Peer relationship problems were predicted by higher Surgency, higher parental education, lower maternal schoolarship, and lower Executive-IQ. Emotional symptoms were predicted by gestational age, Effortful Control and socioeconomic status, and higher Negative Affectivity, and Surgency. Despite vulnerability of children there were cognitive and attentional resources. The difficulties are related to behavior, which were predicted by children factors, such as temperament, sex and gestational age, and socioeconomic factors.
\end{abstract}

Key words: cognition; attention; temperament; behavior; preterm birth 


\section{LISTA DE FIGURAS}

Figura 1 - Percurso de composição da amostra do estudo de crianças nascidas pré-termo e muito baixo peso ......................................... $\quad 52$

Figura 2 - Ilustração da primeira parte do Teste de Atenção por Cancelamento (atenção seletiva)

Figura 3 - Ilustração da segunda parte do Teste de Atenção por Cancelamento (atenção seletiva)

Figura 4 - Ilustração da terceira parte do Teste de Atenção por Cancelamento (atenção alternada).

Figura 5 - Representação gráfica da escala de respostas do The Children's Behavior Questionnaire (CBQ) 


\section{LISTA DE QUADRO}

Quadro 1- Fatores e dimensões do temperamento, avaliado pelo CBQ......... 


\section{LISTA DE TABELAS}

Tabela 1 - Características das da amostra de estudo................................ 67

Tabela 2 - Características neonatais das crianças nascidas pré-termo........

Tabela 3 - Patologias encontradas na história de saúde das crianças nascidas pré-termo no período de internação neonatal.

Tabela 4 - Tratamentos e procedimentos clínicos que as crianças nascidas pré-termo foram submetidas durante a fase neonatal.

Tabela 5 - Características dos pais das crianças nascidas pré-termo nascidas pré-termo...

Tabela 6 - Características do ambiente familiar das crianças nascidas pré-termo da amostra de estudo.

Tabela 7 - Características da história obstétrica materna e da história pré e peri-natal das crianças pré-termo da amostra do estudo.

Tabela 8 - QI e classificação nas escalas Total, Verbal e de Execução do WISC-III das crianças nascidas pré-termo da amostra do estudo...

Tabela 9 - Índice fatorial de Resistência à Distração do WISC-III - QI e classificação dos resultados das crianças nascidas pré-termo da amostra do estudo.

Tabela 10 - Acertos no teste de atenção por cancelamento das crianças pré-termo- escore e classificação.

Tabela 11 - Fatores e dimensões do temperamento, avaliados pelo The Child Behavior Questionnaire - CBQ/ Questionário Sobre o Comportamento da Criança, na fase pré-escolar das crianças nascidas pré-termo.

Tabela 12 - Indicadores do comportamento, avaliados pelo The Strength and Difficulties Questionaire (SDQ)/ Questionário de Capacidades e Dificuldades, na fase pré-escolar das crianças nascidas pré-termo. 
Tabela 13 - Características neonatais das crianças nascidas pré-termo, distribuídas pelo nível de prematuridade.

Tabela 14 - Indicadores de cognição e atenção em grupo de crianças nascidas pré-termo, diferenciadas pelo nível de prematuridade, na fase pré-escolar

Tabela 15 - Indicadores do temperamento e comportamento em grupos de crianças nascidas pré-termo, diferenciadas pelo nível de prematuridade, na fase pré- escolar.

Tabela 16 - Classificação do comportamento em grupos de crianças nascidas pré-termo, diferenciadas pelo nível de prematuridade, na fase pré- escolar.

Tabela 17 - Modelos de predição dos indicadores cognitivos avaliados pelo WISC-III, nas escalas total, verbal e de execução das crianças nascidas pré-termo, na fase pré-escolar.

Tabela 18 - Modelo de predição do total de problemas de comportamento das crianças nascidas pré-termo, na fase préescolar.

Tabela 19 - Modelos de predição de hiperatividade e problemas de conduta das crianças nascidas pré-termo, na fase préescolar.

Tabela 20 - Modelos de predição de problemas de relacionamento com colegas e sintomas emocionais das crianças nascidas prétermo, na fase pré-escolar. 


\section{LISTA DE ABREVIATURAS}
ABEP
Associação Brasileira de Empresa de Pesquisas
AIG
Adequado para idade gestacional
$\mathrm{CBQ}$
The Child Behavior Questionnaire/ Questionário sobre o
comportamento da crianças
CCEB Critério de Classificação Econômica Brasil
CRIB
Clínical Risk Index for Infant Babies
FE
Função executiva
FFCLRP/USP Faculdade de Filosofia Ciência e Letras da Universidade de
São Paulo
FMRP/USP Faculdade de Medicina de Ribeirão Preto da Universidade de
São Paulo
HCFMRP/USP Hospital das Clínicas da Faculdade de Medicina de Ribeirão
Preto da Universidade de São Paulo
PIG
Pequeno para idade gestacional
PT
Pré-termo
PTMB
Prematuro muito baixo peso
QI
Quoeficiente Intelectual
QIE
Quoeficiente Intelectual Execução
QIT
Quoeficiente Intelectual Total
QIV
Quoeficiente Intelectual Verbal
$\mathrm{RD}$
Resistência à Distração
$\mathrm{RN}$
Recém- nascido
SDQ
The Strength and Difficulties Questionaire/ Questionário de
Capacidades e Dificuldades
SIC
Sistema integrado de Consultas
TAC
Teste de Atenção por Cancelamento
TDAH
Transtorno de déficit de atenção e hiperatividade
USP
Universidade de São Paulo
UTIN
Unidade de Terapia Intensiva Neonatal
WISC III
Escala de Inteligência de Wechsler para crianças- Versão III
WHO
World Health Organization 


\section{SUMÁRIO}

PRÓLOGO 20

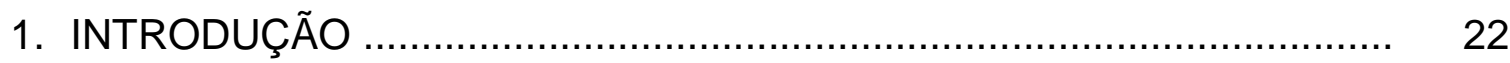

1.1 Princípios de Psicopatologia do Desenvolvimento............................. 23

$1.2 \mathrm{O}$ nascimento prematuro e as possíveis consequências.................... 25

1.3 O impacto do nascimento prematuro na área do comportamento

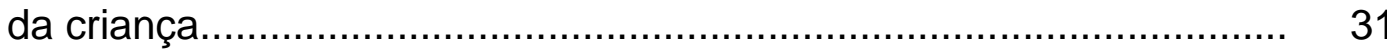

$1.4 \mathrm{O}$ sistema de atenção de crianças nascidas pré-termo...................... $\quad 35$

$1.5 \mathrm{O}$ impacto do nascimento prematuro no temperamento da criança... $\quad 39$

$1.6 \mathrm{O}$ impacto do nascimento prematuro na área do comportamento da

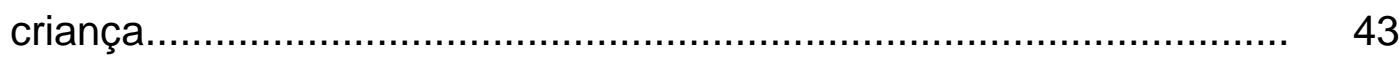

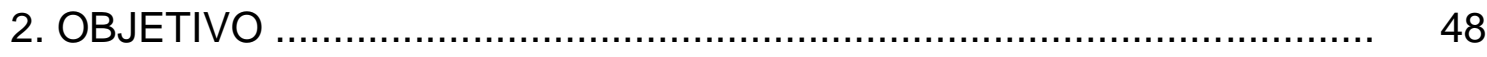

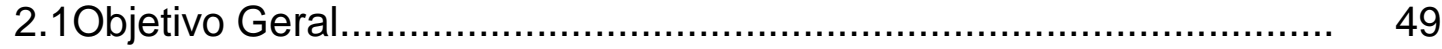

2.2 Objetivos Específicos............................................................. 49

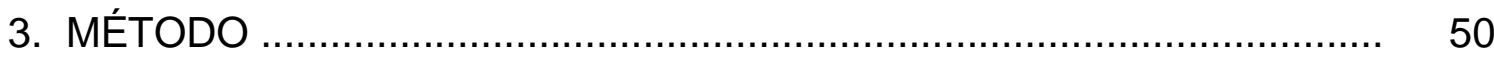

3.1 Delineamento do estudo............................................................. 51

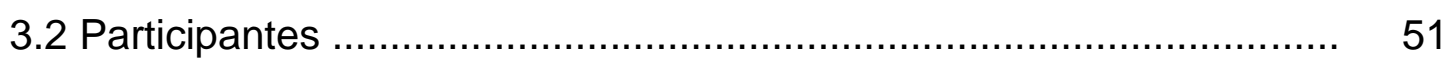

3.3 Aspectos éticos ……............................................................... 53

3.4 Local da pesquisa .............................................................. 53

3.5 Contexto da pesquisa................................................................ 53

3.5.1 Unidade de Terapia Intensiva Neonatal (UTIN) ...................... 54

3.5.2 Unidade de Cuidados Intermediários Neonatais (UCIN)........... $\quad 55$

3.5.3 Ambulatórios de Prematuros .................................................. 55

3.6 Instrumentos e Medidas ................................................................ 56

3.6.1 Avaliação cognitiva............................................................. 56

3.6.2 Avaliação da atenção......................................................... 56

3.6.3 Avaliação do temperamento................................................. 59

3.6.4 Avaliação do comportamento................................................ 62

3.6.5 Avaliação dos dados da criança............................................. 62

3.6.6 Critério de Classificação Econômico Brasil- ABEP..................... 63

3.6.7 Prontuário do paciente no HCFMRP-USP.............................. 63

3.7 Procedimentos .......................................................................... 63 
3.7.1 Coleta de dados

63

3.7.2 Análise e tratamento estatístico dos dados.............................. 64

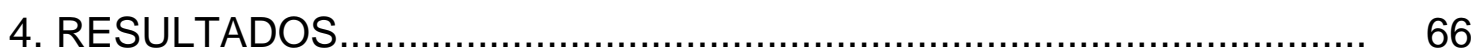

4.1-1 ${ }^{a}$ Sessão- Caracterização da amostra......................................... 67

4.1.1 - Características das crianças nascidas pré-termo da amostra

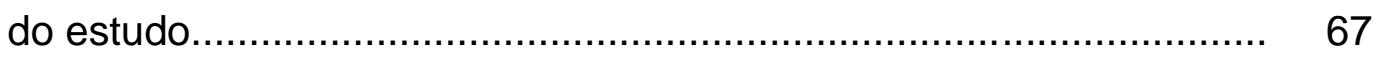

4.2- 2ª Sessão- Caracterização dos indicadores do desenvolvimento...... 75

4.2.1 - Caracterização dos indicadores do desenvolvimento cognitivo na fase pré-escolar, das crianças nascidas pré-termo.........

4.2.2 - Caracterização dos indicadores de atenção na fase préescolar, das crianças nascidas pré-termo

4.2.3 - Caracterização dos indicadores de temperamento na fase pré-escolar, das crianças nascidas pré-termo

4.2.4 - Caracterização dos indicadores de comportamento na fase pré-escolar, das crianças nascidas pré-termo

4.3 - $3^{\text {a }}$ Sessão - Indicadores de desenvolvimento de acordo com o grau de prematuridade

4.3.1 - Comparação entre crianças nascidas pré-termo muito baixo peso, distribuídas pelo nível de prematuridade.

4.3.2 - Comparação dos indicadores cognitivos e de atenção entre os grupos de crianças nascidas pré-termo, de acordo com o nível de prematuridade na fase pré-escolar

4.3.3 - Comparação dos indicadores de temperamento e comportamento entre os grupos de crianças nascidas pré-termo, de acordo com o nível de prematuridade na fase pré-escolar.

4.4 - 4ª Sessão - Predição do comportamento e do desenvolvimento cognitivo.

4.4.1 - Predição dos indicadores cognitivos das crianças nascidas pré-termo na fase pré-escolar.

4.4.2 - Predição dos indicadores do comportamento das crianças nascidas pré-termo, na fase pré-escolar.

5. DISCUSSÃO

5.1 - Características das crianças nascidas pré-termo, quanto à 
história de saúde e contexto familiar............................................... 100

5.2 - Indicadores cognitivos das crianças nascidas pré-termo............... 107

5.3 - Indicadores de atenção das crianças nascidas pré-termo............ 112

5.4 - Indicadores do temperamento das crianças nascidas pré-termo.. 115

5.5 - Indicadores do comportamento das crianças nascidas pré-termo 118

6. CONSIDERAÇÕES FINAIS........................................................... 126

6.1 - Considerações metodológicas.................................................. 127

6.2 - Desdobramentos práticos......................................................... 129

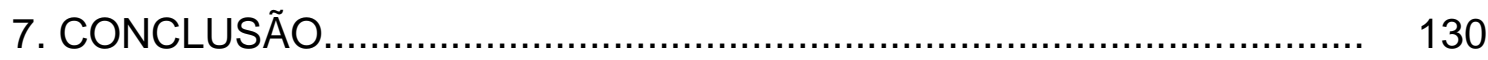

8. REFERÊNCIAS BIBLIOGRÁFICAS............................................... 132

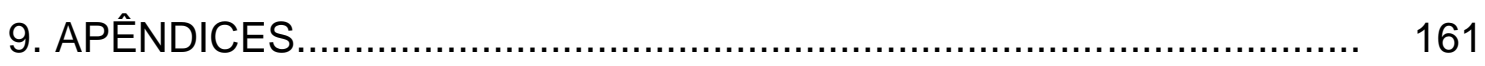

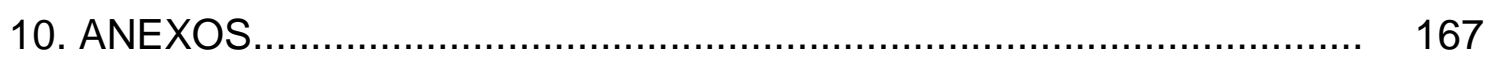




\section{PRÓLOGO}

O presente projeto de Doutorado está vinculado à linha de pesquisa denominada Sobrevivência, Desenvolvimento e Qualidade de vida de bebês prematuros, sob a coordenação da Profa. Dra. Maria Beatriz Martins Linhares, do LAPREDES (Laboratório de Pesquisa em Prevenção de Problemas de Desenvolvimento e Comportamento da Criança, na Faculdade de Medicina de Ribeirão Preto da Universidade de São Paulo- Faculdade de Medicina de Ribeirão Preto-USP). Essa linha de pesquisa tem por objetivo integrar o conhecimento psicológico ao conhecimento médico acerca de questões sobre os efeitos do fator de risco biológico da prematuridade no desenvolvimento da criança. Esta linha envolve pesquisas sobre avaliações longitudinal e transversal do desenvolvimento psicológico da criança em diferentes idades (desde bebê até a fase escolar) e de suas interações com o ambiente social, assim como a avaliação e o suporte psicológico realizado com mães dos bebês durante a internação em Unidade de Terapia Intensiva Neonatal (UTIN).

A partir de 2005, tiveram início, na linha de pesquisa, estudos sobre indicadores de temperamento das crianças nascidas pré-termo, considerando a relevância deste constructo psicológico para entender os problemas de comportamento, reatividade e regulação biocomportamental frente às experiências de dor e estresse no contexto da UTIN. O estudo do temperamento avançou na linha de pesquisa com as oportunidades de participação em 2007 e 2009 no Congresso da SRCD - Society for Research in Child Development (em que este tema foi foco de diversas apresentações de pesquisadores internacionais), do Doutorado-sandwich da aluna do laboratório VC Klein e da visita acadêmico-científica da orientadora, realizados em 2008, no laboratório The Child Development Lab, University of Maryland, College Park, USA coordenado pelo Prof. Dr. Nathan A. Fox. e no laboratório de pesquisa do Prof Dr. Samuel Putnam, no Boldwoin College, USA. A partir desta visita iniciou-se um importante intercâmbio com o Dr. Putnam e Dra. Maria Gartstein (University of Washington), pesquisadores renomados no estudo do temperamento. As versões brasileiras dos questionários sobre temperamento na abordagem psicobiológica de Mary Rothbart (University of Oregan) foram realizadas por VC Klein e MBM Linhares, sendo esta ultima orientadora deste projeto, com a 
autorização dos autores. Novos projetos sobre temperamento em crianças foram desenvolvidos no referido laboratório de pesquisa da FMRP-USP. A aluna participa desta linha de pesquisa desde o ano de 2010 ao iniciar seu estudo de Doutorado.

A aluna realizou a pesquisa de Mestrado em 2002, sob a coordenação da Profa. Dra. Maria Beatriz Martins Linhares no Programa de Pós-graduação em Psicologia, na Faculdade de Filosofia Ciências e Letras de Ribeirão Preto, Universidade de São Paulo e foi bolsista da Coordenação de Aperfeiçoamento de Pessoal de Nível Superior (CAPES), cuja dissertação de mestrado foi defendida em $11 / 11 / 2005$.

Em 2006, a aluna passou a integrar o quadro de psicólogos do Hospital das Clínicas da Faculdade de Medicina de Ribeirão Preto - USP, com atuação na área de Neonatologia, com foco nos Cuidados Intermediários e no Programa de Followup de prematuros.

O presente estudo de Doutorado buscou avançar na compreensão sobre o impacto do risco clínico neonatal de crianças nascidas pré-termo que passaram por internação na UTIN, nas características da cognição, atenção, temperamento e comportamento no período pré-escolar. 


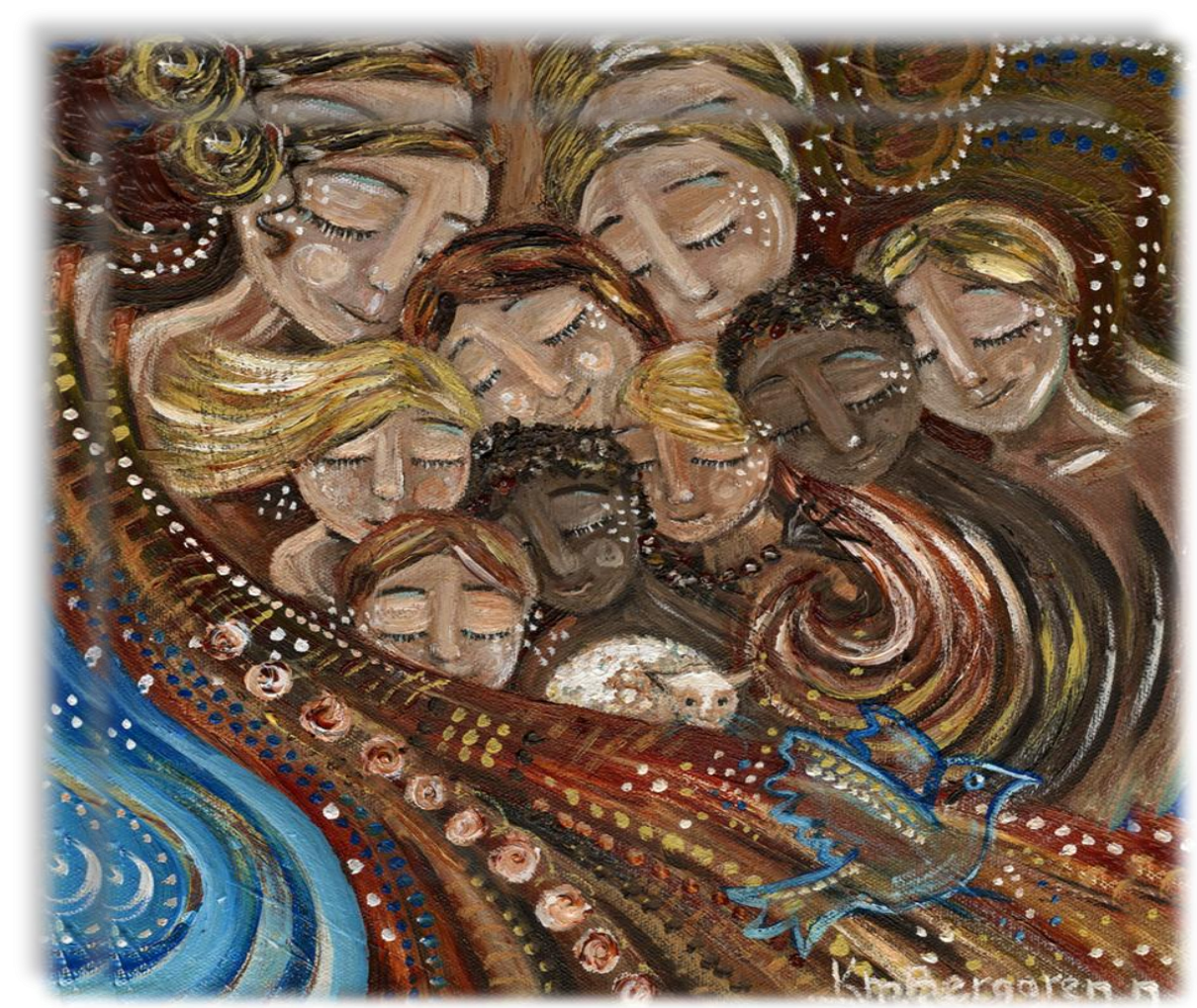

Artigo I - Todos os prematuros nascem livres e iguais em dignidade e direitos. São dotados de razão e consciência. Possuem vida anterior ao nascimento, bem como memória, aprendizado, emoção e capacidade de resposta e interação com o mundo em sua volta (Tavares, 2009). 


\subsection{Princípios de Psicopatologia do Desenvolvimento}

Os anos iniciais da vida de um indivíduo são caracterizados por diversas modificações no crescimento e desenvolvimento (Shepherd, 2002). O termo desenvolvimento, quando aplicado à evolução denota que com o transcorrer do tempo existirá um aumento das interferências individuais sobre o ambiente, assim como o ambiente poderá influenciar o desenvolvimento das crianças (Gallahue \& Ozmun, 2003).

A Psicopatologia do Desenvolvimento investiga a natureza do processo de desenvolvimento, as origens e os cursos de padrões individuais de adaptação comportamental, como também a maneira que os fatores e mecanismos influenciam positiva ou negativamente essas diferentes trajetórias de vida (Sameroff, 2000).

Considerando o curso da evolução do indivíduo, esse pode ser permeado por fatores de risco que ameaçam o desenvolvimento típico provocando desordens ou transtornos no desenvolvimento (Linhares, 2004). Nesse sentido é possível prever que, na formação e maturação biológica de um bebê podem ocorrer problemas que acarretam sequelas no desenvolvimento (Sameroff \& Rosenblum, 2006). Os fatores de risco que podem interferir no desenvolvimento são classificados em biológicos (Bühler, Bernardis, Custodio, \& Limongi, 2007; Fraga, Linhares, Carvalho, \& Martinez, 2008) e ambientais (Resegue, Puccini, \& Silva, 2007; Matos, Cruz, Dumith, Dias, Carret, \& Quevedo, 2015). Os riscos biológicos atuam no sentido de restringir experiências positivas para o desenvolvimento, assim como os riscos ambientais (Andreani, Custódio, \& Crepaldi, 2006).

Entre os fatores de risco biológico verifica-se a asfixia perinatal, a hemorragia peri-intraventricular, a displasia broncopulmonar, os distúrbios bioquímicos e hematológicos, a microcefalia, malformações congênitas, infecções congênitas ou neonatais e a restrição do crescimento intra-uterino (Bear, 2004) infecções do sistema nervoso central, hemorragias cranianas em crianças com distúrbio de coagulação, mal convulsivo, trauma, e graves distúrbios hidroeletrolíticos (Resegue et al., 2007), entre outros fatores. Os riscos ambientais, por sua vez, são as características familiares, que podem expor a criança a mais risco, para o desenvolvimento saudável como as seguintes: baixa renda familiar, baixa escolaridade dos pais, elevados níveis de estresse da família, baixos níveis de 
suporte social (Halpern \& Figueiras, 2004), violência doméstica e urbana (Celia, 1997), maus tratos e abuso sexual (Fuentes \& Serrano, 1988). Nota-se ainda que há uma associação entre o nível socioeconômico e problemas de comportamento em crianças. Entre os diferentes níveis socioeconômicos, os problemas de comportamento são geralmente mais comuns entre as crianças com níveis mais baixos (Elgar, McGrath, Waschbusch, Stewart, \& Curtis, 2004).

Portanto, o risco deve ser observado e interpretado como um fator em potencial, o qual pressupõe possibilidades e não a certeza absoluta do risco constatado de efeitos negativos para a trajetória do desenvolvimento (Linhares, 2004). Ainda que o desenvolvimento de uma criança possa ser prejudicado por esta ser exposta a fatores de risco há um interjogo entre fatores de riscos e mecanismos de proteção que pode atenuar os efeitos negativos do risco ao desenvolvimento da criança (Silk et al., 2007). Entre os mecanismos de proteção podem ser identificados recursos do indivíduo ou dos seus contextos de desenvolvimentos (Garcia, 2001). Quando o indivíduo conta com suporte social e com um autoconceito positivo, estes podem servir de proteção contra os efeitos de experiências estressantes (Sapienza \& Pedromônico, 2005).

Compreendida as relações entre fatores de risco e mecanismos de proteção esta requer a definição do conceito de "resiliência", que é frequentemente referida por processos que explicam a superação de crises e adversidades em indivíduos, grupos e organizações (Tavares, 2001; Yunes \& Szymanski, 2001). A resiliência pode ser entendida como a capacidade dos indivíduos de superar os fatores de risco aos quais são expostos desenvolvendo comportamentos adaptativos e adequados. O processo de resiliência configura-se na interação do indivíduo com vulnerabilidade advinda de situações estressoras internas e/ ou externas na vida, e a capacidade que tem para reagir, minimizando ou neutralizando os efeitos da adversidade (Yunes \& Szymanski, 2001).

Nas trajetórias de desenvolvimento quanto mais cedo os fatores de risco forem detectados, maior a possibilidade de promover estratégias preventivas de proteção do desenvolvimento. Os primeiros anos de vida de um indivíduo exercem papel relevante, pois as experiências iniciais têm impacto decisivo na estrutura do cérebro (Couperus \& Nelson, 2006). Segundo Mustard (2002) acompanhar o desenvolvimento no primeiro ano de vida é de extrema importância devido esta ser a 
fase em que a criança apresenta maior plasticidade cerebral. Entende-se também que com este direcionamento, o impacto negativo de fatores de risco pode ser gradativamente amenizado e a promoção dos fatores protetores potencializada.

\subsection{0 nascimento prematuro e as possíveis consequências}

O desenvolvimento de recursos tecnológicos e assistenciais torna-se essencial para aumentar as chances de sobrevivência dos neonatos de risco, principalmente os prematuros de baixo peso (Silva, Araújo \& Teixeira, 2012).

Em virtude dos avanços na Medicina houve um aumento na taxa de sobrevivência de crianças que nascem pré-termo e/ou o muito baixo peso ao nascer (Stoelhorst et al., 2005). A prematuridade tem sido considerada um fator de risco biológico para o desenvolvimento infantil e, embora os avanços tecnológicos permitam a sobrevida de crianças com idades gestacionais cada vez menores, a imaturidade desses órgãos e sistemas pode ocasionar diversos comprometimentos à saúde da criança (Davidson, João, Rodrigues, \& Scavacini, 2011; Resegue et al., 2007). Por conseguinte, observa-se uma melhora na atenção à saúde dos neonatos, no que se refere aos tratamentos (Zomignani, Zambelli, \& Antonio, 2009) e procedimentos, de tal forma que é possível constatar um crescimento na perspectiva de sobrevivência de recém-nascidos prematuros (Almeida, Paines, \& Balbão, 2008). Contudo, mesmo havendo tantos avanços tecnológicos na área da Neonatologia, a prematuridade continua sendo considerada um problema mundial.

Segundo o Ministério da Saúde são recém-nascidos de risco quando atendem a um dos seguintes critérios: residência em área de risco; recém- nascidos com menos de 37 semanas de idade gestacional; peso ao nascer menor que 2.500 gramas; asfixia grave, Apgar menor que sete no quinto minuto de vida; hospitalização ou intercorrência na maternidade ou em unidade de assistência ao recém- nascidos; necessidades de orientações especiais à alta da maternidade ou em assistência ao recém - nascido; filho de mãe adolescente (menos de 18 anos); ser recém- nascidos de mãe com baixa instrução (menos de oito anos de estudo) e haver histórico de mortes de crianças menor de cinco anos na família (Ministério da Saúde, 2013). 
As variáveis biológicas, peso ao nascimento e idade gestacional colaboram para o desenvolvimento sadio, pois exercem papel importante no organismo das crianças. Contudo, quando esses fatores se encontram fora dos parâmetros normais esperados caracterizam-se como fatores de risco para o desenvolvimento típico infantil (Linhares, Chimello, Bordin, Carvalho, \& Martinez, 2005). O risco evolui no sentido inverso ao peso ao nascimento, ou seja, o risco aumenta à medida que o peso ao nascimento diminui, sendo que tal ocorre igualmente com a idade gestacional (Pinto, Silva, Munari, Almeida, \& Resende, 2008).

Segundo descrito por Aylward (2005) a prematuridade é um marco do risco biológico que expõe a criança a uma cadeia de outras adversidades. Segundo a Organização Mundial de Saúde define-se como fator de risco qualquer circunstância ligada a um aumento na probabilidade de se desenvolver um processo mórbido (World Health Organization [WHO], 2009).

A Organização Mundial de Saúde (OMS) (World Health Organization [WHO], 2012) define como recém-nascido pré-termo, bebês que nascem com menos de 37 semanas de idade gestacional e baixo peso, aqueles que nascem com menos de 2.500 gramas ao nascer. De acordo com Lima et al. (2006), o grupo de baixo peso pode ser subdividido em recém-nascidos com muito baixo peso $(<1.500 \mathrm{~g})$ e de extremo baixo peso $(<1.000 \mathrm{~g})$. O nascimento prematuro constitui-se em um grave problema na área de Saúde da Criança, considerando-se que a maior causa da mortalidade infantil no Brasil está associada às condições perinatais e que, além disso, as taxas de prematuridade têm aumentado ao longo do tempo (Silveira et al., 2008).

A idade gestacional e o peso ao nascimento são importantes indicadores de risco biológico para problemas de desenvolvimento das crianças (Draper et al., 2009; Duvall, Erickson, MacLean, \& Lowem, 2015; Phibbs, Baker, Caughey, Danielson, Schmitt \& Phibbs, 2007). Contudo, Carneiro et al. (2015) destacaram o peso ao nascer como um dos indicadores mais importantes da qualidade de vida da criança.

Considerando o contexto brasileiro, segundo o último levantamento estatístico realizado pelo Sistema de Informações sobre os Nascidos Vivos [SISNAC] do Ministério da Saúde (2013), referente aos dados do ano-base de 2013, o índice de nascimentos prematuros é de $11,4 \%$, em um total de 2.904 .027 bebês nascidos 
vivos. Com relação às regiões brasileiras, as que concentram a maior proporção de nascidos vivos prematuros em relação a outras regiões do Brasil são as regiões Sudeste $(11,7 \%)$ e Sul (11\%), de acordo com o SISNAC, referente ao ano de 2013 (Ministério da Saúde, 2013). No Estado de São Paulo, esse índice sobe para 12\% e, especificamente na cidade de Ribeirão Preto, no interior do Estado, esse índice equivale a 13,85\% de nascimentos prematuros em 2013 (Ministério da Saúde, 2013).

Várias são as causas do nascimento pré-termo e com baixo peso e os possíveis efeitos destes para o bebê, pois estão relacionados com os tipos, a duração da ação e a etapa do desenvolvimento fetal. As principais causas são as seguintes: primigestas jovens ou idosas, pequeno intervalo de tempo entre os partos, aborto tardio, infecções do trato genito-urinário, história de prematuridade anterior e gravidez múltipla, malformação uterina, desnutrição, ausência de assistência pré-natal, baixo peso materno, alcoolismo, tabagismo, uso de drogas ilícitas, diabetes e hipertensão materna (Glesse, Mantesso, Ramalho, Simoni, \& Saba-Chujfi, 2004). As crianças nascidas prematuras estão carregadas por um histórico de vulnerabilidade biológica apresentando um risco maior de problemas de desenvolvimento (Moreira, Magalhães, \& Alves, 2014).

Segundo a OMS (2013), 13 milhões de bebês nascem prematuros no mundo a cada ano e muitos vão ter deficiências graves no neurodesenvolvimento. Desta maneira o nascimento prematuro é caracterizado como um fator de risco na vida de um indivíduo e esta condição pode ameaçar a trajetória de desenvolvimento típico (Linhares, 2009).

Para os bebês que sobrevivem existe um risco aumentado de deficiência incluindo dificuldades de aprendizagem visuais e problemas de audição que demandam uma carga sobre as famílias e os sistemas de saúde (Howson, Kinney, \& Lawn, 2012). Os dados reforçam que as crianças com muito baixo peso têm maiores taxas de déficits cognitivos e acadêmicos, problemas de comportamento, neurossensorial e outros problemas de saúde do que as crianças nascidas prazo com pesos ao nascimento normais (Taylor, Klein, \& Hack, 2000). As crianças nascidas pré-termo extremo e muito baixo peso podem necessitar de educação especial aos cinco anos de idade e posteriormente apresentar problemas de desempenho acadêmico na fase escolar (Kleine, Sanden, \& Ouden, 2006). 
Tão importante quanto saber quantas crianças nascem prematuras é saber sobre as implicações que esta condição de nascimento causa nos sobreviventes. É comprovado pelos estudos que, mesmo com o aumento das taxas de sobrevivência, os bebês prematuros têm a chance aumentada de apresentar problemas futuros no desenvolvimento e no comportamento (Gray, Indurkhya, \& McCormick, 2004).

Segundo Linhares et al. (2005) pode-se assegurar que o conjunto de fatores como a prematuridade e o baixo peso ao nascer sugerem risco ao desenvolvimento, contudo adjunto a estes existem outros fatores que também ocasionam riscos para a saúde do indivíduo. Na perspectiva do desenvolvimento, o nascimento prematuro de um bebê constitui-se na "porta de entrada" para outros fatores de risco biológicos e psicossociais (Linhares et al., 2006). Contudo estes fatores estão relacionados com a intensidade do risco e do período em que a prematuridade acontece. De forma específica os recém-nascidos prematuros com muito baixo peso $(<1.500 \mathrm{~g})$ e extremo baixo peso ao nascer $(<1.000 \mathrm{~g})$ estão em maior risco para problemas de desenvolvimento (Anderson, Doyle, \& Victorian Infant Collaborative Study Group, 2003; Bhutta, Cleves, Casey, Cradock, \& Anand, 2002; Salt \& Redshaw, 2006).

As crianças recém-nascidas de alto risco têm a possibilidade maior para apresentar problemas no período pré e perinatal e, devido a esses fatores, além dos riscos de anormalidade no desenvolvimento podem apresentar atrasos neuropsicomotor (Barbosa, Formiga, \& Linhares, 2007; Campos, Soares, \& Cattuzzo, 2013; Halpern et al., 2002), problemas cognitivos (Anderson, Doyle, \& Victorian Infant Collaborative Study Group, 2004; Linhares et al., 2005; Rugolo, 2012; Spittle, Orton, Anderson, Boyd, \& Doyle, 2012), problemas de desempenho escolar (Bellinger \& McCormick, 2007; Loe, Lee, \& Feldman, 2013; Marlow, Wolke, Bracewell, Samara, \& EPICure Study Group, 2005; Rodrigues, Mello, \& Fonseca, 2006; Spittle, Boyd, Inder, Doyle, 2009), problemas de comportamento (Bordin, Linhares, \& Jorge, 2001; Espírito Santo, Portuguez, \& Nunes, 2009; Loe et al., 2013; Samara, Marlow, Wolke, \& EPICure Study Group, 2008) e Linguagem (Nobre, Carvalho, Martinez, \& Linhares, 2009). Deste modo, a prematuridade em geral pode alterar o funcionamento orgânico e 0 neonato prematuro pode sofrer comprometimento ou intercorrências ao longo do seu desenvolvimento (Ramos \& Cuman, 2009). Essas alterações já podem ser identificadas no início da vida e os efeitos adversos de desenvolvimento são evidentes (Espy, Fang, Charak, Minich, \& 
Taylor, 2009; Sullivan \& McGrath, 2003). Um conjunto substancial de estudos na literatura identificaram déficits neuropsicológicos durante os anos pré-escolares e escola fundamental que persistiram ao longo dos anos (Anderson et al., 2004; Taylor, Minich, Bangert, Filipek, \& Hack, 2004).

O estudo de revisão de artigos publicados nos anos de 2000 a $2007 \mathrm{com}$ delineamento analítico, caso-controle e de coorte investigou o crescimento e o desenvolvimento cerebral de crianças prematuras e as alterações cognitivas e motoras que podem decorrer da prematuridade (Zomignani et al. 2009). Os autores identificaram que a evolução do recém-nascido pré-termo se diferencia da evolução da população de nascidos a termo. As crianças nascidas prematuras apresentam alterações anatômicas cerebrais que se relacionaram a prejuízos cognitivos e regiões do sistema nervoso central. Crianças nascidas prematuras avaliadas na infância tardia e na adolescência demonstraram alterações intelectuais e prejuízos nas seguintes áreas: memória, capacidade para cálculos e função cognitiva global, além de déficits motores, na capacidade de planejamento e de associação, na coordenação motora e na atenção. Por fim, a prematuridade leva a alterações anatômicas e estruturais do cérebro devido à interrupção das etapas de desenvolvimento pré-natal. Tais alterações podem causar déficits funcionais tornando os nascidos prematuros sujeitos a problemas cognitivos e motores, assim como apresentando repercussões nas atividades de vida diária, mesmo na adolescência e idade adulta.

Em outro estudo de revisão sobre os aspectos neurodesenvolvimentais relacionados à prematuridade e ao baixo peso ao nascimento identificou-se, em relação ao desenvolvimento cognitivo, que de sete a $17 \%$ das crianças nascidas com muito baixo peso $(<1.500 \mathrm{~g})$ apresentaram um déficit cognitivo (Vanderbilt \& Gleason, 2010). Destaca-se que 34 a $37 \%$ eram crianças que nasceram com extremo baixo peso $(<1.000 \mathrm{~g})$, lembrando que na população geral este índice é de $1 \%$.

No estudo de Oliveira, Magalhães e Salmela (2011) foram examinadas as relações entre baixo peso ao nascimento, prematuridade, fatores ambientais e o desenvolvimento motor e cognitivo em crianças nascidas pré-termo de muito baixo peso aos 5 e 6 anos de idade, em comparação com os pares nascidos a termo e com peso adequado. Foram encontradas diferenças significativas entre os grupos, 
com melhor desempenho em todas as avaliações no grupo controle. Os resultados reforçam as evidências de que crianças nascidas prematuras e de muito baixo peso são mais propensas a apresentar dificuldades motoras e cognitivas que seus pares nascidos a termo, além de que fatores ambientais parecem interferir no desenvolvimento dessas crianças.

Com o objetivo de investigar os efeitos dos problemas de crescimento no desempenho escolar, Cooke e Foulder-Hughes (2003) avaliaram crianças nascidas pré-termo (32 semanas de idade gestacional) e compararam com grupo controle de crianças nascidas a termo aos sete anos de idade. As crianças prematuras tinham significantemente peso e estatura menor do que o grupo de controle, além de cabeças menores e um índice de massa corporal mais baixo. As crianças prematuras também apresentaram um desempenho significantemente abaixo no desenvolvimento cognitivo e lentidão nas atividades em relação ao grupo controle.

Em contrapartida, o estudo de revisão de Resegue et al. (2007) verificou-se que algumas crianças, que nasceram em condições de vulnerabilidade e estão expostas algum tipo de risco (biológico e ou ambiental) não desenvolveram problemas. Apesar de a prematuridade ser um fator de risco para alterações do desenvolvimento, 80 a $95 \%$ das crianças nascidas pré-termo apresentaram desenvolvimento normal. De acordo com a noção de plasticidade fenotípica (Gluckman et al., 2009), essa possibilidade de os indivíduos ajustarem seu desenvolvimento as demandas do ambiente, permite que aqueles que possuem alguma limitação biológica, mas que têm um ambiente favorável, conseguem igualar-se a aqueles sem limitação.

Paralelamente, aos estudos sobre o desenvolvimento motor e cognitivo encontram-se na literatura estudos sobre o impacto desta situação adversa da prematuridade, no sistema de atenção (Bhutta et al., 2002; Luu et al., 2009; Msall \& Park, 2008; Rugolo, 2005; Salt \& Redshaw, 2006; Van de Weijer-Bergsma, Wijnroks, \& Jongmans, 2008), sobre a regulação da atenção e habilidades social adaptativas (Msall \& Park, 2008), no temperamento (Cassiano \& Linhares, 2015; CosentinoRocha, Klein, \& Linhares, 2014; Grunau, 2003; Klein, 2009) e no comportamento (Delobel-Ayoub et al., 2006; Gracioli \& Linhares, 2014; Klein \& Linhares, 2010).

Verifica-se que além das tradicionais áreas de avaliação motora, linguagem e cognitiva (Roberts, Bellingers, \& MCCormick, 2007), os estudos também buscam 
avaliar aspectos do desenvolvimento relacionados aos transtornos emocionais e de comportamento (Barros, 2012; Cosentino-Rocha, Klein, \& Linhares, 2014) e mais recentemente aos processos regulatórios (Feldman, 2009; Vieira, \& Linhares, 2011) e atencionais (Jaekel, Wolke, \& Bartmann, 2013). Os estudos de função executiva e atenção têm mostrado que os problemas nessas áreas não podem ser explicados totalmente por um déficit cognitivo geral indicando que, esta pode ser uma área específica de dificuldade em crianças prematuras (Bohm, Smedler, \& Forssberg, 2004; Marlow, Hennessy, Bracewell, \& Wolke, 2007; Nosarti et al., 2007). O estudo dessa área específica é particularmente importante, pois pode melhorar a nossa compreensão sobre alguns dos mecanismos subjacentes ao baixo rendimento acadêmico frequentemente encontrado em crianças nascidas prematuras (Huddy, Johnson, \& Hope, 2001).

\subsection{0 impacto do nascimento prematuro na área cognitiva da criança}

Crianças em risco para o desenvolvimento são aqueles que podem apresentar problemas significativos em pelo menos uma área de seu desenvolvimento (Goldfeld, O'Connor, Sayers, Moore, \& Oberklaid, 2012). As crianças em risco para o desenvolvimento podem apresentar o funcionamento na extremidade inferior da normalidade. Experiências adversas na infância incluindo desvantagem socioeconômica, saúde mental dos pais prejudicada, falta de estimulação, experiências ruins na primeira infância e falta de acesso a serviços podem contribuir para o risco de desenvolvimento geral (Sameroff, 2009).

As crianças nascidas prematuras com muito baixo peso tendem a apresentar comprometimento cognitivo, sendo este uma sequela do neurodesenvolvimento mais prevalente neste grupo de crianças (Rodrigues, Mello, Silva, \& Carvalho, 2011).

Sabe-se que a lesão cerebral em bebês prematuros é de enorme importância para a saúde pública, devido ao grande número de crianças que sobrevivem com grave deficiência do desenvolvimento neurológico, incluindo os principais déficits cognitivos e incapacidade motora (Volpe, 2009).

Crianças nascidas pré-termo em idade pré-escolar e escolar apresentam níveis diminuídos de função global intelectual, atenção, memória e habilidades de raciocínio em relação a seus pares a termo (Fonseca, 2002). Associa-se ao 
nascimento prematuro as altas taxas de deficiência do desenvolvimento neurológico, principalmente devido a eventos hipóxico-isquêmicos. As estruturas cerebrais periventriculares e os tratos da substância branca são particularmente vulneráveis a esses danos.

As deficiências neurocomportamentais ocorrem nos recém-nascidos prematuros entre 5 e15\% com uma estimativa de 50 a 70\% em bebês prematuros muito baixo peso ao nascimento, com a possibilidade de apresentar algumas disfunções, incluindo atrasos cognitivos, comportamentais e sociais (Taylor, Margevicius, Schluchter, Andreias, \& Corte, 2015). Sabe-se que alguns danos cerebrais ocorrem intra-útero ou logo após o nascimento. As estratégias neuroprotetoras podem impedir as lesões de progredir, especialmente quando essas estratégias são utilizadas durante os períodos mais sensíveis da plasticidade neural (Pickler, Wetzel, Meinzen-Derr, Tubbs-Cooley, \& Moore, 2015).

A plasticidade é uma propriedade intrínseca do sistema nervoso central, que reflete sua capacidade de responder de forma dinâmica com o meio ambiente e experiências, por meio de modificação de circuitos neurais. No contexto do desenvolvimento saudável, a plasticidade é considerada benéfica, facilitando a mudança adaptativa em resposta a estímulos ambientais. Contudo, pouco se conhece sobre o impacto da plasticidade no contexto do novo cérebro, com lesões (Anderson, Spencer-Smith, \& Wood, 2011; Kobayashi, Wakusawa, Inui, Tanaka, Kobayashi, Onuma, \& Haginoya, 2015).

Crianças nascidas prematuras são frequentemente monitoradas durante os anos pré-escolares devido o seu maior risco para atraso no desenvolvimento neurológico (Perra et al., 2015), pois as crianças que nascem em condição de vulnerabilidade pelo peso e idade gestacional são identificadas como grupo em desvantagem em relação ao sucesso escolar, envolvendo os problemas de inteligência quando comparadas aos seus pares com idade gestacional normal. Nota-se ainda, déficits no funcionamento cognitivo e acadêmico, como inteligência verbal e não-verbal, linguagem, raciocínio aritmético e leitura (Espírito Santo et al., 2009).

Ao avaliar indicadores do desenvolvimento cognitivos na fase pré-escolar de crianças nascidas pré-termo ( $<37$ semanas de idade gestacional) com baixo peso (< $2.500 \mathrm{~g}$ ) e compará-los aos de crianças nascidas a termo, utilizado o Raven, as 
crianças pré-termo apresentaram nível intelectual inferior à média em comparação as nascidas a termo (Linhares et al., 2005).

O primeiro estudo realizado na Turquia para avaliar o prognóstico de crianças nascidas prematuras (<32 semanas de idade gestacional) e muito baixo peso $(<1500 \mathrm{~g})$ em relação ao desenvolvimento neurológico identificou, a partir do WISC$\mathrm{R}$, que a maior parte das crianças (54\%) apresentou desempenho cognitivo dentro da normalidade (Koç, Kavuncuoğlu, Ramoğlu, Aldemir, Aktalay, \& Eras, 2015).

O estudo de corte transversal prospectivo de Espírito Santo et al. (2009) mostra que, ao avaliar o desempenho cognitivo, pela Escala de Inteligência de Wechsler para a idade pré-escolar (WPPSI), com crianças prematuras (<37 semanas de idade gestacional) com baixo peso $(<2.500 \mathrm{~g})$ ao nascimento em idade entre 4 e 5 anos e 11 meses, foi identificada com maior incidência de distúrbios cognitivos.

Em um estudo brasileiro, os autores examinaram as relações entre peso ao nascimento ( $\leq 1.500$ gramas), prematuridade $\mathrm{e}$ os fatores ambientais no desenvolvimento cognitivo de cinco e seis anos de idade e compararam com seus pares a termo. Os resultados indicaram que, as crianças nascidas muito baixo peso apresentaram desempenho aquém, quando comparadas com as a termo no WISCIII. Contudo mesmo estando abaixo do esperado, mostraram-se dentro da normalidade. Identificaram associação entre os resultados da avaliação cognitiva com peso de nascimento (Oliveira et al., 2011).

Estudos no âmbito nacional (Martins, Linhares, \& Martinez, 2005; Méio, Lopes, \& Morsch; 2003; Oliveira et al., 2011) e internacional (Koç et al., 2015; Perra et al., 2015), são inânimes em dizer que as crianças nascidas prematuras com muito baixo peso apresentam seu desempenho cognitivo aquém do esperado quando comparadas com as a termo, contudo ainda estão dentro da normalidade.

O estudo de Ranger et al. (2015), com crianças aos sete anos de idade muito pré-termo (24 a 32 semanas de idade gestacional) identificou um QI acima de 85 pelo WISC- IV, contudo houve associação positiva significativa entre o menor volume cerebral e menor nível cognitivo.

Ao investigar o desenvolvimento neurológico, com relação à alteração do volume da massa cinzenta e substância branca de crianças nascidas prematuras (30 a 34 idade gestacional) em comparação com seus pares a termo, o estudo de SoriaPastor et al. (2009) identificou que a longo prazo há reduções globais e regionais de 
volumes da massa cinzenta em várias áreas do cérebro, incluindo os lobos temporal e parietal. Com relação ao desempenho cognitivo especificamente, os grupos de crianças pré-termo apresentaram desempenho menor.

Com objetivo de avaliar o impacto de comorbidades neonatais respiratórias em prematuros tardio $\left(34^{0 / 7}-36^{6 / 7}\right.$ semanas de gestação), o estudo recente desenvolvido por Wachtel, Zaccario e Mally (2015) identificou que as crianças prematuras com morbidades respiratórias significativas estavam em maior risco de atrasos no desenvolvimento cognitivo, nos primeiros dois anos de idade.

As crianças nascidas prematuras são propensas a ter níveis mais elevados do hormônio de crescimento $(\mathrm{GH})$ nos primeiros dias de vida, em comparação com crianças nascidas a termo. Contudo, pouco se sabe sobre a influência do hormônio de crescimento no desenvolvimento do cérebro, especialmente em recém-nascidos muito prematuros (<30 semanas de gestação). Levando este fato em consideração, o estudo de Scratch et al. (2015) teve como objetivo explorar a relação entre as concentrações de $\mathrm{GH}$ pós-natal e sua associação com o desempenho cognitivos e funcionamento do cérebro aos sete anos de idade. Resultados indicaram que níveis mais elevados de GH foram relacionados com pior desempenho em memória verbal de trabalho e transferência de tarefas de atenção.

O estudo de Sansavini et al. (2014) descreveu as trajetórias cognitivas de crianças extremamente pequenas para idade gestacional, em comparação com seus pares nascidos a termo. Os autores identificaram desempenho significativamente pior na área cognitiva aos 12 meses, não sendo superadas essas desvantagens aos três anos de idade, mesmo sendo levada em consideração a idade corrigida para prematuridade. Prejuízos para o desempenho cognitivo, também foi identificado em crianças prematuras extremas, no estudo de Johnson et al. (2009). Ao avaliar as crianças aos seis anos de idade, os autores identificaram déficits cognitivos em torno de $41 \%$ nas crianças prematuras, em comparação com $1 \%$ para o grupo de crianças a termo. Além disso, em um estudo transversal com crianças prematuras de muito baixo peso entre 18 a 24 meses de idade corrigida, avaliadas pelas escalas Bayley III, 6,9\% apresentaram alteração cognitiva (Fernandes et al., 2012).

Considerando a maioria dos estudos acima citados, em geral o desempenho cognitivo das crianças pré-termo encontra-se em desvantagem em relação às 
crianças nascidas a termo e os prejuízos variam em função do nível de prematuridade e da idade das crianças.

\subsection{0 sistema de atenção de crianças nascidas pré-termo}

Um dos mecanismos potenciais que podem explicar o risco elevado de crianças prematuras em desenvolver problemas cognitivos e comportamentais mais tarde são os processos de atenção. Essa é definida pela capacidade da criança se orientar, alternar entre e manter o foco em eventos, objetos, tarefas e problemas no mundo externo, processos que são dependentes do funcionamento de redes de atenção no cérebro (Van de Weijer-Bergsma et al., 2008). De acordo com Posner \& Rothbart (2000) os processos de atenção ajudam os processos de autorregulação no desenvolvimento.

A atenção é uma condição importante para o aprendizado em sala de aula e em casa (Jaekel et al., 2013). Na população em geral, a desatenção foi classificada como um melhor preditor do desempenho acadêmico para hiperatividade e impulsividade (Duncan et al., 2007). Estudos anteriores relataram pior desempenho escolar e dificuldades cognitivas (funções executivas, memória e atenção seletiva de trabalho) em crianças nascidas pré-termo, em comparação a crianças nascidas a termo (Bhutta et al., 2002; Leversen et al., 2012; Mulder, Pitchford, Hagger, \& Marlow, 2009; Saigal, et al., 2003b).

A partir de uma revisão de literatura sobre o desenvolvimento da atenção em crianças nascidas pré-termo (Van de Weijer-Bergsma et al., 2008) pode-se verificar que os bebês nascidos pré-termo apresentaram orientação visual da atenção menos amadurecida, menor sustentação da atenção e apresentaram mais dificuldade na atenção executiva, quando comparados a bebês nascidos a termo. Além disso, foi verificado que crianças nascidas pré-termo são mais propensas a terem problemas com a inibição de distratores potenciais durante tarefas de atenção executiva e dificuldades de inibir uma resposta impulsiva.

A área de atenção envolve os processos de orientação, regulação e persistência. Prematuros parecem ser mais "distraídos" e menos capazes de controlar suas emoções, assim como são menos capazes de manter o foco a atenção em um objeto, ou sobre o que eles estão fazendo. Tal instabilidade não 
favorece que os recém-nascidos prematuros ativem uma série de mecanismos e processos cognitivos (absorção e seleção de informações, concentração, entre outros) que são funcionais para um ajuste racional nas situações (Perricone \& Morales, 2011).

No entanto, não existe uma única definição de atenção na literatura. Alguns autores sugeriram que isso pode ser devido ao fato de tal construto demandar, possivelmente, uma gama muito grande de operações mentais (Castro, Rueda, \& Sisto, 2012; Cecílio-Fernandes \& Rueda, 2007).

O modelo de sistema de atenção proposto por Posner (1980) distingue três redes atencionais: alerta, orientação e execução. O alerta é o aspecto mais fundamental da atenção e descreve o estado de vigília e de excitação de um organismo. De modo geral, este estado de alerta leva a respostas mais rápidas, mas frequentemente acompanhadas por um aumento de erros (Posner \& Petersen, 1990). A orientação é a seleção de informações sensoriais e controle executivo envolve os mecanismos para resolver conflitos entre os pensamentos, sentimentos e respostas (Posner \& Fan, 2001).

Atualmente verifica-se, na literatura, um crescente interesse pelo estudo da atenção, o que justifica sua importância para o desenvolvimento cognitivo, emocional e social para o indivíduo (Karatekin, 2001). Estudos têm indicado que crianças prematuras têm dificuldades atencionais, nas funções executivas (Elgen, Lundervold, \& Sommerfelt, 2004) e um impacto negativo no desempenho escolar associado (Anderson et al., 2003; Bhutta et al., 2002).

De acordo com o estudo de Gillberg (2003), crianças nascidas pré-termo apresentam menor capacidade de orientar e regular a sua própria atenção, manter a focalização em um objeto e mover sua atenção de um estímulo para outro. $O$ autor destaca que esses são processos cujo o prejuízo pode ser um fator de risco provável para dificuldades na aprendizagem escolar. Os achados reforçam que crianças nascidas muito prematuras (<32 semanas de gestação) e / ou com muito baixo peso (<1.500 g de peso ao nascer) estão em risco maior para apresentar alterações cognitivas, problemas comportamentais e baixo rendimento acadêmico (Aarnoudse-Moens, Weisglas-Kuperus, Van Goudoever, \& Oosterlaan, 2009; Johnson \& Marlow, 2011). Além disso, as crianças nascidas pré-termo apresentam maior prevalência de sintomas de TDAH do que crianças nascidas a termo 
(Aarnoudse-Moens et al., 2009), em particular com sintomas de desatenção (Johnson et al., 2010).

O maior risco para o TDAH para o subtipo desatenção, em crianças muito prematuras e nascidas muito baixo peso, pode ser resultante de mudanças globais na anatomia do cérebro, conectividade ou alteração no desenvolvimento da arquitetura funcional (Johnson et al., 2010). Essas alterações no desenvolvimento do cérebro aumentam a probabilidade de disfunção cognitiva (Mento \& Bisiacchi, 2012) e podem resultar em funcionamento diminuído da atenção, além de lentidão na velocidade de processamento afetando, assim, o desempenho acadêmico (Mulder et al., 2011).

Algumas pesquisas mostram que as dificuldades de aprendizagem e problemas comportamentais estão associadas a déficits na função executiva (Lezak, Howieson, \& Loring, 2004; Mazzocco \& Kover, 2007). As funções executivas são definidas por um conjunto de processos cognitivos, que ocorrem no córtex préfrontal, relacionados à habilidade de responder adaptativamente a situações singulares (Elliott, 2003). A função executiva ajuda a regulação do comportamento e cognição, além de incluir inibição, memória de trabalho, flexibilidade seleção cognitiva, planejamento e organização. O estudo de Weindrich, Jennen-Steinmetz, Laucht e Schmidt (2003) mostrou que o desempenho escolar, aos 11 anos de idade, de crianças com baixo peso está relacionado com o desempenho em um teste de concentração e habilidades de atenção avaliadas pelos pais. $O$ estudo de coorte prospectivo de Kallankari, Kaukola, Olsén, Ojaniemi e Hallman (2015) demonstrou que crianças em idade escolar nascidas muito pré-termo (<32 semanas), sem qualquer alteração neurológica significativa ou comprometimento do desenvolvimento, tiveram pior desempenho em habilidades atividades visoespaciais, competências sensório-motoras, atenção e função executiva, em comparação com crianças nascidas a termo.

Ao observarem a atenção seletiva e sustentada de crianças prematuras com baixo peso ao nascer (entre 1.500 e $2.500 \mathrm{~g}$ ) aos seis anos de idade, Breslau, Chilcoat, DelDotto, Andreski e Brown (1996) mostraram que as crianças com muito baixo peso apresentaram pior desempenho em tarefas de atenção seletiva quando comparadas com às que nasceram com peso acima de $2.500 \mathrm{~g}$. No estudo de Shum, Neulinger, O'Callaghan e Mohay (2008) foram avaliadas crianças 
extremamente prematuras ( $\leq 27$ semanas de idade gestacional) com idade entre sete a nove anos. Os resultados mostraram que as crianças prematuras apresentaram dificuldades com a memória de trabalho, atenção seletiva, atenção e habilidades de transferência. Os dados do estudo de Deforge, Andre, Hascoet, Toniolo, Demange e Fresson (2006) corroboram os demais resultados ao identificar prejuízos na atenção em uma amostra de crianças pré-termo (28 a 36 semanas de idade gestacional) na faixa etária de 8 a 10 anos. Reafirmando os dados acima o estudo de Jaekel et al. (2013) descobriram que, crianças muito baixo peso e muito prematuras, estavam em maior risco para problemas de atenção específicos aos seis e oito anos, mas não para o comportamento hiperativo ou impulsivo, comparados com seus pares nascidos a termo.

No estudo de Bayless e Stevenson (2007) crianças nascidas pré-termo (28 a 32 semanas de idade gestacional) e crianças nascidas a termo entre seis e 12 anos de idade foram avaliados quanto ao QI, a Função Executiva e atenção sustentada e seletiva. Os resultados demonstraram que as crianças nascidas prematuras tiveram dificuldades na função executiva e na atenção, quando comparadas com seus pares nascidos a termo. Esses dados corroboram o estudo recente de Aarnoudse-Moens, Smidts, Oosterlaan, Duivenvoorden, \& Weisglas-Kuperus, (2009) em que foram avaliadas crianças prematuras ( $\leq 30$ semanas de idade gestacional) em idade escolar e comparadas a um grupo de crianças nascidas a termo. Os autores identificaram que o grupo de prematuros demonstrou pior desempenho em comparação com os controles em todos os domínios da função executiva.

Embora a atenção e a autorregulação estejam sendo estudadas separadamente, tem sido realizado esforço para integrá-los considerando hipóteses sobre os mecanismos neurais específicos envolvidos na autorregulação e sua relação com a atenção e de controle com esforço (Rueda, Posner, \& Rothbart, 2004).

O fato de as crianças prematuras, em idade pré-escolar, estarem em risco para apresentar dificuldades nos processos de atenção pode estar associado ao diagnóstico de Transtorno de Déficit de Atenção (Jaekel et al., 2013) e Hiperatividade (Bayless \& Stevenson, 2007; Salt \& Redshaw, 2006). Este dado tem levado pesquisadores a propor que os problemas no início da regulação da atenção podem ser à base da variabilidade individual entre os bebês nascidos prematuros e 
sua vulnerabilidade como um grupo para atraso no desenvolvimento e problemas de aprendizagem (Aylward, 2005).

Poucos são os estudos sobre os processos regulatórios e de atenção. Este fato é destacado na revisão de literatura sobre o desenvolvimento da atenção em crianças nascidas pré-termo, que identificou que poucos estudos exploraram a relação do temperamento da criança e sistemas de atenção (Van de WeijerBergsma et al., 2008).

\subsection{0 impacto do nascimento prematuro no temperamento da criança}

As características de temperamento de crianças podem predizer psicopatologias do desenvolvimento e, desta forma, podem ajudar na compreensão dos transtornos de comportamento (Chang, Blasey, Ketter, \& Steiner, 2003). Desta maneira identifica-se que o temperamento desempenha um importante no interjogo entre fatores de risco e mecanismos de proteção, na trajetória de desenvolvimento da criança.

De acordo com Rothbart (1986) o temperamento é definido como diferenças individuais biologicamente baseadas na reatividade e autorregulação. A reatividade se refere à intensidade e a aspectos temporais dos comportamentos ligados ao sistema nervoso central, autonômo e endócrino. A autorregulação representa os processos que modulam as reações, incluindo comportamentos como aproximação, imitação e atenção. O temperamento seria considerado como a base biológica para a estruturação da personalidade e um dos fatores que influenciam o comportamento, enquanto a personalidade seria um termo mais amplo que inclui outras estruturas importantes além dessas, tais como as estruturas cognitivas e autoconceito.

Em 2006, Rothbart, Posner e Kieras redefinem o temperamento incluindo outros variáveis, além do biológico. No interjogo destacam-se alguns aspectos, tais como: a) diferenças individuais do temperamento em seus extremos podem constituir-se em psicopatologia ou predispor o indivíduo a esta; b) características de temperamento provocam reações em outras pessoas as quais podem promover ou neutralizar os riscos para psicopatologia; c) características de temperamento podem influenciar a seleção dos contextos da pessoa (nichos de desenvolvimento), expondo-a a mais ou menos riscos, para transtornos psicopatológicos; d) 
características do temperamento podem influenciar tanto a maneira de expressão de um transtorno, quanto a sua evolução e a probabilidade de sua recidiva; e) características do temperamento podem influenciar no processamento de informação sobre si mesmo e sobre o mundo, aumentando ou diminuindo a probabilidade para psicopatologia; $f$ ) características do temperamento podem regular ou neutralizar os fatores de risco ou estresse; g) as dimensões do temperamento interagem entre si e algumas delas se desenvolvem tardiamente; $h$ ) disposições do temperamento podem moldar diferentes direções para um resultado desenvolvimental, assim como podem levar a múltiplos resultados; i) características do temperamento e do ambiente de cuidado podem trazer efeitos independentes ao desenvolvimento ou efeitos interativos entre variáveis, aumentando ou diminuindo o risco para um transtorno; j) um determinado transtorno, por si só, pode ter o efeito de mudar aspectos do temperamento do indivíduo.

Segundo Rothbart (1986) algumas dimensões que podem sofrer alterações ao longo do tempo e são consideradas elementos de temperamento, como: a) reatividade negativa (aversão à aproximação e expressão de sentimentos negativos); b) reatividade positiva (aproximação e expressão de sentimentos positivos); c) inibição comportamental para estímulos novos e intensos; d) capacidade de fixar a atenção.

A autorregulação é um aspecto central de muitos modelos de temperamento. No modelo de Rothbart, a autorregulação inclui os processos de atenção e controle com esforço como função para modular as tendências reativas de um indivíduo (Rothbart \& Derryberry, 1981; Ruff \& Rothbart, 1996). Desta forma, é possível que bebês nascidos prematuros sejam frequentemente descritos pelos clínicos e pais com bebês "mais difíceis" e "menos sensíveis" sugerindo que, os recém-nascidos prematuros têm problemas com a autorregulação (Weiss, Jonn-Seed, \& Wilson, 2004). Assim, a percepção parental precoce do temperamento infantil e autorregulação, em particular, pode ser um valioso preditor de desenvolvimento de atenção em recém-nascidos prematuros (Van de Weijer-Bergsma et al., 2008).

Os estudos sobre temperamento descrevem que os fatores e as dimensões do temperamento abrangem processos reativos que abarcam os sistemas motores e sensoriais, e uma ênfase nos processos de autorregulação (Putnam, Gartstein, \& Rothbart, 2006; Rothbart, Cheu e Gartstein, 2001). Sendo assim, são identificados 
três fatores no temperamento: Afetividade Negativa, Extroversão e Controle com Esforço. O fator Afeto Negativo inclui dimensões do tipo frustração, tristeza, medo e desconforto, o fator extroversão inclui dimensões do tipo antecipação positiva, nível de atividade e impulsividade e, por fim, o fator Controle com esforço inclui dimensões do tipo prazer de baixa intensidade, controle inibitório e focalização de atenção. O Controle com esforço inclui, portanto, as habilidades para administrar voluntariamente a atenção (regulação da atenção) e inibem (controle inibitório) ou ativam (controle ativacional) do comportamento para a adaptação (Rothbart \& Bates, 1998).

Embora quase todas as crianças melhorem muito o controle com esforço nos primeiros cinco anos de vida existem grandes diferenças individuais nessa evolução. Como é verdade para outros aspectos do temperamento, as diferenças individuais em controle com esforço são influenciadas por dois fatores biológicos (hereditários e fatores constitucionais) e influências ambientais (Kopp \& Neufeld, 2003). Acredita-se que o controle com esforço envolve habilidades executivas e da atenção (Posner \& Rothbart, 1998). O controle com esforço pode sugerir a capacidade de adiar ou abrandar a atividade motora, suspender ou iniciar uma atividade, direcionar a atenção voluntariamente, ou mesmo ser capaz de baixar o tom de voz (Kochanska, Murray, \& Harlan, 2000). São estes processos regulatórios, para os quais os mecanismos de regulação da atenção contribuem significativamente, e que possibilitam ao indivíduo modular e regular a sua reatividade (Rothbart \& Bates, 1998). O controle com esforço, em particular da atenção, permite mudanças rápidas nas atividades que envolvem áreas cerebrais específicas e tem sido apontado como um dos mecanismos responsáveis pela plasticidade cerebral (Posner \& Rothbart, 2000).

Alguns estudos enfocam o constructo temperamento em amostras de crianças vulneráveis, como as crianças nascidas pré-termo de baixo peso utilizando o referencial teórico de Rothbart (Cassiano \& Linhares, 2015; Cosentino-Rocha, Klein, \& Linhares, 2014; Klein, 2009; Klein, Gaspardo, \& Linhares, 2011; Klein, Gaspardo, Martinez, Grunau, \& Linhares, 2009; Poehlmann et al., 2011).

Os fatores e dimensões do temperamento foram avaliados por meio da abordagem teórico-conceitual de Rothbart, em crianças nascidas pré-termo, comparadas a crianças nascidas a termo na fase dos três primeiros anos de idade 
cronológica (Klein, 2009). As crianças nascidas pré-termo apresentaram maiores escores em ativação motora, sensibilidade perceptual e prazer de alta intensidade e menores escores em aconchego do que as crianças nascidas a termo.

No estudo de Cosentino-Rocha (2012) com objetivo de examinar o efeito das variáveis nascimento prematuro e gênero no temperamento de crianças nascidas pré-termo, na faixa etária de 18 a 36 meses foram identificados que em relação às dimensões dos fatores do temperamento, obteve-se o efeito direto da prematuridade no temperamento. As crianças prematuras apresentaram significativamente maiores escores em prazer de alta intensidade e sensibilidade perceptual e menores escores em desconforto, aconchego e focalização da atenção, em comparação ao grupo de crianças nascidas a termo.

Em um estudo com crianças menores do que as do presente estudo, Kerestes (2005) comparou crianças nascidas pré-termo e crianças nascidas a termo em relação ao temperamento avaliado aos seis e 12 meses de idade. Foi encontrada diferença no nível de atividade do temperamento; os bebês saudáveis nascidos prétermo foram avaliados por suas mães como mais ativos do que os bebês nascidos a termo.

No recente estudo de Cassiano e Linhares (2015) com objetivo de elaborar e testar um modelo combinado de avaliação do temperamento em crianças nascidas pré-termo e a termo, na fase de 18 a 36 meses de idade diferenciadas pela idade gestacional, e do comportamento em interação com suas mães. As autoras identificaram que, em relação às características do temperamento infantil, as crianças nascidas pré-termo revelaram o fator afeto negativo com escore mais baixo do que para os fatores extroversão e controle com esforço. Com relação à comparação entre os grupos as médias dos fatores foram próximas.

Embora os estudos sobre o temperamento das crianças tenham avançados nos últimos anos, poucos focalizam esse relevante constructo nas amostras de crianças nascidas pré-termo.

\section{6 impacto do nascimento prematuro na área do comportamento da criança}

Quanto aos possíveis problemas de comportamento que as crianças podem apresentar ao longo do desenvolvimento, Achenbach (1992) diferenciou três 
categorias de transtornos: problemas externalizantes, quando o comportamento desviante é dirigido para fora (como por exemplo, transtornos de conduta, delinquência e agressividade), problemas internalizantes, quando o desvio é interno (transtornos emocionais como depressão e ansiedade e transtornos alimentares) e problemas de atenção (transtorno de déficit de atenção e hiperatividade).

Com objetivo de comparar a prevalência de problemas de comportamento em crianças muito prematuras e crianças nascidas a termo aos três anos de idade, Delobel-Ayoub et al. (2006) analisaram os fatores associados aos problemas comportamentais e verificaram que as crianças muito prematuras (22 a 32 semanas de idade gestacional) apresentaram risco maior de problemas comportamentais quando comparadas com crianças nascidas a termo. Esta dificuldade comportamental estava associada à presença de lesão cerebral, atraso no desenvolvimento, saúde precária das crianças avaliadas pelos pais e más condições sociais.

Em um artigo de metanálise que revisou 227 estudos sobre resultados comportamentais de lactentes prematuros com peso ao nascimento abaixo de 2.500 gramas foi verificado que as crianças prematuras têm um risco 2,64 vezes maior para o desenvolvimento de TDAH e frequentemente manifestam comportamentos de internalização ou externalização na idade escolar (Bhutta et al., 2002). Em outro estudo multicêntrico, envolvendo a participação de quatro países diferentes, com crianças nascidas prematuras, foram observados escores elevados semelhantes de TDAH, com a implicação de que mecanismos biológicos relacionados com a prematuridade contribuem para esse resultado (Hille et al., 2001).

O estudo realizado por Yu, Buka, McCormick, Fitzmaurice e Indurkhya (2006) teve por objetivo investigar a comorbidade de déficit na aprendizagem verbal e não verbal associada a problemas de comportamento em crianças nascidas prematuras e com baixo peso ao nascer, aos oito anos de idade. Os dados evidenciaram que crianças nascidas prematuras com baixo peso ao nascer, com déficit de aprendizado na área verbal, tiveram duas vezes mais chance de exibir níveis clínicos de problemas de comportamento total e $89 \%$ das crianças demonstraram problemas de comportamento externalizantes. As crianças eram mais irritáveis, choronas, inseguras e tinham mais indicadores de baixa autoestima, traços depressivos, comportamento opositor, tiques, inibição social e comportamento estereotipado. 
No estudo de revisão da literatura científica, Vanderbilt e Gleason (2011) verificaram que o índice de transtornos de atenção e de hiperatividade na população geral é de 5 a $7 \%$, aumentando para 7 a $30 \%$ em crianças com baixo peso ao nascer $(<2.500 \mathrm{~g})$ e para 15 a $40 \%$ em crianças com extremo baixo peso ao nascer. Os autores concluíram que, em todos os grupos etários estudados, os dados sugeriram que o status de prematuro está associado a um maior risco de efeitos adversos à saúde mental e aos desfechos neurodesenvolvimentais, especialmente quando acompanhados de fatores de risco médicos ou psiquiátricos e condições socioeconômicas desfavorecidas. No entanto, os autores recomendaram cuidado na interpretação dos resultados baseados em instrumentos respondidos pelos pais, uma vez que estes avaliam a percepção do adulto em relação à vulnerabilidade das crianças, em vez de avaliar os padrões comportamentais das crianças.

Em outro estudo de metanálise com estudos publicados no período de $1998 \mathrm{e}$ 2008 com crianças nascidas pré-termo ( $\leq 33$ semanas de idade gestacional) e/ou com baixo peso ao nascer $(\leq 1.500 \mathrm{~g}$ ) (Aarnoudse-Moens et al. 2009), objetivou-se analisar os efeitos do nascimento pré-termo e do baixo peso ao nascer no desempenho acadêmico, funcionamento comportamental e função executiva. Os resultados dessa metanálise comprovaram a presença de dificuldades no desempenho acadêmico, sintomas de falta de atenção, problemas comportamentais internalizantes e função executiva pobre em crianças pré-termo e/ou nascidas com muito baixo peso em comparação aos grupos controles.

No estudo de Farooqi, Hagglof, Sedin, Gothefors e Serenius (2007) foram examinadas crianças nascidas pré-termo aos 11 anos, que nasceram com 26 semanas de idade gestacional na Suécia, entre 1990 e 1992, com relação aos problemas comportamentais, emocionais e de competência social, na perspectiva dos pais, professores e as próprias crianças. As crianças foram estudadas e comparadas com um grupo controle, pareados pela idade e sexo. Os resultados mostraram que, em comparação com o grupo controle, os pais e professores das crianças extremamente prematuras relataram mais problemas em relação aos comportamentos internalizantes (ansiedade, depressão e problemas somáticos) e atenção, pensamento e problemas sociais. Deste modo, as crianças estão em risco para problemas de saúde mental, com piores resultados em relação ao desempenho escolar. Essas dificuldades parecem persistir com o avanço da idade, com níveis 
elevados de transtornos depressivos graves declarados por adolescentes nascidos com baixo peso ao nascer (Nomura et al., 2007). A alta prevalência de problemas comportamentais e cognitivos após o nascimento prematuro tem estimulado o interesse em identificar os precursores no desenvolvimento das dificuldades apresentadas em fases posteriores (Olafsen et al., 2008).

Em um estudo recente de comparação de coorte longitudinal sobre 0 comportamento, utilizando o $\mathrm{CBCL}$, com crianças prematuras extremo $(\leq 28$ semanas) ou com extremo baixo peso de nascimento $(\leq 1,000 \mathrm{~g})$ foram avaliados aos 10 e 18 anos de idade. Identificou-se que, aos 10 anos de idade, meninos nascidos extremamente prematuros foram avaliados como tendo substancialmente mais problemas em competência emocional e comportamento do que seus pares nascidos a termo, enquanto aos 18 anos de idade essas diferenças foram consideravelmente menores. Por outro lado, nas meninas, as diferenças foram menores e não houveram muitas mudanças, durante o período da puberdade (Vederhus et al., 2015).

No estudo de Potharst, Van Wassenaer, Houtzager, Van Hus, Last, e Kok, (2011) com crianças muito baixo peso aos cinco anos de idade corrigida foram comparadas as crianças a termo, pelo questionário de comportamento The Strength and Difficulties Questionaire (SDQ), administrado por pais e professores. Foi identificado mais risco para problemas de comportamento nas crianças pré-termo do que nos seus pares.

No estudo de Delobel-Ayoub et al. (2009) comparou-se a frequência de problemas de comportamento em crianças muito prematuras com seus pares nascidos a termo aos 5 anos de idade, a partir da visão dos pais com o instrumento (SDQ). Os pais das crianças pré-termo relataram significativamente mais problemas comportamentais, com uma prevalência duas vezes maior em comparação com crianças a termo para problemas de hiperatividade/desatenção, sintomas emocionais e problemas com os pares. Os autores identificaram que problemas comportamentais foram associados com baixo desempenho cognitivo, atraso no desenvolvimento, hospitalizações da criança, baixa idade materna e bem estar materno.

No estudo recente de coorte descritivo prospectivo de Brown, Burns, Watter, Gibbons e Gray (2015) crianças extremamente prematuro (<28 semanas) ou 
extremo baixo peso ao nascer (< 1000g) foram investigadas entre 4 e 5 anos de idade com relação ao seu comportamento. Os achados indicaram que todos os participantes do estudo foram classificados como 'normal' em escores da escala de síndromes do CBCL, tanto para os comportamentos internalizantes quanto para os externalizantes. Cabe salientar, que o estudo excluiu as crianças com anomalias congênitas importantes, diagnosticado de deficiências neurológicas, incluindo paralisia cerebral, deficiência visual não corrigida pelo uso de lentes corretivas, ou uma deficiência auditiva não corrigida por meio de ajudas.

Em um estudo recente realizado por Correia, Saur e Loureiro (2014), que teve como um dos objetivos comparar o desempenho comportamental de uma coorte de crianças estratificada pelo peso ao nascer em relação à idade gestacional. Participaram do estudo 677 crianças avaliadas por meio do Questionário de Capacidades e Dificuldades, na faixa de 10 a 11 anos de idade. As autoras identificaram que o grupo de crianças com baixo peso ao nascimento apresentou mais sintomas emocionais quando comparadas com o grupo peso normal; que o grupo muito baixo peso apresentou mais comportamentos de hiperatividade em comparação aos demais grupos. Já as crianças do grupo PIG apresentaram escores mais altos para o total de problemas e mais sintomas emocionais.

Foulder-Hughes e Cooke (2003b) avaliaram o motor, o cognitivo e problemas comportamentais em crianças prematuras nascidas com menos de 32 semanas de idade gestacional, na faixa de sete a oito anos de idade que frequentam escolas regulares. As crianças foram pareadas com crianças a termo. Essas crianças tiveram resultados significativamente melhores do que o grupo pré-termo em relação ao motor, cognitivo e medidas comportamentais. As crianças com menor peso ao nascer e mais prematuras apresentaram escores menores. Crianças prematuras foram mais propensas a ter sinais de desatenção e impulsividade e ter um diagnóstico de TDAH.

Desta maneira, nota-se nas pesquisas sobre problemas de comportamento (Gray et al., 2004; Reijneveld et al. 2006; Stoelhorst, Martens, et al., 2003; Stoelhorst, Rijken, et al., 2003) em diferentes idades (da fase pré-escolar estendendo-se à pré-adolescência) que a prematuridade encontra-se associada a problemas de atenção, assim com uma grande variedade de problemas emocionais e comportamentais (Elgen, Sommerfelt, \& Markestad, 2002), transtorno de déficit de 
atenção (Loe et al., 2013; Saigal, Pinelli, Hoult, Kim, \& Boyle, 2003a), problemas internalizantes (Anderson et al., 2003; Bhutta, et al. 2002; Loe et al., 2013), problemas externalizantes (Klein, Rocha, Martinez, Putnam, \& Linhares, 2013) e problemas sociais (Dahl et al., 2006; Resegue et al., 2007).

Com base nos estudos sobre o desenvolvimento de prematuros pode-se verificar algumas lacunas sobre as relações entre o nascimento prematuro e as intercorrências associadas e os indicadores de cognição, atenção, temperamento e comportamento analisados de forma integrada. 


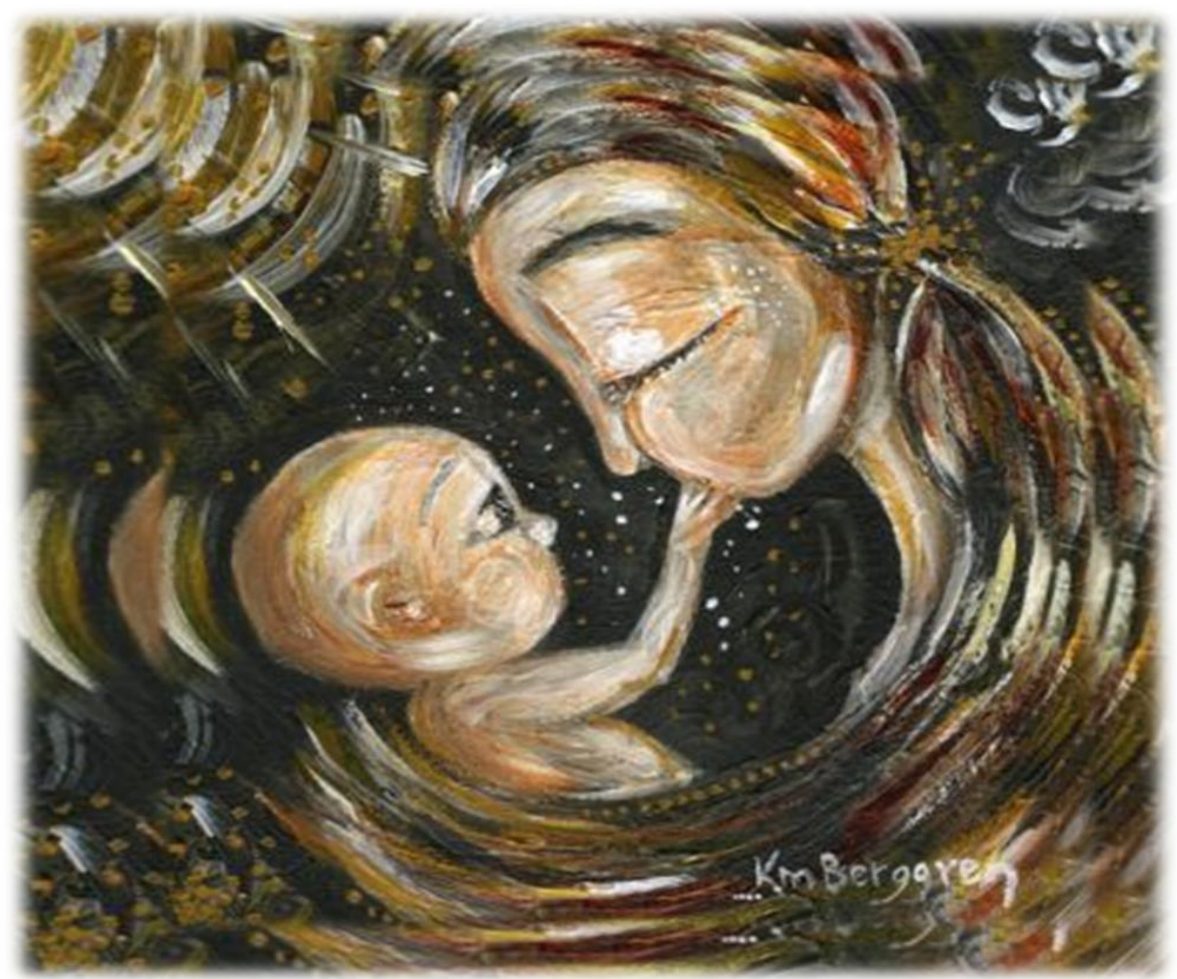

Artigo II- Todo prematuro tem o direito de ser, em todos os lugares, reconhecido como pessoa perante a lei (Tavares, 2009). 


\subsection{Objetivo Geral}

O presente estudo teve por objetivo examinar as associações entre as condições clínicas neonatais e os indicadores de cognição, atenção, temperamento e comportamento na fase pré-escolar, em crianças nascidas pré-termo.

\subsection{Objetivos Específicos}

a) Caracterizar a cognição, a atenção, o temperamento e o comportamento na fase pré-escola, em crianças nascidas pré-termo;

b) Comparar os indicadores de cognição, atenção, temperamento e comportamento em grupos diferenciados pelo nível de prematuridade ao nascimento;

c) Examinar a influência dos indicadores clínicos neonatais, a cognição, a atenção, o temperamento e o comportamento associados ao sexo, escolaridade dos pais e nível socioeconômico familiar, na cognição das crianças nascidas pré-termo, na fase pré-escolar;

d) Examinar a influência dos indicadores clínicos neonatais, a cognição, a atenção e o temperamento associados ao sexo da criança, escolaridade dos pais e nível socioeconômico familiar, no comportamental das crianças nascidas pré-termo na fase pré-escolar. 


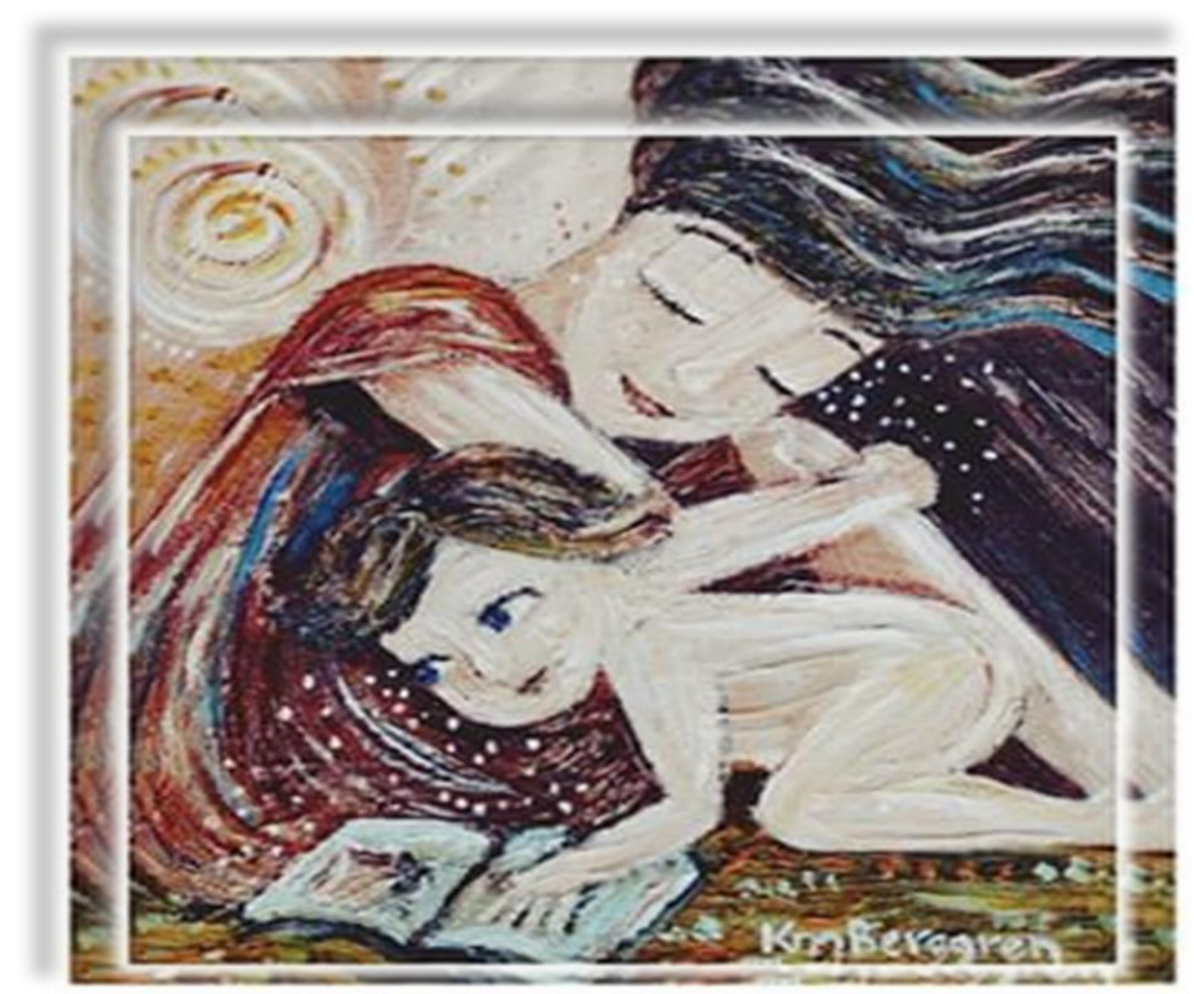

Artigo III - Nenhum prematuro será arbitrariamente exilado de seu contexto familiar de modo brusco ou por tempo prolongado. A preservação deste vínculo, ainda quando silenciosa e discreta, é parte fundamental de sua vida (Tavares, 2009). 


\subsection{Delineamento do estudo}

Estudo de corte transversal, análise de comparação entre grupos e análise de predição.

\subsection{Participantes}

A amostra do presente estudo foi composta por 50 crianças nascidas prétermo (PT) com muito baixo peso (MBP), de ambos os sexos, na faixa de seis anos a sete anos e 11 meses de idade cronológica, nascidas no Hospital das Clínicas da Faculdade de Medicina de Ribeirão Preto-USP (HCFMRP-USP).

Os critérios de inclusão, que definiram os participantes elegíveis para o estudo foram, os seguintes: crianças nascidas pré-termo $(<37$ semanas de idade gestacional), com muito baixo peso (< 1.500 gramas) com idade de 6 a 7 anos e 11 meses de idade cronológica, nascidas no HCFMRP/USP e que passaram por internação na UTIN do referido hospital.

Os critérios de exclusão, por sua vez, foram os seguintes: malformação congênita, cuidador principal com transtorno psiquiátrico, crianças com deficiências graves que não conseguissem realizar os testes de avaliação, crianças abrigadas ou adotadas e crianças cujos cuidadores não autorizaram participar do estudo.

A Figura 1 apresenta a descrição da trajetória de composição da amostra do estudo. 


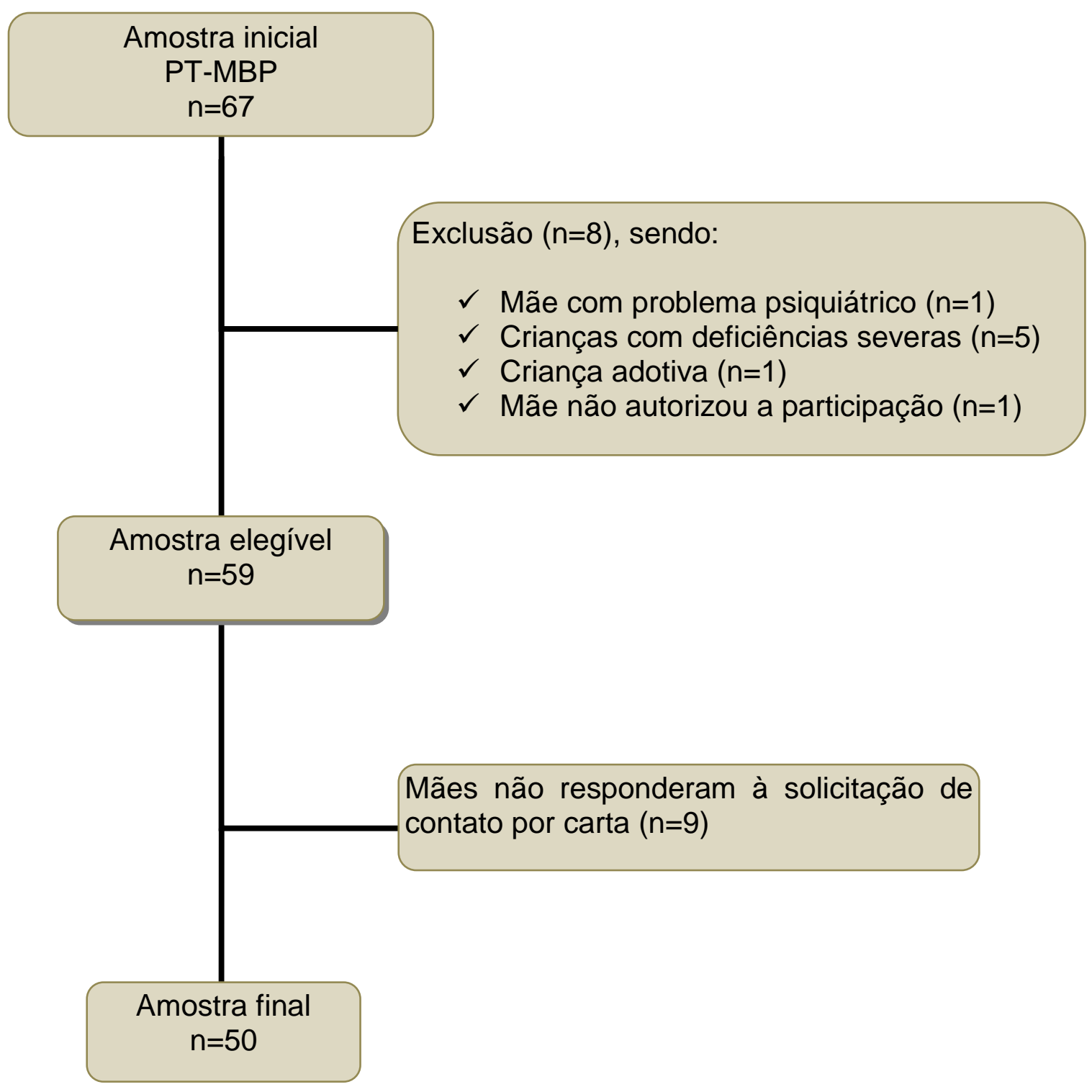

Figura 1- Percurso de composição da amostra do estudo de crianças nascidas pré-termo e muito baixo peso (PT-MBP).

Na Figura 1 verifica-se que, para a composição da amostra do estudo, foi feita uma busca no Sistema Integrado de Consultas (SIC) do HCFMRP-USP, para localização de endereços e retornos de rotina ao referido hospital, que atendiam aos critérios de inclusão. A amostra inicial foi de 67 crianças, sendo que destas foram excluídas oito crianças. Os motivos da exclusão foram os seguintes: uma criança a mãe apresentava transtorno psiquiátrico (identificado a partir do relato materno), cinco crianças tinham deficiências graves (deficiência mental, visual, auditiva ou de linguagem), o que dificultava a aplicação dos testes e uma mãe não aceitou 
participar do estudo. A amostra elegível foi de 59 crianças, porém nove não responderam às cartas enviadas. Portanto, a amostra final foi de 50 crianças.

\subsection{Aspectos Éticos}

O presente estudo atendeu às exigências éticas para as pesquisas envolvendo seres humanos, o desenvolvimento deste estudo está amparado nas resoluções no 466, de 12/12/2012. O presente projeto foi aprovado pelo Comitê de Ética em Pesquisa do Hospital das Clínicas da Faculdade de Medicina de Ribeirão Preto-USP, em 22/11/2010 de acordo com o Processo HCRP no 11847/2010 (ANEXO A). As mães foram informadas sobre o objetivo do estudo e assinaram ao Termo de Consentimento Livre e Esclarecido (APÊNDICE A) e estas também foram orientadas que poderiam desistir de sua participação a qualquer momento. Foram oferecidas devolutivas sobre as avaliações da criança às mães participantes do estudo.

\subsection{Local da Pesquisa}

O presente estudo foi desenvolvido junto aos Serviços de Neonatologia e Psicologia Pediátrica do HCFMRP-USP. A coleta de dados foi realizada em salas de consultórios, que permitiram a entrevista com o cuidador, a observação, a execução das atividades dos testes pelas crianças e 0 registro das respostas e comportamentos das mesmas. A análise de dados foi realizada no Laboratório de Pesquisa em Prevenção de Problemas de Desenvolvimento e Comportamento da criança (LAPREDES), na Faculdade de Medicina de Ribeirão Preto- USP.

\subsection{Contexto da pesquisa}

As crianças da amostra do estudo nasceram no HCFMRP-USP e passaram pelos seguintes contextos ambientais do hospital: 


\subsubsection{Unidade de Terapia Intensiva Neonatal (UTIN)}

A UTIN do HCFMRP-USP é composta por 17 leitos e possui três enfermarias para recém-nascidos admitidos de outros serviços ou com patologias crônicas e um salão com oito leitos para recém-nascidos prematuros. Possui uma equipe interdisciplinar composta por: médicos contratados fixos e médicos, contratados em sistema de rodizio de plantão, e residentes da Pediatria, Enfermeiras, técnico de enfermagem e auxiliares de enfermagem, uma fisioterapeuta, uma terapeuta ocupacional, uma fonoaudióloga e duas psicólogas. Além disso, tem equipes de apoio do hospital, das seguintes áreas: Cardiologia, Cirurgia Pediátrica, Neurologia, Genética, Urologia, Endocrinologia, Radiologia entre outras. Diariamente são realizadas visitas médicas com docentes da Faculdade de Medicina da USP para discussão individual de cada caso. Dentro das rotinas da UTIN encontram-se alguns fatores de proteção de cuidados desenvolvimental importantes para 0 neurodesenvolvimento dos recém-nascidos pré-termo internados, tais como diminuição da luminosidade durante a madrugada, preferência pela luz natural à artificial durante o dia e proteção das incubadoras com cueiros para evitar a luz direta no recém-nascido, rolinhos para contenção do recém-nascido, manipulação mínima dos prematuros extremos, apoio psicológico às famílias, visita dos pais liberada durante o período de internação na UTIN e reuniões semanais da equipe para discussão de normas e rotinas do setor. São realizadas também, visitas da família ampliada e dos irmãos, sendo que esta última é acompanha e monitorada pela psicóloga do serviço. Além disso, desde 2008 , a solução de sacarose a $25 \%$ faz parte do protocolo de intervenção não-farmacológica de rotina para o alívio da dor aguda nos recém-nascidos internados na UTIN submetidos a procedimentos invasivos e dolorosos do tipo: lancetagem de calcâneo, acesso venoso central, acesso venoso puncionado para nutrição parenteral e medicações, punção para coleta de sangue para exames, punção para inserção de cateter de acesso central, inserção de sonda orogástrica e aspiração de vias aéreas. 


\subsubsection{Unidade de Cuidados Intermediários Neonatais (UCIN)}

A UCIN do HCFMRP/USP possui uma enfermaria com seis leitos para recémnascidos prematuros extremos e um salão com 21 leitos para outras patologias. Possui uma equipe interdisciplinar composta por: médicos contratados fixos e médicos contratados, em sistema de rodizio de plantão, e residentes da Pediatria, sete enfermeiras, um técnico de enfermagem e 23 auxiliares de enfermagem, uma fisioterapeuta, uma terapeuta ocupacional, duas fonoaudiólogas e duas psicólogas. Além disso, tem as equipes de apoio do hospital, das seguintes áreas: Cardiologia, Cirurgia Pediátrica, Neurologia, Genética, Urologia, Endocrinologia, Radiologia entre outras. Diariamente são realizadas visitas médicas com Docentes da Faculdade de Medicina da USP para discussão individual de cada caso. De rotina são realizadas também visitas da família ampliada e dos irmãos, sendo que esta última é acompanha e monitorada pelas psicólogas do serviço. Há também, semanalmente, um grupo de apoio psicológico às mães dos pacientes.

Assim como na rotina da UTIN, na UCIN encontram-se os mesmos fatores de proteção em cuidado desenvolvimental importantes para o neurodesenvolvimento dos recém-nascidos pré-termo internados e a implantação da solução de sacarose para alívio de dor aguda nos recém-nascidos internados na UCIN submetidos a procedimentos invasivos e dolorosos.

\subsubsection{Ambulatórios de Prematuros}

Os dois Ambulatórios de Neonatologia estão localizados no mesmo hospital. O Ambulatório de Patologia Pulmonar funciona às segundas-feiras, das 13:00 às 17:00 horas e presta atendimento a crianças nascidas prematuras que desenvolveram broncodisplasia pulmonar. O Ambulatório de Neonatologia funciona às quintas-feiras, das 8:00 às 12:00 horas, e presta atendimento às crianças nascidas prematuras com muito baixo peso em boa evolução. Em ambos os ambulatórios as crianças são acompanhadas desde a alta hospitalar até a idade de sete anos de idade, por meio de consultas médicas e do serviço de Psicologia Pediátrica, o qual realiza acompanhamento longitudinal do desenvolvimento e comportamento das crianças realizado por três psicólogas contratadas e duas 
psicólogas do Programa de Aprimoramento Profissional em Psicologia do Desenvolvimento na Área da Saúde do HCFMRP-USP.

O serviço de Psicologia Pediátrico- Neonatologia é coordenado por docente psicóloga da FMRP-USP.

\subsection{Instrumentos e materiais}

3.6.1 Avaliação Cognitiva - Escala de Inteligência Wechsler para Crianças (WISCIII) (Wechsler, 2002). Escala utilizada para a avaliação da inteligência de crianças com idade entre 6 e 16 anos. É constituída por seis subtestes na Escala Verbal que avaliam, principalmente, os fatores de inteligência que dependem de aprendizagem e aquisições prévias, a saber: Informação, Compreensão, Semelhança, Vocabulário, Aritmética e Dígitos. A Escala de Execução, por sua vez, subdivide-se em seis subtestes e um suplementar, os quais avaliam principalmente aspectos maturativos cerebrais. Esta escala é formada por atividades de Completar Figuras, Arranjos de Figuras, Cubos, Armar objetos, Códigos, Procurar Símbolos e Labirintos. O WISC-III fornece o QIT (Quociente de Inteligência Total), o QIV (Quociente de Inteligência Verbal) e o QIE (Quociente de Inteligência de Execução). O índice fatorial, Resistência à Distração (Aritmética e Dígitos) também foi utilizado. As classificações intelectuais são as seguintes: Muito superior ( $\geq 129)$, Superior (120-128), Médio superior (110-119), Médio (90-109), Médio inferior (80-89), Limítrofe (70-79) e Intelectualmente deficiente (569). Há uma versão padronizada, do WISC-III, para a população brasileira, que contem em seu manual e tabelas normativas, além disso estudos na literatura apontam que o teste apresenta uma sustentação sólida em relação à validade, como medida do funcionamento intelectual das crianças. Os índices de análise de fatores e as correlações com outras medidas de capacidade intelectual e aproveitamento escolar apoiam a validade de constructo do instrumento.

Neste projeto foi utilizada a forma compacta do referido teste que incluiu os seguintes subtestes: Informações, Aritmética, Vocabulário e Compreensão, (da área Verbal) e Completar Figuras, Arranjo de Figuras, Cubos e Armar Objetos, (área de Execução) e os itens para avaliar a Resistência a distrabilidade (Dígito e aritmética), de acordo com o manual (Wechsler, 2002; 59 e 60 pp.). Este instrumento deve ser 
utilizado apenas por psicólogo, de acordo com a Resolução CFP N. 005/2012 do Art. 13 da Lei n. ${ }^{\circ} 4.119 / 62$, do Conselho Federal de Psicologia.

3.6.2 Avaliação da atenção - Teste de Atenção por Cancelamento (Montiel \& Seabra, 2009; 2012), avalia a atenção seletiva (capacidade de atentar a um estímulo determinado dentre outros estímulos) e a atenção alternada (capacidade do indivíduo mudar o foco de atenção). Escala utilizada para a avaliação da atenção de indivíduos com idade entre 5 a 14 anos e adulto jovem.

O Teste de Atenção por Cancelamento é composto por três matrizes impressas com diferentes tipos de estímulos, em que a tarefa do indivíduo consiste em assinalar todos os estímulos iguais a um estímulo-alvo anteriormente determinado. $O$ escore bruto para escore total de acertos para idade de seis anos varia de 1 a 109 e pontuação padrão varia de 41 a184.

A primeira fase do teste é destinada à avaliação da atenção seletiva, que consiste na capacidade do indivíduo de atentar a um estímulo determinado dentre outros estímulos diferentes. Para esta tarefa é utilizada uma prova de cancelamento de figuras com uma matriz impressa composta por seis diferentes tipos de estímulos: círculo, quadrado, triângulo, cruz, estrela e traço. Os estímulos são de cor preta em fundo branco, distribuídos em 15 linhas, sendo que cada linha é composta por 20 figuras, totalizando 300 figuras. Deve-se, portanto, assinalar o estímulo-alvo sempre que este recorrer, sendo o tempo máximo de execução da tarefa de um minuto. $O$ escore bruto nesta primeira parte, para idade de seis anos varia de 1 a 50 e pontuação padrão varia de 54 a135. Para idade de sete anos, a pontuação padrão varia de 66 a 122.

A figura 2 representa uma ilustração da primeira parte do Teste de Atenção por Cancelamento, com a representação das respostas corretas.

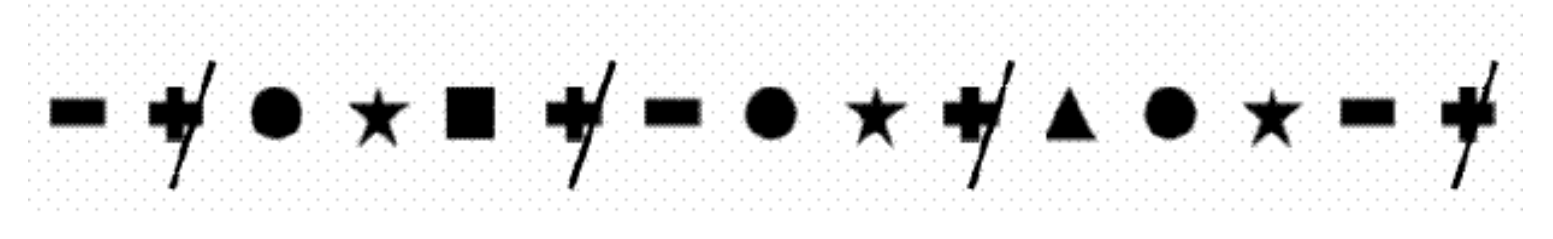


Figura 2- Ilustração da primeira parte do Teste de Atenção por Cancelamento, cujo objetivo é avaliar a atenção seletiva.

Fonte: Montiel \& Seabra (2012).

A segunda fase do instrumento tem por objetivo, assim como na primeira fase, avaliar a atenção seletiva, porém com maior grau de dificuldade. A configuração estrutural da matriz não se modifica, sendo composta por 15 linhas com 20 figuras em cada linha, totalizando 300 figuras. A tarefa é semelhante, porém, nesta segunda fase o estímulo-alvo é composto por duas figuras impressas na parte superior da folha. O escore bruto nesta segunda parte, na idade de seis anos, varia de 1 a 7 e pontuação padrão varia de 91 a182. Para idade de sete anos, a pontuação padrão varia de 100 a 192.

A Figura 3 apresenta uma ilustração da segunda parte do Teste de Atenção por Cancelamento, com a representação das respostas corretas.

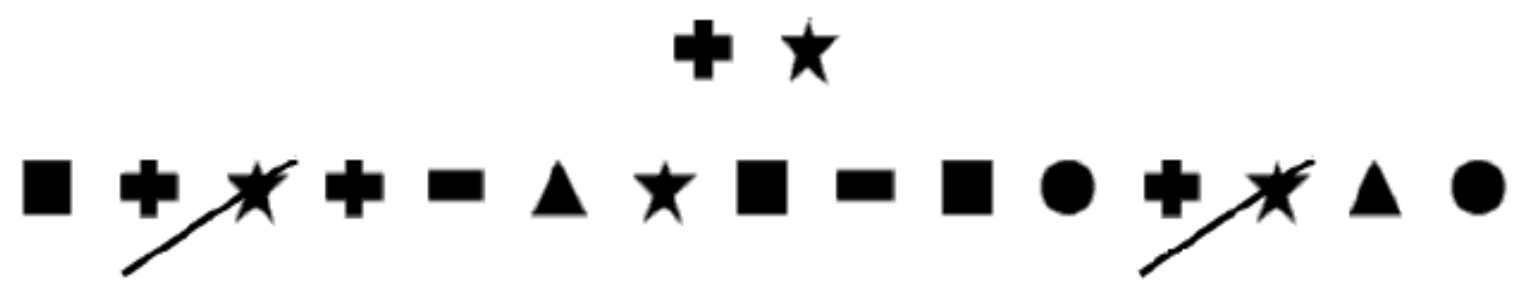

Figura 3-Ilustração da segunda parte do Teste de Atenção por Cancelamento, cujo objetivo é avaliar a atenção seletiva.

Fonte: Montiel \& Seabra (2012).

Na terceira e última fase, o teste tem por objetivo avaliar a atenção alternada, ou seja, a capacidade do indivíduo mudar o foco de atenção. Para a execução desta tarefa é utilizada uma prova de cancelamento de figuras com uma matriz impressa. São apresentados seis diferentes tipos de estímulos (círculo, quadrado, triângulo, cruz, estrela e traço), de cor preta com fundo branco, totalizando 300 figuras ao todo, onde 20 figuras são distribuídas por 15 linhas em ordem diferente das duas primeiras partes do teste. Nesta última fase, no entanto, o estímulo-alvo muda a cada linha e aparece representado como a figura inicial de cada linha. Diferentemente das fases anteriores, o número de vezes em que o estímulo-alvo aparece se alterna, aparecendo no mínimo duas e no máximo seis vezes ao longo 
das linhas. $O$ escore bruto para idade de seis anos é de 1 a 52 e pontuação padrão varia de 52 a 224. Para idade de sete anos, a pontuação padrão varia de 84 a 155. Para a realização desta fase, também é disponibilizado o tempo máximo de um minuto.

A Figura 4 ilustra a terceira fase do Teste de Atenção por Cancelamento, com a representação das respostas corretas.

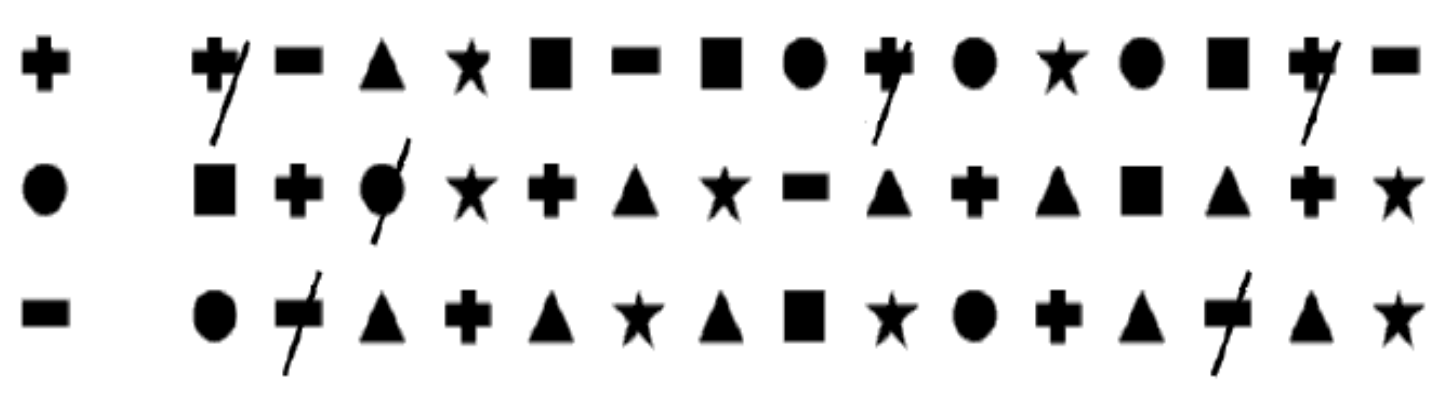

Figura 4- Ilustração da terceira parte do Teste de Atenção por Cancelamento, cujo objetivo é avaliar a atenção alternada.

Fonte: Montiel \& Seabra (2012).

3.6.3 Avaliação do temperamento - The Child Behavior Questionnaire - CBQ/ Questionário Sobre o Comportamento da Criança (3 a 7 anos) (Rothbart, Ahadi, Hershey., \& Fisher, 2001) versão brasileira Klein, Putnam e Linhares (2009), (vide "Mary Rothbart's Temperament Questionnaires" website http://www.bowdoin.edu/ sputnam/rothbart-temperament-questionnaires). O questionário é composto por 195 itens que mensuram 15 dimensões de temperamento em crianças de três a sete anos. São obtidos três fatores principais do temperamento, a saber: Afeto negativo, que consiste na média dos escores das dimensões raiva/frustração, desconforto, medo, tristeza e do escore invertido (subtraído do algarismo 8) de capacidade de se acalmar; Extroversão, que consiste na média dos escores das dimensões nível de atividade, prazer de alta intensidade, impulsividade e do escore invertido (subtraído do algarismo 8) de timidez; Controle com esforço, que consiste na média dos escores das dimensões focalização de atenção, controle inibitório, prazer de baixa intensidade e sensibilidade perceptual. As escalas aproximação/ antecipação e riso e sorriso são analisadas de forma independente. O CBQ é um instrumento respondido pela mãe/cuidadora da criança. $O$ respondente deve indicar a frequência com que a criança apresentou determinada reação em contextos específicos, nas 
últimas duas semanas, atribuindo um valor em uma escala de Likert que varia de 1 (nunca) a 7 (sempre).

O questionário foi traduzido e adaptado para língua portuguesa (Brasil), com autorização dos autores, por Klein e Linhares. O estudo de Klein (2009) avaliou a consistência interna do questionário foi calculada por meio do alfa de Chronbah em uma amostra de 103 crianças, incluindo 33 crianças nascidas pré-termo participantes do estudo da autora e 70 crianças nascidas a termo participantes do estudo de Correia (2009), obtendo-se os seguintes valores de alfa: nível de atividade $=0,75$; prazer de alta intensidade $=0,63$; impulsividade $=0,60$; timide $=$ 0,86 ; raiva/frustração $=0,74$; desconforto $=0,55 ;$ medo $=0,56$; tristeza $=0,36$; capacidade de se acalmar $=0,51$; focalização de atenção $=0,50$; controle inibitório $=$ 0,77 ; prazer de baixa intensidade $=0,48$; sensibilidade perceptual $=0,66$; aproximação/ antecipação $=0,64$; riso e sorriso $=0,64$.

O Quadro 1 apresenta as definições dos fatores e dimensões do CBQ. 
Quadro1- Fatores e dimensões do temperamento, avaliado pelo CBQ .

\begin{tabular}{|c|c|c|}
\hline Fatores & Dimensões & Definições \\
\hline \multirow{5}{*}{ 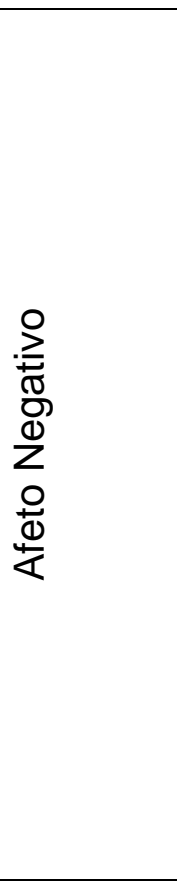 } & Raiva/frustração & $\begin{array}{l}\text { Quantidade de afeto negativo relacionado com a } \\
\text { interrupção de uma tarefa em curso ou bloqueio de } \\
\text { objetivos. }\end{array}$ \\
\hline & Desconforto & $\begin{array}{l}\text { Quantidade de afeto negativo relacionado com as } \\
\text { qualidades sensoriais da estimulação, incluindo } \\
\text { intensidade, frequência ou complexidade da luz, } \\
\text { movimento, som e textura. }\end{array}$ \\
\hline & Medo & $\begin{array}{l}\text { Quantidade de afeto negativo, incluindo inquietude, } \\
\text { preocupação ou nervosismo relacionado com dor ou } \\
\text { perturbação antecipada e/ou situações potencialmente } \\
\text { ameaçadoras. }\end{array}$ \\
\hline & Tristeza & $\begin{array}{l}\text { Quantidade de afeto negativo, humor e energia } \\
\text { rebaixados relacionados com a exposição a sofrimento, } \\
\text { desapontamento e perda de objetos. }\end{array}$ \\
\hline & \begin{tabular}{|l|} 
Reatividade \\
decrescente/ \\
capacidade de \\
se acalmar \\
\end{tabular} & $\begin{array}{l}\text { Grau de recuperação a partir de picos de perturbação, } \\
\text { excitação ou alerta geral. }\end{array}$ \\
\hline \multirow{4}{*}{ 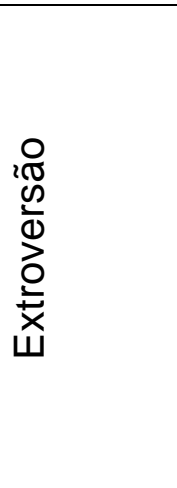 } & $\begin{array}{l}\text { Nível de } \\
\text { atividade }\end{array}$ & $\begin{array}{l}\text { Nível de atividade motora ampla que inclui frequência e } \\
\text { extensão da locomoção. }\end{array}$ \\
\hline & $\begin{array}{l}\text { Prazer de alta } \\
\text { intensidade }\end{array}$ & $\begin{array}{l}\text { Quantidade de prazer ou diversão relacionado com } \\
\text { situações que envolvem uma grande intensidade, } \\
\text { frequência, complexidade, novidade e incongruência de } \\
\text { estímulos. }\end{array}$ \\
\hline & Impulsividade & Rapidez na iniciação da resposta \\
\hline & Timidez & $\begin{array}{l}\text { Aproximação lenta ou inibida em situações que } \\
\text { envolvem novidade ou incerteza. }\end{array}$ \\
\hline \multirow{6}{*}{ 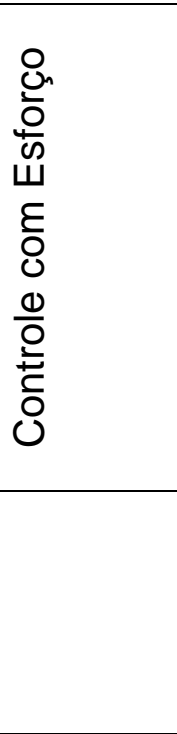 } & $\begin{array}{l}\text { Focalização de } \\
\text { atenção }\end{array}$ & $\begin{array}{l}\text { Tendência para manter a atenção focada sobre canais } \\
\text { relacionados com a tarefa. }\end{array}$ \\
\hline & $\begin{array}{l}\text { Sensibilidade } \\
\text { perceptual }\end{array}$ & $\begin{array}{l}\text { Quantidade de detecção de estímulos leves, de baixa } \\
\text { intensidade, provenientes do ambiente externo. }\end{array}$ \\
\hline & $\begin{array}{l}\text { Controle } \\
\text { inibitório }\end{array}$ & $\begin{array}{l}\text { A capacidade de planejar e suprimir uma resposta de } \\
\text { aproximação inadequada perante instruções ou em } \\
\text { situações novas ou incertas. }\end{array}$ \\
\hline & $\begin{array}{l}\text { Prazer de baixa } \\
\text { intensidade }\end{array}$ & $\begin{array}{l}\text { Quantidade de prazer ou diversão relacionado com } \\
\text { situações que envolvem baixa intensidade, frequência, } \\
\text { complexidade, novidade e incongruência de estímulos. }\end{array}$ \\
\hline & $\begin{array}{l}\text { Aproximação/ } \\
\text { Antecipação }\end{array}$ & $\begin{array}{l}\text { Quantidade de entusiasmo e antecipação positiva com } \\
\text { relação a atividades prazerosas esperadas. }\end{array}$ \\
\hline & Riso e sorriso & $\begin{array}{l}\text { Quantidade de afeto positivo em resposta a mudanças } \\
\text { na intensidade, frequência, complexidade e } \\
\text { incongruência dos estímulos. }\end{array}$ \\
\hline
\end{tabular}




\subsubsection{Avaliação do Comportamento - Questionário de Capacidades e Dificuldades} (SDQ) (Goodman, 1999), traduzido para o português e adaptado as características sócio-culturais brasileiras por Fleitlich, Córtazar e Goodman (2000) e os dados psicométricos sobre validade e fidedignidade foram descritos por Woerner, FleitlichBilyk, Martinussen, Fletcher, Cucchiaro, Dalgalarrondo, Lui e Tannock (2004). Este é um questionário de rastreamento de problemas de saúde mental infantil, que avalia a presença ou ausência de indicadores comportamentais, a partir dos critérios estabelecidos pelo DSM-IV. Avalia comportamento da criança com base nos últimos seis meses, com objetivo de medir comportamentos sociais adequados (capacidades) e não adequados (dificuldades) em crianças e adolescentes, na faixa etária de três a 16 anos. Trata-se de um instrumento de rápida aplicação composto por 25 itens, sendo 10 itens sobre capacidades, 14 sobre dificuldades e um neutro, composto por cinco subescalas, cada uma com cinco afirmações. As subescalas são as seguintes: Sintomas emocionais, Problemas de conduta, Hiperatividade, Problemas de relacionamento com colegas e Comportamento pró-social (ANEXO B).

$O$ instrumento apresenta três versões, indicadas para serem respondidas pelas próprias crianças (a partir de 11 anos), seus pais ou responsáveis e pelos professores. No presente estudo foi utilizada a versão respondida pelos pais ou responsáveis.

$\mathrm{Na}$ aplicação do questionário os pais ou cuidadores devem assinalar para cada sentença: falso, mais ou menos verdadeiro ou verdadeiro, devendo ser assinalada apenas uma única opção por item. As respostas são codificadas em zero, um e dois pontos e em cada escala os pontos são somados, sendo que para cada uma das cinco escalas a pontuação pode variar de zero a 10 pontos. A pontuação total do instrumento para a obtenção do escore total de dificuldades é, no máximo, de 40 pontos, visto que a escala de comportamento pró-social não é incluída nesse escore, destacando-se que quanto maior a pontuação dos escores obtidos, maior a indicação de problemas comportamentais, exceto para a escala de comportamento pró-social. Trata-se de um instrumento de uso livre disponível no site www.sdqinfo.com.

3.6.5 Avaliação dos dados de caracterização da criança - Esta ficha foi desenvolvida pela própria autora, para coletar os dados das crianças com relação 
aos dados de identificação, gestação da criança, condição ambiental e social das mesmas. (APÊNDICE B)

3.6.6 Critério de Classificação Econômico Brasil - CCEB da Associação Brasileira de Empresa de Pesquisa (ABEP, 2012), aplicada para caracterizar a classificação socioeconômica das famílias por meio da atribuição de pesos a um conjunto de itens de conforto doméstico. O Critério de Classificação Econômica Brasil avalia o poder de compra das famílias, definindo-as em classes econômicas. Deste modo estima-se a renda familiar média, como segue: Classe A varia de 46 a 35 pontos, correspondendo a uma renda mensal familiar de $\mathrm{R} \$ 11.037,00$; Classe $B 1$ varia de 34 a 29 pontos, correspondendo a uma renda mensal familiar de $R \$ 6.006,00$; Classe B2 varia de 28 a 23 pontos, correspondendo a uma renda mensal familiar de $\mathrm{R} \$$ 3.118,00; Classe C1 varia de 22 a 18 pontos, correspondendo a uma renda mensal familiar de $\mathrm{R} \$ 1.865,00$; Classe $\mathrm{C} 2$ varia de 17 a 14 pontos, correspondendo a uma renda mensal familiar de $\mathrm{R} \$ 1.277,00$; Classe $D$ e $E$ variam de 13 a 0 pontos, correspondendo a uma renda mensal familiar de $R \$ 895,00$. (ANEXO C)

3.6.7 Prontuário do paciente no HCFMRP-USP, utilizado para consulta das informações sobre as características neonatais das crianças e história de saúde. (APÊNDICE C)

\subsection{Procedimentos}

\subsubsection{Coleta de dados}

A coleta de dados aconteceu no período de 01/2012 a 12/2013.

O procedimento de coleta de dados foi realizado em duas sessões, no mesmo dia. Nesta sessão com o cuidador foram realizadas as seguintes atividades: a assinatura do termo de consentimento livre e esclarecido, entrevista inicial e o preenchimento dos questionários SDQ, CBQ e CCEB.

$\mathrm{Na}$ coleta de dados com o cuidador foi feito a alternância entre as avaliações do comportamento (SDQ) e temperamento (CBQ), para que não houvesse influência de um instrumento sobre o outro provocando o efeito "carry over". Deste modo, ora o 
SDQ era aplicado em primeiro lugar antes do $\mathrm{CBQ}$, ora em segundo lugar, após o CBQ.

Em seguida, com as crianças foram realizadas as seguintes avaliações: Teste de atenção (Teste de Atenção por Cancelamento) e o WISC- III (forma compacta). Posteriormente, foram realizadas as consultas aos prontuários médicos das crianças para coletar dados sobre história de saúde das crianças.

A fim de assegurar uma melhor compreensão das mães em relação à gradação das respostas do instrumento de CBQ (escala de Likert variando de 1= Nunca a $7=$ Sempre, em resposta a perguntas de frequência) a Figura 5 foi apresentada, pois nela está a representação gráfica da forma de respostas, de acordo com o procedimento adotado por Klein et al. (2009).

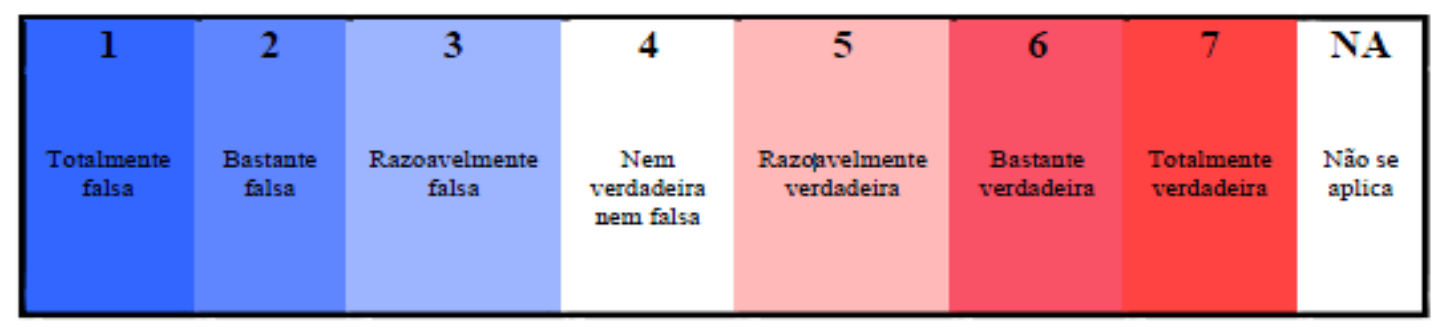

Figura 5- Representação gráfica da escala de respostas do The Children's Behavior Questionnaire (CBQ).

A coleta de dados foi realizada por duas psicólogas especialistas em Psicologia Pediátrica e experientes em avaliação psicológica de crianças, sendo uma a pesquisa principal deste estudo e a outra uma auxiliar de pesquisadora (apoio técnico em pesquisa, bolsista CNPq).

\subsubsection{Análise e Tratamento estatístico dos dados}

Os dados obtidos por meio dos instrumentos de avaliação foram pontuados e analisados conforme suas normas técnicas. Os dados foram quantificados e colocados em planilhas do Statistical Package for the Social Sciences (SPSS), em um banco de dados. Foi realizada a análise estatística descritiva das variáveis 
categóricas por meio de frequência e porcentagem e das variáveis contínuas por meio de média, desvio padrão e amplitude de variação.

Para fins de análise pelo nível de prematuridade das crianças foi realizada a divisão dos grupos utilizando-se a idade gestacional. Os grupos foram divididos em pré-termo extremo/ muito pré-termo (crianças que nasceram < 32 semanas de idade gestacional) e pré-termo moderado/ tardio (crianças nascidas com idade gestacional entre 32 a 36 semanas). A amostra foi dividida nesses dois grupos considerando-se o $\mathrm{n}$ dos grupos e as características clínicas de imaturidade representada pela idade gestacional. $\mathrm{Na}$ análise de comparação entre grupos independentes foram utilizados o teste t de Student, para as variáveis numéricas, e o teste de Qui-quadrado, para as variáveis categóricas.

Antes de processar as análises de regressão foram realizadas as análises de correlação entre as varáveis preditoras e preditas e foram incluídas nos modelos a serem testados apenas as que obtiveram nível de significância estatística p 0,05 . Além disso, foi testada a multicolinearidade entre as variáveis preditoras, a fim de não incluir nas modelos variáveis altamente correlacionadas (VIF <5).

Posteriormente, foram construídos modelos de predição dos indicadores de comportamento e de cognição (variáveis preditas), respectivamente, analisados por meio da análise de regressão linear múltipla. Considerando-se $0 \mathrm{n}$ de 50 participantes foram testadas no máximo oito variáveis por vez, respeitando a regra de testar uma variável para cada cinco participantes. O melhor modelo para cada desfecho foi aquele em que a combinação de variáveis apresentou o maior poder explicativo $\left(\mathrm{R}^{2}\right)$ composto por variáveis preditoras que apresentassem maior significância estatística ( $p \leq 0,05)$.

Os dados foram processados por meio do programa estatístico Statistic Package for Social Sciences (SPSS, 22.0, Chicago, II, USA). Foi adotado o nível de significância de $5 \%(p \leq 0,05)$ para todos as análise do estudo. 


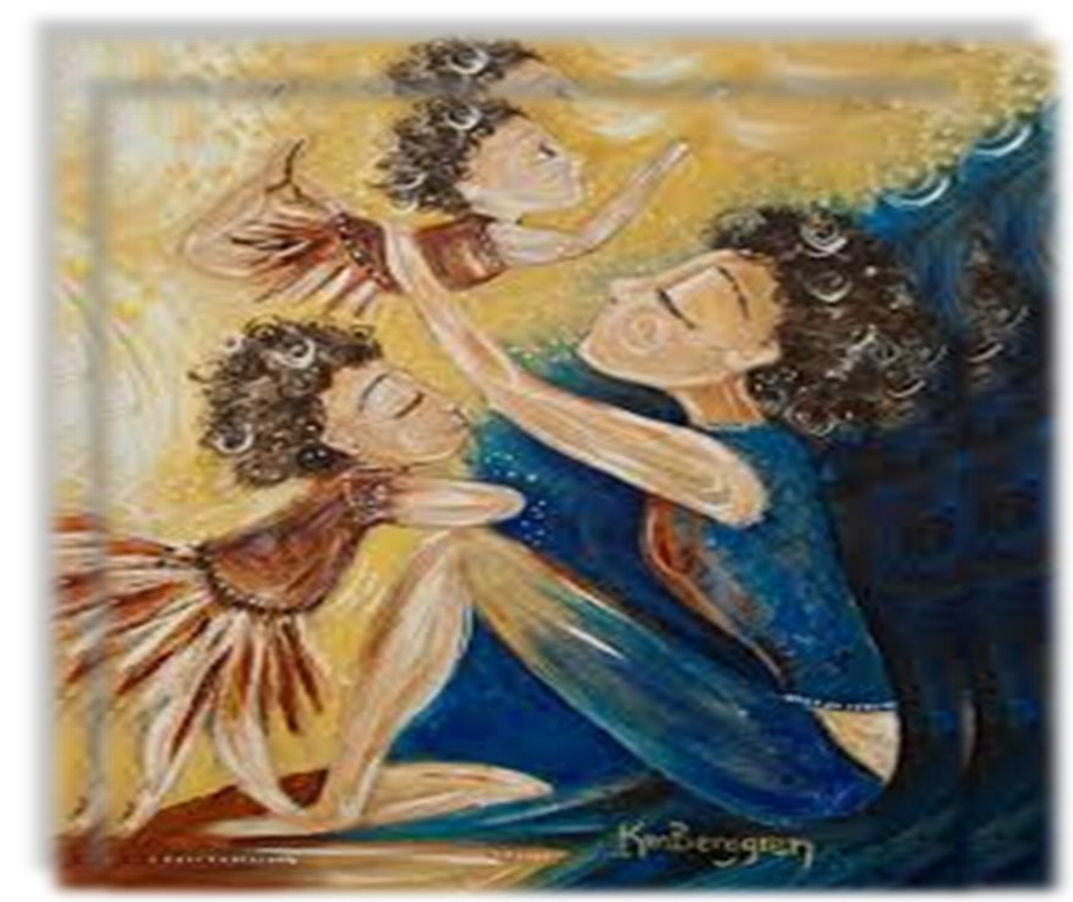

Artigo IV - Todo prematuro tem direito ao tratamento estabelecido pela ciência, sem distinção de qualquer espécie, seja de raça, cor, sexo, ou de outra natureza, origem nacional ou social, riqueza, nascimento, ou qualquer outra condição. Sendo assim, todo prematuro tem o direito de ser cuidado por uma equipe multidisciplinar capacitada a compreendê-lo, interagir com ele e a tomar decisões harmônicas em seu benefício e em prol de seu desenvolvimento (Tavares, 2009). 
Os resultados do presente estudo serão apresentados em quatro seções. $\mathrm{Na}$ primeira seção estão reunidos os dados referentes à caracterização das crianças nascidas pré-termo nas fases pré-natal, perinatal e neonatal quanto aos indicadores biológicos, socioeconômicos e de história obstétrica materna. Na segunda seção, serão apresentados os indicadores de desenvolvimento obtidos por meio das avaliações cognitiva, de atenção, do temperamento e do comportamento. Na terceira seção, por sua vez, serão apresentados os dados de comparação entre os indicadores de atenção, cognição e comportamento em grupos diferenciados pelo nível de prematuridade (grupos de pré-termo extremo/ muito pré-termo e pré-termo moderado/ pré-termo tardio). Na quarta e última seção, encontram-se os modelos de predição dos indicadores do comportamento e indicadores de cognição respectivamente.

\section{1 - 1ª Seção: Caracterização da amostra}

\section{1.1 Características das crianças nascidas pré-termo da amostra do estudo}

A Tabela 1 apresenta as características sóciodemográficas das crianças nascidas pré-termo da amostra do estudo.

Tabela 1- Características das crianças da amostra de estudo $(n=50)$.

\begin{tabular}{lc}
\hline Características sóciodemográficas das crianças & Valores \\
\hline Sexo - n (\%) & $25(50)$ \\
$\quad$ Feminino & $25(50)$ \\
$\quad$ Masculino & \\
Idade das crianças (anos, meses) Média (DP; mín.-máx) & $6,7( \pm 0,6 ; 6-7,6)$ \\
Série Escolar - n (\%) & \\
$\quad$ 1 ano & $30(60)$ \\
2 o ano & $11(22)$ \\
Educação Infantil/ Pré-escola & $7(14)$ \\
Educação Especial & $2(4)$ \\
Tipo de escola - n (\%) & \\
Pública & $48(96)$ \\
Particular & $2(4)$ \\
\hline $\mathrm{n}=$ número de crianças; \% porcentagem; DP = desvio padrão; mín.= valor mínimo, \\
máx.= valor máximo.
\end{tabular}


$\mathrm{Na}$ Tabela 1 observa-se que a amostra teve uma distribuição equitativa quanto ao sexo das crianças. As crianças foram avaliadas em média aos seis anos e sete meses de idade, sendo que $82 \%$ destas cursavam o ensino fundamental - ciclo I. A maior parte das crianças (96\%) estudava em escolas públicas.

As características da história anterior de saúde das crianças nascidas prétermo estão reunidas na Tabela 2. 
Tabela 2- Características neonatais das crianças nascidas pré-termo $(n=50)$.

Características da história anterior de saúde das crianças

Peso ao nascimento (gramas) - Média (DP; mín.-máx.)

Idade gestacional (semanas) - Média (DP; mín.-máx.)

Nível de prematuridade - $f(\%)$

Pré-termo extremo/ muito pré-termo

Moderado

Tardio

Adequação do peso para idade gestacional ${ }^{(1)}-\mathrm{n}(\%)$

PIG

AIG

Apgar 5ํminuto (escore) - Média (DP; mín-máx)

Tempo de internação em UTIN (dias) - Média (DP; mín-máx)

Tempo de internação total (dias) - Média (DP; mín-máx)

Tipo de alimentação no período de internação pós -natal- n (\%)

Leite humano

Artificial (fórmula)

Misto (leite humano e fórmula)

Tipo de alimentação na alta hospitalar - n (\%)

Leite humano

Artificial (fórmula)

Misto

$24(48)$

\section{Valores}

$1.190( \pm 279 ; 650-1.500)$

$31( \pm 2 ; 26-35)$

$29(58)$

$16(32)$

$18(36)$

$32(64)$

$9( \pm 1,13 ; 5-10)$

$20( \pm 20 ; 1-89)$

$57( \pm 35 ; 10-181)$

$\mathrm{n}=$ número de crianças; \% porcentagem; $\mathrm{DP}=$ desvio padrão; mín.= valor mínimo, máx.= valor máximo. ${ }^{(1)}$ Adequação do peso para idade gestacional: PIG - Pequeno para idade gestacional, AIG - Adequado para idade gestacional, segundo classificação de Lubchenco et al. (1966). Prétermo extremo/ muito pré- termo= crianças nascidas com idade gestacional $<32$ semanas; Prétermo moderado= crianças nascidas com idade gestacional entre 32 e 33 semanas e pré-termo tardio $=$ crianças nascidas com idade gestacional entre 34 e 36 semanas, segundo classificação Chabra (2013).

Os resultados da Tabela 2 mostram que, em média, as crianças apresentaram peso ao nascimento de $1.190 \mathrm{~g}$ e idade gestacional de 31 semanas. A maior parte das crianças nasceu adequada para a idade gestacional (64\%), ou seja, estavam com peso ao nascimento esperado para idade gestacional. A média do escore do Apgar do $5^{\circ}$ minuto foi alta, de nove pontos, sugestivo de boa vitalidade ao nascimento. Quanto ao tempo de internação na UTIN verificou-se que as crianças 
ficaram em média 20 dias, com grande amplitude de variação, podendo chegar até três meses de internação. Com relação ao tempo de internação total, as crianças ficaram em média 57 dias, também com extensa amplitude de variação podendo chegar até seis meses. Nota-se que, em relação ao tipo de alimentação, no período de internação as crianças formam alimentadas, em sua maioria, por leite humano; contudo na alta hospitalar houve uma maior porcentagem de crianças com alimentação mista, composta por leite humano e fórmula (leite artificial).

A Tabela 3 apresenta a prevalência das patologias encontradas na história de saúde das crianças nascidas pré-termo no período de internação neonatal.

Tabela 3- Patologias encontradas na história de saúde das crianças nascidas pré-termo no período de internação neonatal $(n=50)$.

\begin{tabular}{lll}
\hline Patologias & $\mathbf{n}$ & $\%$ \\
\hline Hiperbilirrubinemia & 41 & 82 \\
Desconforto respiratório precoce & 28 & 56 \\
Síndrome da membrana hialina & 21 & 42 \\
Anemia & 20 & 40 \\
Apnéia de repetição & 18 & 36 \\
Hipoglicemia & 15 & 30 \\
Displasia broncopulmonar & 11 & 22 \\
Septicemia & 10 & 20 \\
Hemorragia Intracraniana & & \\
$\quad$ Grau I & 6 & 12 \\
$\quad$ Grau II & 3 & 6 \\
Distúrbio de coagulação & 4 & 8 \\
Convulsão & 4 & 8 \\
Pneumotórax & 4 & 8 \\
Retinopatia da prematuridade & 3 & 6 \\
Doença pulmonar crônica & 2 & 4 \\
Insuficiência respiratória aguda & 1 & 2 \\
Cardiopatia & 1 & 2 \\
Enterocolite Necrotizante & 1 & 2 \\
\hline
\end{tabular}

$\mathrm{n}=$ número de crianças; \% prevalência.

Os dados da Tabela 3 indicam que, na amostra de crianças estudadas, as patologias na história de saúde associadas ao nascimento prematuro foram predominantemente do tipo de distúrbios respiratórios, tais como: desconforto 
respiratório precoce, síndrome da membrana hialina, displasia broncopulmonar, apnéia de repetição e doença pulmonar crônica. Em seguida, nota-se a presença de hiperbilirrubinemia, anemia, apneia de repetição, hipoglicemia, infecções e hemorragias intracranianas.

A Tabela 4 mostra os tratamentos e procedimentos clínicos que as crianças nascidas pré-termo foram submetidas durante a fase neonatal.

Tabela 4- Tratamentos e procedimentos clínicos que as crianças nascidas pré-termo foram submetidas durante a fase neonatal $(n=50)$.

\begin{tabular}{lcc}
\hline $\begin{array}{l}\text { Tratamentos e procedimento durante a internação } \\
\text { neonatal }\end{array}$ & $\mathbf{n}$ & $\%$ \\
\hline Ventilação mecânica (não invasiva- CPAP) & 46 & 92 \\
Fototerapia & 40 & 80 \\
Nutrição parenteral & 28 & 56 \\
Transfusão de sangue & 18 & 36 \\
Surfactante & 17 & 34 \\
Cirurgias & 13 & 26 \\
$\quad$ Cardíaca & 11 & 22 \\
$\quad$ Outros tipos de cirurgias & 2 & 4 \\
Intubação & 12 & 24 \\
\hline n = número de crianças; \% prevalência; CPAP = Pressão Positiva Contínua Nasal.
\end{tabular}

Nota-se na Tabela 4 que os procedimentos realizados predominantemente com as crianças durante a internação foram os seguintes: a ventilação mecânica, a fototerapia e a nutrição parenteral. Em seguida, verificam-se os procedimentos de transfusão de sangue, administração de surfactante, cirurgias e intubação.

A Tabela 5 reúne as características dos pais das crianças nascidas pré-termo da amostra de estudo. 
Tabela5- Características dos pais das crianças nascidas pré-termo nascidas prétermo $(n=50)$.

\begin{tabular}{lc}
\hline Características dos pais das crianças nascidas pré-termo & Valores \\
\hline Idade das mães (anos) - Média (DP; mín.-máx.) & $34( \pm 7 ; 21-49)$ \\
Escolaridade da mãe - $f(\%)$ & \\
Ensino fundamental incompleto & $8(16)$ \\
Ensino fundamental completo & $7(15)$ \\
Ensino médio incompleto & $2(4)$ \\
Ensino médio completo & $26(53)$ \\
Ensino superior incompleto & $2(4)$ \\
Ensino superior completo & $4(8)$ \\
Anos de estudo da mãe - Média (DP; mín.-máx.) & $10( \pm 3,3 ; 1-16)$ \\
Ocupação da mãe - $f$ (\%) & \\
Empregada (em atividade remunerada) & $34(68)$ \\
Do lar & $16(32)$ \\
Idade dos pais - (anos) - Média (DP; mín.-máx.) & $38( \pm 9 ; 27-65)$ \\
Escolaridade do pai & \\
Ensino fundamental incompleto & $17(39)$ \\
Ensino fundamental completo & $5(11)$ \\
Ensino médio incompleto & $3(7)$ \\
Ensino médio completo & $17(39)$ \\
Ensino superior incompleto & $2(4)$ \\
Ocupação do pai - $f(\%)$ & $41(95)$ \\
Empregado (em atividade remunerada) & $2(5)$ \\
Desempregado &
\end{tabular}

f= frequência; \% porcentagem; DP = desvio padrão; mín.= valor mínimo, máx.= valor máximo.

Como pode- se observar na Tabela 5, a idade média das mães era de 34 anos e a dos pais de 38 anos. As mães tinham escolaridade média de 10 anos, sendo que houve predomínio de mães que concluíram o $2^{\circ}$ grau, seguidas de mães com ensino fundamental completo. Apenas $8 \%$ das mães tinham ensino superior completo. Os pais estudaram em média oito anos, sendo que em relação à escolaridade dos pais, a maior parte tinha ensino médio completo e ensino fundamental incompleto (39\%) seguido de ensino fundamental completo. 
Com relação ao nível ocupacional, tanto as mães quanto os pais trabalhavam fora do lar. Deve-se destacar que das 50 crianças apenas uma era cuidada pela avó aposentada de 57 anos de idade, com nível escolar de $1^{\circ}$ grau incompleto.

A Tabela 6 apresenta as características do ambiente familiar das crianças nascidas pré-termo da amostra do estudo $(n=50)$.

Tabela 6- Características do ambiente familiar das crianças nascidas pré-termo da amostra de estudo $(n=50)$.

\begin{tabular}{lc}
\hline Características do ambiente familiar & Valores \\
\hline Estado civil dos cuidadores principais das crianças - $\mathrm{f}(\%)$ & $36(72)$ \\
$\quad$ União estável & $7(14)$ \\
Separados / Divorciados & $6(12)$ \\
Solteiro & $1(2)$ \\
$\quad$ Viúvo & $4( \pm 1,14 ; 2-7)$ \\
Número de pessoas residentes na casa - Média (DP; mín.-máx.) & $5( \pm 1,7 ; 2-11)$ \\
Número de cômodos da casa - Média (DP; mín.-máx.) & \\
Tipo de moradia - $f(\%)$ & $35(70)$ \\
$\quad$ Própria & $8(16)$ \\
Alugada & $7(14)$ \\
$\quad$ Emprestada & \\
Classe Econômica (CCEB) - $f(\%)$ & $1(2)$ \\
Classe A & $18(36)$ \\
Classe B & $29(58)$ \\
Classe C & $2(4)$ \\
Classe D & \\
\hline
\end{tabular}

$\mathrm{f}$ = frequência; \% porcentagem; $\mathrm{DP}=$ desvio padrão; mín.= valor mínimo, máx.= valor máximo; CCEB- Critério de classificação Econômica Brasileira pela Associação Brasileira de Empresas e Pesquisa (ABEP).

Verifica-se na Tabela 6 que a maior parte dos pais tinha uma união estável e a maioria das crianças residia com a família nuclear, residindo no lar uma média de quatro pessoas. Contudo, verificou-se uma amplitude de variação de duas até sete pessoas residentes na casa com a criança. O número médio de cômodos foi de cinco, apresentando uma densidade habitacional de aproximadamente um morador por cômodo. Observa-se que os tipos de moradia em sua maioria eram casas próprias. O nível socioeconômico das famílias das crianças foi classificado predominantemente em torno dos níveis B e C, correspondendo a 94\% dos participantes. 
A Tabela 7 reúne as características da história obstétrica materna e da história pré e peri- natal das crianças pré-termo da amostra do estudo

Tabela 7- Características da história obstétrica materna e da história pré e perinatal das crianças pré-termo da amostra do estudo $(n=50)$.

\section{Características da história obstétrica das mães e pré e peri- Valores natal das crianças}

História Obstétrica - Média (DP; mín.-máx.)

№ de gestações

№ de partos

$2( \pm 1 ; 1-5)$

№ de abortos

$0( \pm 1 ; 0-4)$

História pré e peri-natais

Gravidez - $f(\%)$

Não planejada

Planejada

Pré-natal - $f(\%)$

Realizou

Não realizou

№ de consultas pré-natal - Média (DP; mín.-máx.)

$6( \pm 3 ; 0-10)$

Início do pré-natal - $f$ (\%)

a partir do $1^{\circ}$ mês

a partir do $2^{\circ}$ mês

a partir do 3ํำ mês

a partir do 4ํㅡês

Tipo de parto - $f(\%)$

Cesárea

Normal

$\mathrm{f}=$ frequência; \% porcentagem; $\mathrm{DP}=$ desvio padrão; mín.= valor mínimo, máx.= valor máximo.

Na Tabela 7 os dados evidenciam que, com relação à história obstétrica das mães, estas tiveram em torno de duas gestações, dois partos e nenhum aborto. A maioria das mães não planejou a gravidez. Contudo, a maior parte das mesmas iniciou o pré-natal a partir do primeiro trimestre de gravidez e realizaram em média seis consultas médicas. A maior parte das crianças nasceu de parto cesárea. 


\section{2- 2ª Seção: Caracterização dos indicadores de desenvolvimento}

\subsection{1- Caracterização dos indicadores do desenvolvimento cognitivo na fase pré-escolar, das crianças nascidas pré-termo}

A Tabela 8 apresenta os resultados do desempenho no WISC-III, nas escalas Total, Verbal e Execução, em termos de QI e classificação, das crianças nascidas pré-termo da amostra do estudo, na fase pré-escolar.

Tabela 8- QI e classificação nas escalas Total, Verbal e de Execução do WISC- III das crianças nascidas pré-termo da amostra do estudo $(n=50)$.

\begin{tabular}{lccc}
\hline $\begin{array}{l}\text { QI Classificação - } \\
\text { WISC III }\end{array}$ & Escala Total & Escala Verbal & $\begin{array}{r}\text { Escala de } \\
\text { Execução }\end{array}$ \\
\hline $\begin{array}{l}\text { QI- Média (DP; mín.-máx.) } \\
\text { Classificação - n (\%) }\end{array}$ & $92( \pm 21 ; 59-142)$ & $99( \pm 21 ; 66-145)$ & $94( \pm 18,67 ; 67-142)$ \\
$\quad$ Muito superior & $3(6)$ & $5(10)$ & $3(6)$ \\
Superior & $3(6)$ & $2(4)$ & $2(4)$ \\
Média Superior & $6(12)$ & $7(14)$ & $6(12)$ \\
Média & $15(30)$ & $18(36)$ & $15(30)$ \\
Média Inferior & $8(16)$ & $6(12)$ & $12(24)$ \\
Limítrofe & $5(10)$ & $7(14)$ & $9(18)$ \\
Intelectualmente & $10(20)$ & $5(10)$ & $3(6)$ \\
deficiente & & & \\
\hline
\end{tabular}

$\mathrm{n}$ = número de crianças; \% porcentagem; DP = desvio padrão; DP = desvio padrão; mín.= valor mínimo; máx.= valor máximo.WISC-III= Escala Wechsler de Inteligência para Crianças; $\mathrm{QI}=$ Quoeficiente Intelectual. Escores e classificação $\geq 129$ (Muito superior), 120-128 (Superior), 110-119 (Médio superior), 90-109 (Médio), 80-89 (Médio inferior, 70-79 (Limítrofe), $\leq 69$ (Intelectualmente deficiente).

A Tabela 8 revela que as crianças da amostra de estudo apresentaram um Q। médio nas três escalas entre 90 e 100 pontos. Nota-se que a maior parte das crianças da amostra de estudo, apresentou resultados com classificação na média ou acima da média nos QIs Total (70\%), Verbal (76\%) e de Execução (76\%). Notase que, as crianças obtiveram classificação limítrofe ou intelectualmente deficiente em $30 \%$ na escala total, $24 \%$ na escala a verbal e $24 \%$ na escala de execução. A classificação de deficiência intelectual global foi de $20 \%$ na amostra do estudo. 
A Tabela 9 apresenta o índice fatorial de Resistência à Distração do WISC- III em termos de escore e classificação das crianças nascidas pré-termo da amostra do estudo.

Tabela 9- Índice fatorial de Resistência à distração do WISC III - Escore e classificação dos resultados das crianças nascidas pré-termo da amostra do estudo $(\mathrm{n}=50)$.

\begin{tabular}{lc}
\hline Índice de Resistência à Distração & Valores \\
\hline Média (DP; mín.-máx.) & $102( \pm 20)(64-137)$ \\
Classificação - n (\%) & $3(6)$ \\
Muito superior & $4(8)$ \\
Superior & $9(18)$ \\
Média Superior & $16(32)$ \\
Média & $7(14)$ \\
Média Inferior & $7(14)$ \\
Limítrofe & $4(8)$ \\
Intelectualmente Deficiente &
\end{tabular}

$\mathrm{n}=$ número de crianças; \% porcentagem; $\mathrm{DP}=$ Desvio Padrão; mín.= valor mínimo, máx.= valor máximo. WISC-III=Escala Wechsler de Inteligência para crianças; Escores e classificação: Muito superior ( $\geq 129)$, Superior (120-128), Médio superior (110-119), Médio (90-109), Médio inferior (80-89), Limítrofe (70-79), Intelectualmente deficiente ( $\leq 69)$.

A Tabela 9 identifica que $64 \%$ das crianças apresentaram resultados na média ou acima da média no índice fatorial de Resistência à Distração. Observa-se que $14 \%$ da amostra teve desempenho superior ou muito superior e $22 \%$ tiveram desempenho limítrofe ou intelectualmente deficiente no índice de Resistência à Distração. Porém, apenas $8 \%$ da amostra mostrou desempenho deficiente neste fator.

\subsection{2- Caracterização dos indicadores de atenção na fase pré-escolar, das crianças nascidas pré-termo}

A Tabela 10 mostra os acertos no teste de Atenção por Cancelamento das crianças nascidas pré-termo da amostra do estudo, na fase pré-escolar. Os cálculos na fase 2 foram feitas sob 46 crianças e na fase 3 sob 48 crianças, pois as crianças zeraram nestas fases e neste caso, o teste não propõe escore e classificação. 
Tabela 10- Acertos no teste de atenção por cancelamento das crianças pré-termoescore e classificação.

\begin{tabular}{lcccc}
\hline $\begin{array}{l}\text { Teste de Atenção por } \\
\text { Cancelamento }\end{array}$ & Total & $\begin{array}{c}\text { Fase 1 } \\
\text { (Seletiva) } \\
(\mathbf{n = 5 0 )}\end{array}$ & $\begin{array}{c}\text { Fase 2 } \\
\text { (Seletiva) } \\
(\mathbf{n = 4 6 )}\end{array}$ & $\begin{array}{c}\text { Fase 3 } \\
\text { (Alternada) } \\
(\mathbf{n}=\mathbf{4 8})\end{array}$ \\
\hline $\begin{array}{c}\text { Escore - Média (DP) } \\
\text { mín.- máx. }\end{array}$ & $95( \pm 22)$ & $95( \pm 16)$ & $97( \pm 49)$ & $92( \pm 26)$ \\
Classificação - $\mathbf{n}(\%)$ & $44-141$ & $56-127$ & $0-152$ & $0-136$ \\
Muito alta & & & & \\
Alta & $2(4)$ & 0 & $8(16)$ & $2(4)$ \\
Média & $6(12)$ & $8(16)$ & $11(22)$ & $8(16)$ \\
Baixa & $29(58)$ & $32(64)$ & $24(48)$ & $27(54)$ \\
Muito Baixa & $9(18)$ & $7(14)$ & $1(2)$ & $5(10)$ \\
\hline
\end{tabular}

$\mathrm{n}=$ número de crianças; \% porcentagem; $\mathrm{DP}=$ desvio padrão; mín.= valor mínimo, máx.= valor máximo. Fase 1= atenção seletiva; Fase 2= atenção seletiva em um grau maior de dificuldade; Fase $3=$ atenção alternada. Teste de Atenção por Cancelamento: escore de acertos (classificação) < 70 (muito baixo), 70 a 84 (baixa), 85 a114 (média), 115-129 (alta) e >130 (muito alta).

A Tabela 10 permite constatar que, tanto no escore de acertos total quanto nas três fases do teste de Atenção por Cancelamento, a maior parte das crianças apresentou resultados na média, embora haja grande amplitude de variação. Notase que no total $74 \%$ das crianças obtiveram classificação média, alta ou muito alta e apenas $26 \%$ situaram-se abaixo na média. Na Fase 1, por sua vez, $80 \%$ esteve na média ou acima, enquanto $20 \%$ esteve abaixo da média. Na Fase 2, $86 \%$ das crianças classificaram-se na média ou acima, enquanto $14 \%$ das crianças estiveram muito abaixo da média. Finalmente, na Fase 3, 74\% das crianças situaram-se na média ou acima e $26 \%$ abaixo da média.

\subsection{3- Caracterização dos indicadores de temperamento na fase pré-escolar, das crianças nascidas pré-termo}

A Tabela 11 apresenta os escores médios dos fatores e dimensões do temperamento, avaliados por meio do The Child Behavior Questionnaire - CBQ/ Questionário Sobre o Comportamento da Criança, na fase pré-escolar das crianças nascidas pré-termo. 
Tabela 11- Fatores e dimensões do temperamento, avaliados pelo The Child Behavior Questionnaire - CBQ/ Questionário Sobre o Comportamento da Criança, na fase préescolar das crianças nascidas pré-termo $(n=50)$.

Fatores e dimensões do temperamento (escore do CBQ) Média (DP; mín- máx)

\begin{tabular}{lc}
\hline Afeto Negativo & $4,4( \pm 0,50 ; 3,25-5,33)$ \\
\hline Reatividade decrescente/ capacidade de se acalmar & $4,45( \pm 8 ; 3,0-5,85)$ \\
Raiva/ frustração & $4,64( \pm 0,8 ; 2,69-6,62)$ \\
Desconforto & $4,5( \pm 0,8 ; 2,58-6,08)$ \\
Medo & $4,63( \pm 0,9 ; 2,45-6,42)$ \\
Tristeza & $4,81( \pm 0,8 ; 2,83-6,75)$ \\
Aproximação/ Antecipação & $5,47( \pm 0,7 ; 3,54-7,0)$ \\
Riso e sorriso & $5,21( \pm 0,6 ; 3,77-6,54)$ \\
\hline Extroversão & $4,88( \pm 0,5 ; 3,74-5,98)$ \\
\hline Nível de atividade & $4,85( \pm 0,8 ; 3,46-6,54)$ \\
Prazer de alta intensidade & $4,75( \pm 0,7 ; 3,33-6,77)$ \\
Impulsividade & $4,88( \pm 0,6 ; 3,62-6,0)$ \\
Timidez & $3,48( \pm 1,0 ; 1,33-5,58)$ \\
\hline Controle com Esforço & $4,7( \pm 0,42 ; 3,82-5,52)$ \\
\hline Prazer de baixa intensidade & $4,99( \pm 0,5 ; 3,85-6,50)$ \\
Sensibilidade perceptual & $4,99( \pm 0,7 ; 3,25-6,50)$ \\
Controle inibitório & $4,67( \pm 0,9 ; 2,54-6,23)$ \\
Focalização de atenção & $4,24( \pm 0,73 ; 2,57-5,79)$ \\
\hline O escore do CBQ vara de &
\end{tabular}

O escore do CBQ varia de 1 a 7.

Verifica-se na Tabela 11 que, quanto à avaliação do temperamento, na avaliação dos cuidadores, as crianças do presente estudo apresentaram escores moderados nos três fatores do CBQ situando-se entre 4 e 5 . No Afeto negativo foram encontrados escores menores que 5 nas dimensões: aproximação/ antecipação e sorriso/riso. No Fator Extroversão, se notou que quase na totalidade das dimensões houve escores em torno de 4, com exceção da dimensão Timidez $(3,48)$. No fator Controle com esforço, por sua vez, os escores mais altos foram 
identificados nas dimensões de prazer de baixa intensidade e sensibilidade perceptual.

4.2.4- Caracterização dos indicadores do comportamento na fase pré-escolar, das crianças nascidas pré-termo.

A Tabela 12 reúne os indicadores do comportamento, avaliados pelo Questionário de Capacidades e Dificuldades, na fase pré-escolar das crianças nascidas pré-termo. 
Tabela 12- Indicadores do comportamento, avaliados pelo Questionário de Capacidades e Dificuldades, na fase pré-escolar das crianças nascidas pré-termo $(n=50)$.

\begin{tabular}{lc}
\hline Comportamento - escore e classificação no SDQ & Valores \\
\hline Total de problemas de comportamento & $13( \pm 7 ; 1$ - 32) \\
Escore- Média (DP; mín.-máx.) & \\
Classificação - n (\%) & $28(56)$ \\
$\quad$ Normal & $6(12)$ \\
$\quad$ Limítrofe & $16(32)$ \\
$\quad$ Anormal & \\
Comportamento pró- social & $9( \pm 1,7 ; 3-10)$ \\
Escore - Média (DP; mín.-máx.) & \\
Classificação - n (\%) & $48(96)$ \\
$\quad$ Normal & $2(4)$ \\
$\quad$ Anormal & \\
Hiperatividade & $5( \pm 3 ; 0$ - 10) \\
Escore- Média (DP; mín.-máx.) & \\
Classificação - n (\%) $\quad 25(50)$ \\
$\quad$ Lormal & $6(12)$ \\
$\quad$ Limítrofe & $19(38)$
\end{tabular}

\section{Sintomas emocionais}

Escore - Média (DP; mín.-máx.)

$4( \pm 2,5 ; 0-8)$

Classificação - n (\%)

Normal

Limítrofe

Anormal

$26(52)$

\section{Problemas de conduta}

Escore - Média (DP; mín.-máx.)

$3( \pm 2,4 ; 0-10)$

Classificação - n (\%)

Normal

Limítrofe

Anormal

$22(44)$

\section{Problemas de relacionamento com os colegas}

Escore -Média (DP; mín.-máx.)

$1( \pm 1,6 ; 0-6)$

Classificação - n (\%)

Normal

Limítrofe

Anormal

$\mathrm{n}=$ número de crianças; \% porcentagem; $\mathrm{DP}=$ desvio padrão; mín.= valor mínimo; máx.= valor máximo. Os escores na pontuação total variam de 0 a 40, nas subescalas variam de 0 a 2 . Escores e classificação: Total- Normal (0-13), Limítrofe (14-16), (Anormal (17-40); Comportamento pró-social - Norma (6-10), Limítrofe (5), Anormal (0-4); Hiperatividade - Normal (0-5), Limítrofe (6), Anormal (7-10); Sintomas emocionais- Normal (0-3), Limítrofe (4), Anormal (5-10); Problemas de conduta - Normal (0-2), Limítrofe (3), Anormal (4-10); Problemas de relacionamento com os colegas Norma (0-2), Limítrofe (3), Anormal (4-10). 
Evidencia-se na Tabela 12 que, na escala de comportamento, de acordo com os cuidadores, embora $56 \%$ das crianças apresentaram classificação normal na pontuação total, $32 \%$ das crianças apresentaram classificação anormal. Nas subescalas nota-se que a maior parte das crianças teve classificação normal em: Comportamento pró-social (96\%) e Problemas de relacionamentos com os colegas (76\%). Por outro lado, na subescala Problemas de conduta houve uma distribuição equitativa de $44 \%$ nas classificações normal e anormal. Destaca-se que nas subescalas Sintomas emocionais (64\%), Problemas de conduta (56\%) e Hiperatividade $(50 \%)$, as crianças encontraram-se na classificação limítrofe ou anormal.

4.3- 3a Seção: Indicadores de desenvolvimento de acordo com o grau de prematuridade

4.3.1 Comparação das características entre as crianças nascidas pré-termo muito baixo peso, distribuídas pelo nível de prematuridade.

A Tabela 13 apresenta as características das crianças nascidas pré-termo, distribuídas pelo nível de prematuridade. 
Tabela 13- Características neonatais das crianças nascidas pré-termo, distribuídas pelo nível de prematuridade.

\begin{tabular}{|c|c|c|c|}
\hline Características neonatais & $\begin{array}{c}\text { Grupo } \\
\text { Pré-termo extremo / } \\
\text { muito pré-termo } \\
(\mathrm{n}=29)\end{array}$ & $\begin{array}{c}\text { Grupo } \\
\text { Pré-termo moderado/ } \\
\text { pré-termo tardio } \\
(n=21)\end{array}$ & $\begin{array}{c}\text { Valor de } \\
p\end{array}$ \\
\hline \multicolumn{4}{|l|}{ Sexo- $n(\%)$} \\
\hline Feminino/ Masculino & $13(45) / 16(55)$ & $12(57) / 9(43)$ & 0,39 \\
\hline Peso ao nascimento - Média (DP; mín.- máx.) & $1.061,38( \pm 270 ; 650-1.500)$ & $1.361,19( \pm 181 ; 875-1.500)$ & $<0,0001$ \\
\hline Idade gestacional - Média (DP; mín.- máx.) & $29,14( \pm 1,382 ; 26-31)$ & $32,71( \pm 0,956 ; 32-35)$ & $<0,0001$ \\
\hline PIG/ AIG & $12(41) / 17(59)$ & $6(29) / 15(71)$ & 0,35 \\
\hline Índice de Apgar do 5o minuto - Média (DP; mín.- máx.) & $8,62( \pm 1,21 ; 5-10)$ & $9,38( \pm 0,86 ; 7-10)$ & 0,02 \\
\hline Tempo de internação na UTIN (dias) - Média (DP; mín.- máx.) & $28( \pm 22,5 ; 1-89)$ & $9( \pm 10 ; 1-33)$ & $<0,0001$ \\
\hline Tempo de internação hospitalar total (dias) - Média (DP; mín.- máx.) & $73( \pm 36 ; 20-181)$ & $36( \pm 20 ; 10-88)$ & $<0,0001$ \\
\hline
\end{tabular}

$\mathrm{n}=$ número de crianças; \% porcentagem; $\mathrm{DP}$ = desvio padrão; mín= valor mínimo, máx= valor máximo. IG= idade gestacional; Adequação do peso para idade gestacional, PIG - Pequeno para idade gestacional, AIG - Adequado para idade gestacional, segundo classificação de Lubchenco et al. (1966); Pré-termo extremo/ muito pré-termo= crianças nascidas com idade gestacional < 32 semanas; pré-termo moderado = crianças nascidas com idade gestacional entre 32 e 33 semanas e pré-termo tardio = crianças nascidas com idade gestacional entre 34 e 36 semanas, segundo classificação de Chabra (2013). 
Nota-se, na Tabela 13, que o grupo das crianças pré-termo extremo/ muito pré-termo foi composto por $55 \%$ meninos e o grupo de crianças com pré-termo moderado/ pré-termo tardia foi de $43 \%$. Não houve diferença estatisticamente significativa entre os grupos, nessa variável.

Como era de se esperar, houve diferenças estatisticamente significativas entre os grupos com relação às características neonatais. Observa-se que o grupo de crianças nascidas pré-termo extremo/ muito pré-termo apresentou significativamente menor peso ao nascimento, idade gestacional e menor índice de Apgar do $5^{0}$ minuto em comparação ao grupo de pré-termo moderado/pré-termo tardio. No entanto os grupos foram semelhantes quanto às porcentagens de crianças PIG e AIG, com predomínio de crianças AIG, em ambos os grupos. Nota-se diferença estatisticamente significativa entre os grupos no tempo de internação total e na UTIN. Observa-se que o grupo de crianças pré-termo extremo/ muito pré-termo ficou em média mais tempo internadas na UTIN e no hospital do que grupo de crianças pré-termo moderado/ pré-termo tardio.

4.3.2 Comparação dos indicadores cognitivos e de atenção entre os grupos de crianças nascidas pré-termo, de acordo com o nível de prematuridade na fase pré-escolar.

A Tabela 14 apresenta a comparação entre os grupos de crianças nascidas pré-termo, diferenciadas pela idade gestacional, quanto aos indicadores de cognição e atenção avaliados na fase pré-escolar. 
Tabela 14- Indicadores de cognição e atenção em grupo de crianças nascidas pré-termo, diferenciadas pelo nível de prematuridade, na fase pré-escolar.

\begin{tabular}{|c|c|c|c|}
\hline Indicadores de Cognição e atenção & $\begin{array}{c}\text { Pré-termo extremo/ } \\
\text { muito pré-termo } \\
(\mathrm{n}=29) \\
\text { Média (DP; mín.- máx.) }\end{array}$ & $\begin{array}{l}\text { Pré-termo moderado/ } \\
\text { pré-termo tardio } \\
\quad(n=21) \\
\text { Média (DP; mín.- máx.) }\end{array}$ & Valor de $p$ \\
\hline \multicolumn{4}{|l|}{ Cognição (Escore -WISC-III) } \\
\hline QI- Total & $89,62( \pm 21,44 ; 59-132)$ & $96,38( \pm 20,95 ; 59-142)$ & 0,27 \\
\hline QI- Verbal & $95,93( \pm 22,17 ; 66-142)$ & $103,43( \pm 18,52 ; 67-145)$ & 0,21 \\
\hline QI- Execução & $90,72( \pm 18,50 ; 67-142)$ & $98,57( \pm 18,36 ; 71-136)$ & 0,14 \\
\hline Fator- Resistência à Distração & $95,79( \pm 21,93 ; 64-131)$ & $101,86( \pm 16,75 ; 72-137)$ & 0,29 \\
\hline \multicolumn{4}{|c|}{ Teste de atenção por cancelamento (Escore- TAC) } \\
\hline Total & $39,83( \pm 19,05 ; 3-74)$ & $45,10( \pm 14,38 ; 14-86)$ & 0,29 \\
\hline Fase1 (Atenção seletiva) & $94,10( \pm 17,72 ; 56-127)$ & $96,14( \pm 13,30 ; 71-120)$ & 0,66 \\
\hline Fase 2 (Atenção seletiva) & $95,62( \pm 36,40 ; 0-146)$ & $98,86( \pm 44,08 ; 0-152)$ & 0,78 \\
\hline Fase 3 (Atenção alternada) & $86,0( \pm 29,91 ; 0-136)$ & $100,71( \pm 18,09 ; 58-135)$ & 0,05 \\
\hline
\end{tabular}


É possível observar na Tabela 14 que, com relação à cognição não houve diferença estatisticamente significativa entre os grupos. As crianças de ambos os grupos apresentaram classificação na média.

$\mathrm{Na}$ avaliação da atenção observa-se apenas diferença estatisticamente significativa entre os grupos na atenção alternada. O grupo pré-termo extremo/muito pré-termo apresentou menor escore em atenção alternada em comparação ao grupo pré-termo moderado/ pré-termo tardio. No restante, não houve diferença entre os grupos, indicando que os grupos apresentaram desempenho semelhante com relação à atenção seletiva.

4.3.3 Comparação dos indicadores de temperamento e comportamento entre os grupos de crianças nascidas pré-termo, de acordo com o nível de prematuridade na fase pré-escolar.

A Tabela 15 apresenta a comparação entre os grupos de crianças nascidas pré-termo quanto aos indicadores de temperamento e comportamento na fase préescolar 
Tabela 15- Indicadores do temperamento e comportamento em grupos de crianças nascidas pré-termo, diferenciadas pelo nível de prematuridade, na fase pré-escolar.

\begin{tabular}{|c|c|c|c|}
\hline $\begin{array}{l}\text { Indicadores de temperamento e } \\
\text { comportamento }\end{array}$ & $\begin{array}{c}\text { Pré-termo extremo/ } \\
\text { muito pré-termo } \\
(\mathrm{n}=\mathbf{2 9}) \\
\text { Média (DP; mín.- Max.) }\end{array}$ & $\begin{array}{l}\text { Pré-termo moderado/ } \\
\text { pré-termo tardio } \\
(\mathrm{n}=\mathbf{2 1}) \\
\text { Média (DP; mín.- Max.) }\end{array}$ & Valor de $p$ \\
\hline \multicolumn{4}{|l|}{ Temperamento (Escore do CBQ) } \\
\hline Afeto negativo & $4,3( \pm 0,50 ; 3,25-5,19)$ & $4,4( \pm 0,40 ; 3,72-5,33)$ & 0,36 \\
\hline Extroversão & $4,9( \pm 0,50 ; 3,74-5,98)$ & $5,0( \pm 0,55 ; 3,92-6,0)$ & 0,52 \\
\hline Controle com esforço & $4,7( \pm 0,40 ; 3,87-5,52)$ & $5,0( \pm 0,43 ; 3,82-5,50)$ & 0,91 \\
\hline \multicolumn{4}{|l|}{ Comportamento (Escore SDQ) } \\
\hline Total & $14( \pm 6,80 ; 2-32)$ & $12,2( \pm 7,14 ; 1-26)$ & 0,29 \\
\hline Comportamento pró- social & $8,7( \pm 2,0 ; 3-10)$ & $9,3( \pm 1,10 ; 6-10)$ & 0,17 \\
\hline Hiperatividade & $6( \pm 3,10 ; 0-10)$ & $4,4( \pm 3,62 ; 0-8)$ & 0,15 \\
\hline Sintomas emocionais & $4,1( \pm 2,40 ; 0-8)$ & $4( \pm 2,60 ; 0-8)$ & 0,51 \\
\hline Problemas de conduta & $3( \pm 2,40 ; 0-10)$ & $3,2( \pm 2,60 ; 0-8)$ & 0,75 \\
\hline Problemas de relacionamento com os colegas & $1,5( \pm 1,43 ; 0-4)$ & $1,4( \pm 1,70 ; 0-6)$ & 0,90 \\
\hline
\end{tabular}

$\mathrm{DP}=$ desvio padrão; mín.= valor mínimo, máx.= valor máximo. CBQ - Questionário Sobre o Comportamento da Criança; O escore do CBQ varia de 1 a 7. SDQ-Questionário de Capacidades e Dificuldades- Escores e classificação: Total- Normal (013), Limítrofe (14-16), (Anormal (17- 40); Comportamento pro-social - Norma (6-10), Limítrofe (5), (Anormal (0- 4); Hiperatividade - Normal (0-5), Limítrofe (6), (Anormal (7- 10); Sintomas emocionais- Normal (0-3), Limítrofe (4), (Anormal (510); Problemas de conduta - Normal (0-2), Limítrofe (3), (Anormal (4-10); Problemas de relacionamento com os colegas Norma (0-2), Limítrofe (3), (Anormal (4-10). 
Nota-se na Tabela 15 que não houve diferença estatisticamente significativa entre os grupos de crianças nascidas pré-termo, diferenciadas pela prematuridade, nos indicadores de temperamento e comportamento.

Tanto as crianças nascidas pré-termo extremo/muito pré-termo, quanto às crianças nascidas pré-termo moderado/pré-termo tardio apresentaram indicadores semelhantes nos três fatores de temperamento com escores moderados no afeto negativo, extroversão e controle com esforço.

No que se refere ao comportamento, os grupos não mostraram diferenças estatisticamente significativas. Apresentaram desempenho normal para o escore total e para as subáreas, com padrões semelhantes para os indicadores.

A Tabela 16 apresenta a comparação entre os grupos, de criança nascidas pré-temo, quanto à classificação do comportamento avaliado pelo SDQ. 
Tabela 16- Classificação do comportamento em grupos de crianças nascidas pré-termo, diferenciadas pelo nível de prematuridade, na fase pré-escolar.

\begin{tabular}{|c|c|c|c|}
\hline Comportamento - SDQ & $\begin{array}{l}\text { Pré-termo extremo/ } \\
\text { muito pré-termo } \\
(\mathrm{n}=29)\end{array}$ & $\begin{array}{l}\text { Pré-termo moderado/ } \\
\text { pré-termo tardio } \\
(\mathrm{n}=21)\end{array}$ & $\begin{array}{l}\text { Valor } \\
\text { de } p\end{array}$ \\
\hline \multicolumn{4}{|l|}{ Classificação- f (\%) } \\
\hline Total & & & 0,34 \\
\hline Normal & $15(52)$ & $13(62)$ & \\
\hline Limítrofe & $4(14)$ & $2(9)$ & \\
\hline Anormal & $10(34)$ & $6(29)$ & \\
\hline Comportamento pró- social & & & 0,50 \\
\hline Normal & $27(93)$ & $21(100)$ & \\
\hline Limítrofe & $0(0)$ & $0(0)$ & \\
\hline Anormal & $2(7)$ & $0(0)$ & \\
\hline Hiperatividade & & & 0,85 \\
\hline Normal & $11(38)$ & $14(67)$ & \\
\hline Limítrofe & $5(17)$ & $1(5)$ & \\
\hline Anormal & $13(45)$ & $6(29)$ & \\
\hline Sintomas emocionais & & & 0,57 \\
\hline Normal & $13(45)$ & $12(57)$ & \\
\hline Limítrofe & $6(21)$ & $1(5)$ & \\
\hline Anormal & $10(34)$ & $8(38)$ & \\
\hline Problemas de conduta & & & 0,56 \\
\hline Normal & $13(45)$ & $9(43)$ & \\
\hline Limítrofe & $4(14)$ & $2(9)$ & \\
\hline Anormal & $12(41)$ & $10(48)$ & \\
\hline \multicolumn{4}{|l|}{ Problemas de relacionamento } \\
\hline com os colegas & & & 0,62 \\
\hline Normal & $22(76)$ & $16(76)$ & \\
\hline Limítrofe & $2(7)$ & $1(5)$ & \\
\hline Anormal & $5(17)$ & $4(19)$ & \\
\hline
\end{tabular}

$\mathrm{f}=$ frequência; \% porcentagem; SDQ-Questionário de Capacidades e Dificuldades- Escores e classificação: Total- Normal (0-13), Limítrofe (14-16), (Anormal (17-40); Comportamento pro-social Norma (6-10), Limítrofe (5), (Anormal (0-4); Hiperatividade - Normal (0-5), Limítrofe (6), (Anormal (7-10); Sintomas emocionais- Normal (0-3), Limítrofe (4), (Anormal (5-10); Problemas de conduta - Normal (0-2), Limítrofe (3), (Anormal (4-10); Problemas de relacionamento com os colegas Norma (0-2), Limítrofe (3), (Anormal (4-10). 
A Tabela 16 aponta que, em relação a classificação do comportamento das crianças nascidas pré-termo, na idade pré-escolar, não houve diferença estatisticamente significativa entre os grupos de crianças, tanto para o escore total, quanto para as subescalas avaliadas pelo SDQ. Portanto, os grupos apresentaram padrões semelhantes com relação aos indicadores de comportamento.

\section{4- 4ª Seção: Predição dos indicadores do comportamento e desenvolvimento cognitivo}

\subsection{1- Predição dos indicadores cognitivos das crianças nascidas pré-termo na fase pré-escolar.}

A Tabela 17 apresenta modelos de predição dos indicadores cognitivos, avaliados pelo WISC-III, considerando-se respectivamente os escores Total, Verbal e Execução das crianças nascidas pré-termo na fase pré-escolar. 
Tabela 17 - Modelos de predição dos indicadores cognitivos avaliados pelo WISC-III, nas escalas Total, Verbal e de Execução das crianças nascidas pré-termo, na fase pré-escolar $(n=50)$.

\begin{tabular}{|c|c|c|c|c|c|c|c|c|}
\hline \multirow[t]{2}{*}{ Variáveis Predita } & \multirow[t]{2}{*}{ Variáveis preditoras } & \multirow{2}{*}{$\begin{array}{c}\mathbf{R}^{2} \\
\text { Ajustado }\end{array}$} & \multirow[t]{2}{*}{ B } & \multirow[t]{2}{*}{$\beta$} & \multirow[t]{2}{*}{$\mathbf{t}$} & \multicolumn{2}{|c|}{ IC } & \multirow{2}{*}{$\begin{array}{l}\text { Valor de } \\
\qquad p\end{array}$} \\
\hline & & & & & & mín. & máx. & \\
\hline \multirow[t]{2}{*}{ WISC III - QI Total } & WISC III- QI Verbal & 0,73 & 0,35 & 0,35 & 3,13 & 0,125 & 0,58 & 0,003 \\
\hline & Escolaridade da mãe & & 2,90 & 0,20 & 3,02 & 0,96 & 4,82 & 0,004 \\
\hline \multirow[t]{4}{*}{ WISC III- QI Verbal } & $\begin{array}{l}\text { CBQ- Controle com } \\
\text { esforço }\end{array}$ & 0,35 & 13,40 & 0,27 & 2,30 & 1,66 & 25,10 & 0,03 \\
\hline & TAC Total- Teste de & & & & & & & \\
\hline & atenção por cancelamento & & 0,42 & 0,42 & 3,56 & 0,18 & 0,66 & 0,001 \\
\hline & Escolaridade da mãe & & 2,54 & 0,18 & 2,11 & 0,12 & 4,96 & 0,040 \\
\hline \multirow[t]{4}{*}{ WISC III - QI Execução } & TAC-Total- Teste de & & & & & & & \\
\hline & atenção por cancelamento & 0,37 & 0,35 & 0,40 & 3,40 & 0,14 & 0,56 & 0,001 \\
\hline & Escolaridade da mãe & & 2,82 & 0,22 & 2,32 & 0,37 & 5,27 & 0,025 \\
\hline & CCEB- Abep & & 1,00 & 0,26 & 2,18 & 0,08 & 1,93 & 0,03 \\
\hline
\end{tabular}

$\mathrm{R}^{2}$ Ajustado= coeficiente de correlação ao quadrado ajustado pelo tamanho da amostra; $\mathrm{B}=$ coeficiente não padronizado; $\beta=$ coeficiente padronizado; IC= intervalo de confiança (95\%); mín.= valor mínimo; máx.= valor máximo. 
É possível observar na Tabela 17, que o modelo de predição da escala Total do WISC-III das crianças da amostra do estudo incluiu duas variáveis preditoras: escala Verbal do WISC-III e escolaridade materna. A combinação entre essas duas variáveis foi responsável por $73 \%$ da variabilidade no escore Total no WISC- III. É possível identificar que, quanto maior escore na escala Verbal do WISC- III e a escolaridade materna, maior escore na escala Total do WISC-III. De acordo com o coeficiente de regressão padronizado ( $\beta$ ), verifica-se a inteligência verbal apresentou maior peso para explicar o QI Total no WISC-III.

Nota-se que, com relação ao modelo de predição da escala verbal do WISC III, o controle com esforço do temperamento, a atenção e a escolaridade materna foram variáveis preditoras que compuseram este modelo. A combinação entre essas variáveis foi responsável por $35 \%$ da variabilidade no escore verbal do WISC-III. Crianças que tiveram menor escore na escala Verbal apresentaram menor controle com esforço, menor escore na atenção, associados com menor escolaridade materna. De acordo com o coeficiente de regressão padronizado $(\beta)$, verifica-se que a atenção apresentou maior peso no modelo de predição da escala Verbal nas crianças.

O modelo de predição da escala não Verbal do WISC -III incluiu três variáveis preditoras: atenção, escolaridade materna e o nível socioeconômico. A combinação entre essas três variáveis foi responsável por $37 \%$ da variabilidade no QI de Execução no WISC-III. As crianças que tiveram menor escore em atenção, cujas mães tinham menos escolaridade e nível socioeconômico mais baixo apresentaram menor escore na escala de Execução do WISC- III. De acordo com o coeficiente de regressão padronizado $(\beta)$, verifica-se também que a atenção apresentou maior peso no modelo de predição da inteligência não verbal das crianças, na fase préescolar. 
4.4.2- Predição dos indicadores do comportamento das crianças nascidas prétermo, na fase pré-escolar

A Tabela 18 apresenta o modelo de predição do total de problemas de comportamento das crianças nascidas pré-termo na fase pré-escolar. 
Tabela 18- Modelo de predição do total de problemas de comportamento das crianças nascidas pré-termo, na fase préescolar $(n=50)$.

\begin{tabular}{|c|c|c|c|c|c|c|c|c|}
\hline \multirow[t]{2}{*}{ Variável Predita } & \multirow[t]{2}{*}{ Variáveis preditoras } & \multirow{2}{*}{$\begin{array}{c}\mathbf{R}^{2} \\
\text { Ajustado }\end{array}$} & \multirow[t]{2}{*}{ B } & \multirow[t]{2}{*}{$\beta$} & \multirow[t]{2}{*}{$t$} & \multicolumn{2}{|c|}{ IC } & \multirow{2}{*}{$\begin{array}{l}\text { Valor } \\
\text { de }\end{array}$} \\
\hline & & & & & & mín. & máx. & \\
\hline SDQ- Comportamento & CBQ- Extroversão & 0,46 & 4,65 & 0,35 & 3,16 & 1,683 & 7,609 & 0,003 \\
\hline \multicolumn{9}{|l|}{ Total } \\
\hline & CBQ- Afeto negativo & & 5,76 & 0,39 & 3,71 & 2,636 & 8,895 & 0,001 \\
\hline & CBQ- Controle com esforço & & $-5,88$ & $-0,36$ & $-3,32$ & $-9,442$ & $-2,315$ & 0,002 \\
\hline & TAC Total- Teste de atenção & & & & & & & \\
\hline & por cancelamento & & $-0,54$ & $-0,20$ & $-1,89$ & $-0,111$ & 0,004 & 0,07 \\
\hline
\end{tabular}

$\mathrm{R}^{2}$ Ajustado= coeficiente de correlação ao quadrado ajustado pelo tamanho da amostra; $\mathrm{B}=$ coeficiente não padronizado; $\beta=$ coeficiente padronizado; $I C=$ intervalo de confiança $(95 \%)$; mín.= valor mínimo; máx.= valor máximo. SDQ=Questionário de Capacidades e Dificuldades; $\mathrm{CBQ}=$ Questionário Sobre o Comportamento da Criança; $\mathrm{TAC}=$ Teste de atenção por cancelamento. 
Como pode ser observado na Tabela 18, o modelo de predição do escore total de problemas do comportamento avaliado pelo SDQ das crianças da amostra de estudo foi composto pelas seguintes variáveis preditoras do temperamento: afeto negativo, extroversão e controle com esforço e atenção. Esses fatores associaramse com escore total do comportamento. A combinação entre essas quatro variáveis foi responsável por $46 \%$ da variabilidade do escore total dos problemas de comportamento. Verificou-se que, maiores escores em fatores extroversão e afeto negativo e menores escores do controle com esforço e atenção foram significativamente associados ao maior escore no total de problemas de comportamento. De acordo com os coeficientes de regressão padronizados $(\beta)$, os fatores do temperamento apresentaram maior peso na predição do comportamento.

A Tabela 19 indica o modelo de predição da hiperatividade e dos problemas de conduta das crianças nascidas pré-termo da amostra de estudo, na fase préescolar. 
Tabela 19- Modelos de predição de hiperatividade e problemas de conduta das crianças nascidas pré-termo, na fase pré-escolar $(n=50)$

\begin{tabular}{|c|c|c|c|c|c|c|c|c|}
\hline \multirow[t]{2}{*}{ Variáveis Preditas } & \multirow[t]{2}{*}{ Variáveis preditoras } & \multirow{2}{*}{$\begin{array}{c}\text { R2 } \\
\text { Ajustado }\end{array}$} & \multirow[t]{2}{*}{ B } & \multirow[t]{2}{*}{$\beta$} & \multirow[t]{2}{*}{$t$} & \multicolumn{2}{|c|}{ IC } & \multirow{2}{*}{$\begin{array}{l}\text { Valor de } \\
\text { p }\end{array}$} \\
\hline & & & & & & mín. & máx. & \\
\hline \multirow[t]{4}{*}{ SDQ- Hiperatividade } & CBQ- Afeto negativo & 0,28 & 1,833 & 0,26 & 2,109 & 0,084 & 3,582 & 0,04 \\
\hline & CBQ- Controle com esforço & & $-2,840$ & $-0,36$ & $-2,943$ & $-4,782$ & $-0,897$ & 0,005 \\
\hline & TAC Total- Teste de & & & & & & & \\
\hline & atenção por cancelamento & & $-0,057$ & $-0,36$ & $-2,89$ & $-0,097$ & 0,017 & 0,006 \\
\hline \multirow{3}{*}{$\begin{array}{l}\text { SDQ- Problemas de } \\
\text { conduta }\end{array}$} & CBQ- Afeto negativo & 0,35 & 1,462 & 0,29 & 2,318 & 0,193 & 2,731 & 0,02 \\
\hline & Sexo (1) & & $-2,334$ & $-0,5$ & $-3,855$ & $-3,553$ & $-1,116$ & 0,0001 \\
\hline & WISC III- QI Verbal & & $-0,032$ & $-0,279$ & $-2,312$ & $-0,060$ & $-0,004$ & 0,02 \\
\hline
\end{tabular}

$\mathrm{R}^{2}$ Ajustado= coeficiente de correlação ao quadrado ajustado pelo tamanho da amostra; $\mathrm{B}=$ coeficiente não padronizado; $\beta=$ coeficiente padronizado; IC= intervalo de confiança $(95 \%) ; m i ́ n .=$ valor mínimo; máx.= valor máximo. SDQ= Questionário de Capacidades e Dificuldades; $\mathrm{CBQ}=$ Questionário Sobre o Comportamento da Criança; TAC=Teste de atenção por cancelamento; WISC-III= Escala de Inteligência Wechsler para Crianças. Sexo, menino= 1 ; meninas= 2 , no banco de dados. 
Nota-se, pela Tabela 19, que o modelo de predição de hiperatividade, na amostra de crianças do presente estudo, foi composto pelas seguintes variáveis preditoras do temperamento: afeto negativo e controle com esforço, que estavam significativamente associadas ao escore total do teste de atenção por cancelamento. A combinação entre essas três variáveis foi responsável por $28 \%$ da variabilidade no escore da hiperatividade, avaliada pelo SDQ. Verificou-se que mais fator afeto negativo do temperamento e menos controle com esforço e a atenção associaramse a mais hiperatividade. De acordo com o coeficiente de regressão padronizado ( $\beta)$, verifica-se que, tanto o controle com esforço quanto a atenção apresentaram maior peso na predição de hiperatividade.

O modelo de predição do escore de problemas de conduta, por sua vez, das crianças da amostra de estudo, foi composto pela associação significativa entre as seguintes variáveis preditoras: afeto negativo do temperamento, escala verbal do WISC-III e sexo das crianças. A combinação entre essas três variáveis foi responsável por $35 \%$ da variabilidade no escore de problemas de conduta. Verificou-se que quanto mais afeto negativo, mais problemas de conduta. Nota-se ainda que mais afeto negativo no temperamento, menor escore na escala verbal e ser do sexo masculino associa-se significativamente com mais problemas de conduta na fase pré-escolar. De acordo com o coeficiente de regressão padronizado $(\beta)$, o sexo masculino apresentou maior peso na predição de problemas de conduta na fase pré-escolar.

A Tabela 20 apresenta os modelos de predição dos problemas de relacionamento com colegas e sintomas emocionais das crianças nascidas prétermo, na fase pré-escola. 
Tabela 20 - Modelos de predição de problemas de relacionamento com colegas e sintomas emocionais das crianças nascidas prétermo, na fase pré-escolar $(\mathrm{n}=50)$.

\begin{tabular}{|c|c|c|c|c|c|c|c|c|}
\hline \multirow[t]{2}{*}{ Variáveis Preditas } & \multirow[t]{2}{*}{ Variáveis preditoras } & \multirow{2}{*}{$\begin{array}{c}\mathbf{R}^{2} \\
\text { Ajustado }\end{array}$} & \multirow[t]{2}{*}{ B } & \multirow[t]{2}{*}{$\beta$} & \multirow[t]{2}{*}{$\mathbf{t}$} & \multicolumn{2}{|c|}{ IC } & \multirow{2}{*}{$\begin{array}{c}\text { Valor de } \\
\text { p }\end{array}$} \\
\hline & & & & & & mín. & máx. & \\
\hline SDQ- Problemas de & Modelo 1 & & & & & & & \\
\hline \multirow[t]{4}{*}{ relacionamento com colegas } & CBQ- Extroversão & 0,31 & 1,46 & 0,511 & 4,026 & 0,727 & 2,19 & 0,0001 \\
\hline & Escolaridade do pai & & 0,301 & 0,30 & 2,077 & 0,008 & 0,59 & 0,04 \\
\hline & WISC II- Execução & & $-0,03$ & $-0,36$ & $-2,518$ & $-0,050$ & $-0,005$ & 0,02 \\
\hline & Escolaridade da mãe & & $-0,255$ & $-0,243$ & $-1,87$ & $-0,53$ & 0,019 & 0,07 \\
\hline \multirow[t]{3}{*}{ SDQ- Sintomas emocionais } & Idade gestacional & 0,47 & $-0,388$ & $-0,341$ & $-3,131$ & $-0,64$ & $-0,14$ & 0,003 \\
\hline & CCEB- ABEP & & 0,095 & 0,183 & 1,708 & $-0,017$ & 0,21 & 0,10 \\
\hline & esforço & & $-1,88$ & $-0,325$ & $-3,05$ & $-3,121$ & $-0,64$ & 0,004 \\
\hline
\end{tabular}


É possível observar na Tabela 20, que nos problemas de relacionamento com os colegas apareceram dois modelos significativos de predição. O primeiro modelo de predição de problemas de relacionamento com colegas, nas crianças da amostra de estudo foi composto pelas variáveis preditoras de extroversão do temperamento, escolaridade do pai e escala de execução do WISC- III. A combinação entre essas três variáveis foi responsável por $31 \%$ da variabilidade no escore de problemas de relacionamento com colegas, avaliados pelo SDQ, na fase pré-escolar. Verificou-se que mais extroversão, menor escore na escala não verbal e maior escolaridade paterna associaram-se com mais problemas de relacionamento com colegas. De acordo com o coeficiente de regressão padronizado ( $\beta$ ), verifica-se que o fator extroversão do temperamento apresentou maior peso na predição dos problemas de relacionamento com os colegas, na fase pré-escolar.

O segundo modelo de predição dos problemas de relacionamento com os colegas, das crianças da amostra foi composto pelas variáveis preditoras extroversão do temperamento e escolaridade materna. A combinação entre essas duas variáveis foi responsável por $20 \%$ da variabilidade no escore de problemas de relacionamento com colegas avaliadas pelo SDQ. Verificou-se que mais extroversão e menos escolaridade materna esteve associado a mais problemas de relacionamento com os colegas. De acordo com o coeficiente de regressão padronizado $(\beta)$, verifica-se que também neste modelo o fator extroversão do temperamento apresentou maior peso no modelo de predição dos problemas de relacionamento com os colegas, na fase pré-escolar.

O modelo de predição de sintomas emocionais, por sua vez, das crianças da amostra foi constituído significativamente pela combinação de cinco variáveis preditoras: idade gestacional, nível de classificação socioeconômica familiar e os três fatores do temperamento (extroversão, afeto negativo e controle com esforço). A combinação entre essas cinco variáveis foi responsável por $47 \%$ da variabilidade no escore de sintomas emocionais, no SDQ, na fase pré-escolar. Nota-se que menor idade gestacional, maior nível socioeconômico, mais extroversão e afeto negativo e menos controle com esforço associaram-se com mais sintomas emocionais, nas crianças na fase pré-escolar. De acordo com o coeficiente de regressão padronizado $(\beta)$, verifica-se que o fator afeto negativo do temperamento apresentou maior peso no modelo de predição dos sintomas emocionais. 


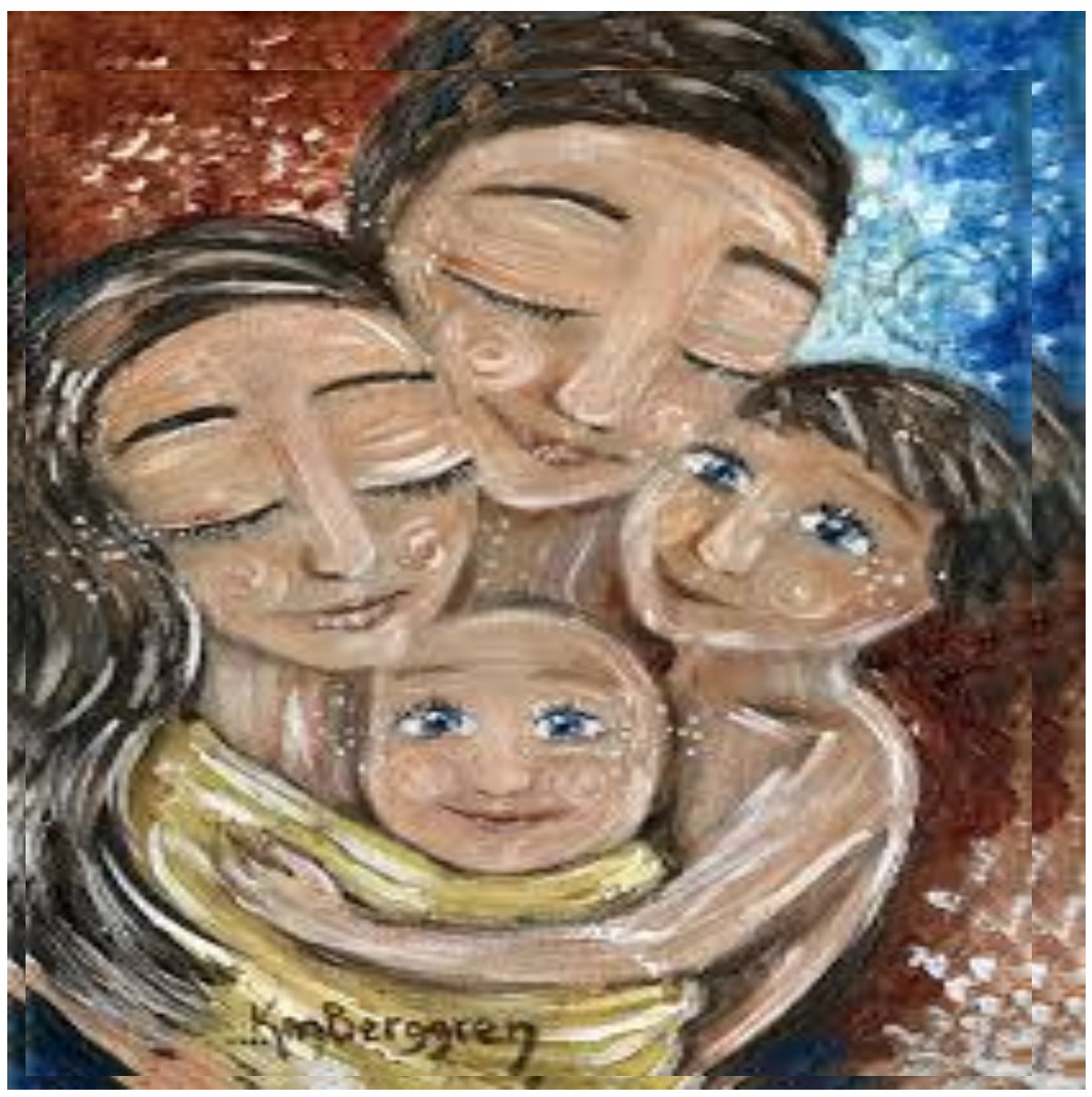

Artigo V - Todo prematuro tem direito à liberdade de opinião e expressão, portanto deverá ter seus sinais de aproximação e afastamento identificados, compreendidos, valorizados e respeitados pela equipe de cuidadores. Nenhum procedimento será considerado ético quando não levar em conta para sua execução as necessidades individuais de contato ou recolhimento do bebê prematuro. 
A discussão dos resultados está organizada a fim de contemplar os objetivos do estudo. Primeiramente, será analisada a caracterização geral das crianças da amostra estudada levando-se em consideração a sua história de saúde e indicadores do seu contexto familiar. Em seguida, serão discutidos os achados sobre os indicadores cognitivos, de atenção, do temperamento e comportamento das crianças, respectivamente, do ponto de vista da sua caracterização e da relação com o nível de prematuridade ao nascer. Além disso, serão discutidos os fatores de predição dos indicadores de cognição e comportamento, respectivamente.

\subsection{Características das crianças nascidas pré-termo quanto à história de saúde e contexto familiar.}

Em relação às características das crianças nascidas pré-termo, observou-se uma distribuição equilibrada entre meninos e meninas na amostra do presente estudo. As crianças foram avaliadas em média aos seis anos e sete meses de idade, sendo que a grande maioria destas cursava o ensino fundamental (88\%) em escolas públicas (96\%).

Com relação à história anterior de saúde das crianças, observou-se uma média de peso ao nascimento de 1.190 gramas e de idade gestacional de 31 semanas, assim como detectou-se que $64 \%$, tinham o peso ao nascer adequado para a idade gestacional. A amostra era composta por crianças com muito baixo peso ao nascimento. A literatura aponta duas classificações a da OMS (2012) e Chaba (2013). Destaca-se, no entanto, que ambas as classificações acima citadas, têm aspectos fortes, porém ainda têm problemas no que se refere à divisão dos grupos de prematuros. Enquanto uma se ocupa em subdividir os muito pré-termo e os extremos, a outra subdivide melhor os moderados e os tardios; nesse sentido elas podem ser complementares.

A estratificação dos grupos de prematuros é relevante, pois estes não se constituem em grupo homogêneo (Ribeiro \& Lamônica, 2014). Nota-se que as crianças prematuras extremo nascem três meses ou mais antes da idade do termo (40 semanas de idade gestacional), e, consequentemente, o cérebro do bebê é imaturo e propenso a lesões (Griffiths et al., 2014). Na medida em que, essas crianças crescem, as diferenças na anatomia do cérebro causada pela prematuridade ainda persistem (Gozzo et al., 2009; Griffiths et al., 2013; Skranes et 
al., 2008). Nota-se, portanto, maior risco nas crianças que nasceram antes de 28 semanas de idade gestacional, ou seja, crianças pré-termo extremo (Serenius et al., 2013).

A gravidade das dificuldades no desenvolvimento encontradas em crianças prematuras parece depender da idade gestacional e do peso ao nascimento (Aarnoudse-Moens et al., 2009; Kerstjens, Winter, Bocca-Tjeertes, Ten Vergert, Reijneveld, \& Bos, 2011). No presente estudo houve uma preocupação em identificar o padrão de funcionamento das crianças de diferentes idades gestacionais, levando-se em consideração que as crianças pré-termo extremo e muito prematuras apresentam algumas diferenças maturacionais, quando comparadas às crianças nascidas pré-termo moderado ou tardio.

$\mathrm{Na}$ comparação entre grupos de crianças pré-termo extremo/ muito pré-termo (<32 semanas de IG) e crianças pré-termo moderado/ tardio (32 a 36 semanas de IG) do presente estudo nota-se que o primeiro grupo citado foi composto por $55 \%$ meninos e o segundo por $43 \%$. Como era de se esperar, houve diferenças estatisticamente significativas entre os grupos com relação às características neonatais, em que grupo de crianças nascidas pré-termo extremo/ muito pré-termo apresentaram menor peso ao nascimento, menor idade gestacional, menor Apgar do 5o minuto e ficaram mais tempo internadas na UTIN e no hospital, em comparação às crianças nascidas pré-termo moderado e tardio.

Achados do presente estudo corroboram os resultados de Lemos, Frônio, Neves e Ribeiro (2010), ao identificarem que as morbidades e complicações neonatais foram significativamente maiores no grupo de crianças nascidas com peso ao nascimento inferior a $1.000 \mathrm{~g}$ e idade gestacional menor do que 33 semanas, do que em prematuros de baixo peso.

A prematuridade e o baixo peso ao nascer (Drotar et al., 2006; Silva \& Nunes, 2005) são fatores importantes e que podem desencadear complicações neonatais imediatas, além de serem considerados fatores preditores de alterações no desenvolvimento a curto prazo (Khan et al., 2006; Roberts et al., 2008) e a médio e longo prazo (Nair, Chacko, Paul, Nair, George, \& Kumar, 2009). Desta maneira, percebe-se que a prematuridade é um fator de risco biológico ao desenvolvimento global da criança podendo variar, em termos de efeitos negativos, nas diferentes áreas do desenvolvimento infantil (Oliveira, Flores, \& Souza, 2012). Contudo, deve- 
se verificar a interação do fator biológico e social como fatores de risco potencializadores nos efeitos ao desenvolvimento (Halpern \& Figueiras, 2004; Mancini, Megale, Brandão, Melo, \& Sampaio, 2004).

$\mathrm{Na}$ amostra do presente estudo, a média do escore do índice Apgar do 5o minuto foi alta, de nove pontos. Nota-se que mesmo as crianças apresentando o risco biológico da prematuridade, que as torna mais vulneráveis, as mesmas apresentaram bom sinais de vitalidade, de acordo com índice de Apgar. Os achados vão ao encontro dos resultados de Ramos e Cuman (2009), que encontraram índice de Apgar entre nove e 10 em 52\% das crianças pré-termo da sua amostra. Nossos resultados sugerem que as crianças eram vulneráveis devido a prematuridade, contudo havia sinais de bom prognóstico de evolução clínica.

Quanto ao tempo de internação na UTIN, verificou-se que as crianças do presente estudo ficaram em média 20 dias internadas, porém houve grande amplitude de variação individual, podendo chegar a três meses de hospitalização. Com relação ao tempo de internação total, as crianças ficaram em média 57 dias, também com extensa amplitude de variação individual, podendo chegar a seis meses. Trata-se, portanto, de um período longo de internação com grandes desafios para sobrevivência e desenvolvimento dos bebês. Além de sobreviver ao nascimento, às crianças permaneceram sob tratamento intensivo para manterem-se vivas e alcançarem condições de estabilidade e ganho de peso para alta clínica.

Os bebês nascidos prematuros, neste longo período de internação podem ficar expostos a experiências atípicas de privação ou excesso de estímulos em um período sensível e primordial para o crescimento cerebral rápido e diferenciação neuronal (Couperus \& Nelson, 2006). O ambiente da UTIN caracteriza-se pelos cuidados especiais e de proteção para os bebês nascidos pré-termo, porém também inclui múltiplos estímulos que provocam dor, estresse e desconforto, tanto para os bebês quanto para seus familiares (Klein et al., 2011). Esses estímulos experimentados de forma contínua podem interferir nos comportamentos regulatórios iniciais dos bebês (Feldman, 2009) e no controle de alerta fisiológico que se integra aos processos de atenção no desenvolvimento (Calkins \& Fox 2002).

Neste sentido, o ambiente hospitalar da UTIN com iluminação intensa, ruído excessivo e a realização de procedimentos dolorosos, é uma fonte constante de estresse para os bebês (Gaspardo, Martinez, \& Linhares, 2010). Assim, esse 
ambiente de estimulação excessiva e prolongada durante o desenvolvimento inicial do cérebro traz consequências para o recém-nascido pré-termo, que podem levar a dificuldade em permanecer em um estado comportamental ativo ou inativo de alerta, na regulação do sono, a prejudicar a atenção e levar a dificuldades de aprendizagem em longo prazo (Bremmer, Byers, \& Kiehl, 2003). Desde modo, os prematuros que necessitaram de internação na UTIN são mais propensos a apresentar alterações no desenvolvimento neurosensorimotor (Lamônica \& Picolini, 2009).

Em um recente estudo de revisão considerando a influência dos procedimentos dolorosos e estressantes e o impacto destes no desenvolvimento neurológico posteriores de crianças nascidas pré-termo identificou que o stress relacionado com dor neonatal foi associado a alterações, tanto no início do desenvolvimento quanto nos resultados de desenvolvimento posteriores (Valeri, Holsti, \& Linhares, 2015). Nota-se, portanto que os problemas nos processos de integração hierarquizada de autorregulação desde o nascimento à idade pré-escolar podem contribuir para problemas de desenvolvimento durante a infância que afetam o desenvolvimento mais tarde na idade escolar (Berger, 2011).

Verificou-se que, em relação ao tipo de alimentação, no período de internação as crianças foram alimentadas, em sua maioria (66\%), exclusivamente por leite humano. Contudo na alta hospitalar houve uma diminuição do aleitamento materno exclusivo e um aumento da porcentagem de crianças com alimentação mista, composta por leite humano e fórmula (48\%). Esses achados podem estar relacionados com a rotina do hospital em que aconteceu a coleta de dados do presente estudo, pois, durante o tempo de internação, o pediatra reforça a importância do aleitamento materno. A mãe é orientada a oferecer inicialmente o seio materno e a complementação com leite artificial, quando indicada, se dá de acordo com a prescrição alimentar proposta.

O estabelecimento do aleitamento materno nos recém-nascidos pré-termo constitui um grande desafio, podendo persistir até a alta hospitalar (Junior Santoro \& Martinez, 2007). Esses autores identificaram uma taxa de desmame ou do não acesso à amamentação nas crianças nascidas pré-termo assistidas pela rotina do serviço do Hospital das Clínicas de Ribeirão Preto, no momento da alta hospitalar de $61,1 \%$. A porcentagem encontrada no nosso estudo é semelhante do estudo citado realizado em período anterior na mesma instituição hospital. 
A literatura evidencia a importância do acesso das mães de recém-nascidos pré-termo a serviços de apoio ao aleitamento materno a fim de que possam manter a produção láctea suficiente para alimentar os bebês (Nascimento \& Issler, 2004). Entretanto, aspectos práticos de estímulo à amamentação ainda não estão plenamente incorporados nas rotinas de atendimento dos prematuros na maior parte das unidades neonatais no país (Meier, 2001).

Vale salientar que esta prática de ordenha de leite humano é rotina no hospital em que foi realizada a presente pesquisa. Sabe-se que o aleitamento materno é o modo mais natural e seguro de alimentação para criança pequena devendo ser exclusivo até os seis meses de idade (Delgado \& Halpern, 2005; Nascimento \& Issler, 2004; Silva \& Guedes, 2013). Entretanto devido a problemas que podem acometer o prematuro, eles têm necessidades nutricionais específicas para tentar suprir esforços realizados à adaptação na vida extrauterina. Deve-se destacar que a alimentação inicial é fundamental para o desenvolvimento cognitivo posterior das crianças. Os benefícios da amamentação, tanto nutricionais, imunológicos, cognitivos como socioeconômicos são bem reconhecidos (Chaves, Lamounier, \& César, 2007). Além disto, o ápice de crescimento do cérebro humano inicia-se durante o terceiro trimestre de gestação e continua nos dois primeiros anos de vida, o que combina com o período de lactação (Viberg et al., 2008). Desta maneira alguns estudos destacam a importância do leite materno para o desenvolvimento cerebral (Dee, Li, Lee, \& Grummer-Strawn, 2007; Kramer et al., 2008) descrevendo uma associação positiva entre aleitamento materno e melhor desenvolvimento na infância, adolescência e vida adulta (Clark et al., 2006; Morley et al., 2004).

Por outro lado, achados do presente estudo mostraram alta prevalência de patologias, associadas ao nascimento prematuro, na história de saúde das crianças, durante sua evolução clínica na hospitalização. Essas patologias foram predominantemente do tipo de distúrbios respiratórios, tais como: desconforto respiratório precoce, síndrome da membrana hialina, displasia broncopulmonar, apnéia de repetição e doença pulmonar crônica. Esses achados confirmam os resultados de outros estudos com prematuros, como os de Silveira e Enumo (2012), Silveira et al. (2008) e Sousa, Galende e Botelho (2012), que verificaram altos índices de doenças respiratórias na fase neonatal em crianças nascidas prematuras. 
Nos bebês nascidos pré-termo essas intercorrências são comuns de acontecerem no período pós-natal (Balda \& Guinsburg, 2004; Oliveira, 2011).

Além dessas patologias, no presente estudo verificou-se a presença de hiperbilirrubinemia, anemia e hipoglicemia na história de saúde das crianças. As infecções, as hemorragias intracranianas e as convulsões ocorreram em menor porcentagem, situando-se abaixo de $10 \%$ dos casos da amostra do presente estudo. O estudo de Silveira e Enumo (2012) também encontrou um índice próximo aos nossos achados de $8 \%$ para problemas neurológicos na amostra de prematuros estudada. Verifica-se, portanto, que a amostra do presente estudo tinha as doenças prevalentes em população de bebês nascidos prematuros e apresentava baixo risco para problemas neurológicos.

As crianças do presente estudo foram submetidas a tratamentos $e$ procedimentos durante a hospitalização, com maior frequência de ventilação mecânica, nutrição parenteral e fototerapia. Os achados corroboram os encontrados por Carneiro, Costa, Vieira, Reis, Carneiro e Caldeira, (2015), em que 75,5\% dos neonatos pré-termo de muito baixo peso fizeram uso de ventilação mecânica e $37,5 \%$ de surfactante. $O$ autor acrescenta ainda, que esses resultados refletem um bom acesso dessas crianças à tecnologia de cuidados médicos disponível.

Verificou-se no presente estudo que, com relação aos procedimentos médicos durante a internação, houve maior prevalência de ventilação mecânica, fototerapia e nutrição parenteral. Identificou-se em relação às cirurgias, que das treze cirurgias identificadas, mais da metade foram cirurgias cardíacas. Os achados do presente estudo são consistentes com os de Beani et al. (2007), que encontraram a presença da persistência da abertura do canal arterial (PCA) em torno de $80 \%$ das crianças pré-termo com recomendação de cirurgia. As crianças do presente estudo, portanto, revelaram patologias típicas de prematuros, como também foi encontrado em outros estudos, a saber: frequentes alterações respiratórias (Castro \& Leite, 2007; Silveira \& Enumo, 2012), persistência do canal arterial (PCA), hemorragia intracraniana (Gibelli, 2009), hipoglicemia (Nobre et al., 2009), infecção (Silveira \& Enumo, 2012) e doença pulmonar crônica (Formiga \& Linhares, 2009; Katz-Salamon, Gerner, Jonsson, \& Lagercrantz, 2000). A amostra do presente estudo trata-se, portanto, de crianças com características típicas de crianças nascidas prematuras. Nota-se, como mencionado por Aylward (2002), que a prematuridade torna-se uma "porta de 
entrada" para diversos problemas de saúde, caracterizando a grande vulnerabilidade biológica dos prematuros que se constituiu em risco para problemas em seu desenvolvimento.

Portanto, como destacado no estudo de Roberts, Bellinger e McCormik (2007), deve-se avaliar a influência interrelacionada da variável biológica do indivíduo e do ambiente na promoção da aprendizagem e do desenvolvimento. Com relação às características familiares destaca-se que as crianças do presente estudo viviam em sua maioria com suas famílias nucleares. Apenas uma criança era cuidada pela avó aposentada de 57 anos de idade com nível escolar de $1^{\circ}$ grau incompleto. As mães tinham em média 34 anos e os pais 37 anos. As mães tinham escolaridade média de 10 anos, sendo que houve predomínio de mães e pais que concluíram o $2^{\circ}$ grau completo. Destaca-se que ambos os pais trabalhavam fora do lar.

O estudo de Ramos e Cuman (2009) encontrou que a metade das mães de crianças nascidas pré-termo eram solteiras $(51 \%)$, o que sugere que possivelmente as mães não tinham apoio de um companheiro e, portanto, não tinham com quem dividir suas dificuldades e responsabilidades. Diferentemente do estudo de Ramos e Cuman, no presente estudo, a maior parte dos pais tinha uma união estável e a maioria das crianças residia com a família nuclear, em casa própria e com uma média de quatro pessoas na condição de moradores. Os achados sugerem que potencialmente as mães das crianças do presente estudo tinham suporte social no contexto familiar.

Em relação às características da história obstétrica, pré e peri- natal das mães, observou-se que as mesmas tiveram em torno de duas gestações, dois partos e nenhum aborto. Na história pré-natal, a maioria das mães, não planejou a gravidez. Contudo, a maior parte das mães iniciou o pré-natal a partir do primeiro trimestre de gravidez e realizaram em média seis consultas médicas. Este número de consultas indica que houve o seguimento pré-natal regular mensal, considerando que a gravidez não foi a termo. Este é um aspecto protetor importante no período da gestação. Esses achados sobre condições de risco associadas ao nascimento prematuro também foram evidenciados em outros estudos (Martins, Santos, Sousa, Costa, \& Simões, 2011; Ramos e Cuman, 2009), em que o seguimento pré-natal de prematuros incluiu de quatro a seis consultas. Deve-se destacar que cinco ou menos 
consultas no pré-natal constitui-se em fator de risco para prematuridade, conforme indicado por Silveira et al. (2008).

Os bebês nasceram mais de parto cesárea do que de parto normal. Os achados vão na mesma direção dos estudos de Frigo, Azambuja Zocche, Palavro, Turatti, Neves, e Schaefer, (2015) e Grandi, Tapia e Cardoso (2015), que identificaram maior porcentagem de parto cesáreo no nascimento de prematuros, em comparação ao parto vaginal. Os achados da literatura mostram que há um percentual elevado de cesáreas, que é um importante fator de risco para a ocorrência da prematuridade; que pode ser potencializado pelos fatores: idade materna, baixa escolaridade, baixo nível socioeconômico e gemelaridade (Marque, Dias, \& Azevedo, 2006; Ramos \& Cuman, 2009).

Em suma, a amostra de crianças nascidas pré-termo de muito baixo peso do presente estudo apresentaram características clínicas, semelhantes a outras amostras de prematuros atendidos em serviços públicos de saúde do nosso país.

\subsection{Indicadores cognitivos das crianças nascidas pré-termo}

Com relação à avaliação cognitiva, as crianças nascidas pré-termo estudadas apresentaram um QI total médio em torno de 90 a 100 pontos de acordo com a padronização brasileira do WISC-III. A maior parte das crianças (60\%) apresentou resultados com classificação na média nos Qls Total, Verbal e de Execução do WISC-III. Observou-se que, nas classificações extremas do teste (Muito superior, Superior e Intelectualmente deficiente) houve menor porcentagem de crianças nessas classificações. Verificou-se que apenas $10 \%$ do total da amostra apresentaram indicadores de deficiência intelectual. Com relação ao Ql do índice fatorial específico de resistência à distração do WISC- III observou-se que as crianças apresentaram resultados com classificação média em 64\%, 14\% apresentaram desempenho superior à média e $22 \%$ crianças tiveram desempenho limítrofe ou deficiente neste fator. Os achados do presente estudo corroboram os resultados dos estudos de Aarnoudse-Moens et al. 2009 e Martini (2012), em que uma amostra de crianças nascidas muito pré-termo, em idade pré-escolar obtiveram QI na média. 
Os resultados do presente estudo assemelham-se aos encontrados no estudo de Campos, Malloy-Diniz, Nascimento e Amorim (2011), que compararam o desempenho cognitivo de crianças nascidas pré-termo (33 semanas de idade gestacional e peso ao nascimento abaixo de $1.500 \mathrm{~g}$ ) com crianças nascidas a termo, aos sete anos de idade. Os autores identificaram que, apesar de o desempenho intelectual do grupo de crianças nascidas prematuras ter apresentado escore inferior ao do grupo controle, nos QIs Total, Verbal e Execução do WISC-III, as crianças do estudo apresentaram QI dentro dos padrões de normalidade. Outros estudos também encontraram nível de inteligência dentro dos parâmetros da normalidade em diferentes amostras de crianças nascidas com muito baixo peso (Foulder-Hughes \& Cooke,2003 b; Martins et al., 2005). Em uma amostra de crianças prematuras extremo, aos cinco anos de idade cronológica corrigida para prematuridade os achados são semelhantes, pois as crianças apresentaram Qls Total, Verbal e Execução dentro normalidade, mesmo quando comparada aos seus pares nascidos a termo (Potharst et al., 2011).

No estudo de Oliveira et al. (2011), ao avaliar crianças nascidas prematuras de muito baixo peso com idade de cinco e seis anos, por meio do WISC- III foi verificado que as crianças apresentaram pior desempenho do que as crianças do grupo controle nascidas a termo. Contudo o desempenho médio ficou dentro dos limites da normalidade para a idade.

Os achados do presente estudo mostraram indicadores cognitivos mais positivos na amostra de crianças nascidas pré-termo e muito baixo peso, em comparação com os resultados de outros estudos com crianças nascidas pré-termo. Nota-se que estudos realizados com crianças nascidas com menos de 32 semanas de gestação ou com peso de nascimento abaixo de $1.500 \mathrm{~g}$ têm apontado uma série de problemas cognitivos e paralisia cerebral quando comparadas com seus pares nascidos a termo (Aarnoudse-Moens et al., 2009; Lee, Yeatman, Luna, \& Feldman, 2011; Litt, Taylor, Margevicius, Schluchter, Andreias, \& Hack, M. 2012).

Cabe salientar que, crianças nascidas prematuras podem apresentar um funcionamento intelectual global dentro da normalidade, porém ao serem comparadas com as crianças nascidas a termo encontram-se em desvantagem, na fase escolar (Rodrigues et al., 2006). 
É importante ressaltar que o grupo de crianças nascidas extremamente baixo peso encontra-se em maior risco do que os nascidos a termo, nascidas de parto normal e com peso acima de $2.500 \mathrm{~g}$. Além disso, as crianças podem apresentar problemas de desenvolvimento que vão desde alterações neurossensoriais e deficiência intelectual global para distúrbios mais sutis na cognição, aprendizagem e comportamento (Conrad, Richman, Lindgren, \& Nopoulos, 2010; Johnson \& Marlow, 2011). Sendo assim, nota-se que as crianças nascidas pré-termo podem apresentar o desempenho cognitivo abaixo do esperado, podendo ter futuramente, como consequências negativas no desempenho acadêmico (Aarnoudse-Moens et al., 2009; Roberts, Bellinger \& MCCormick, 2007).

Em um estudo de revisão de literatura sobre o desenvolvimento neurológico após o nascimento prematuro, Jarjour (2015) identificou graus mais leves de deficiência na área da cognição, comportamento e aprendizado em fases posteriores como, na adolescência e nos adultos jovens. Neste sentido, o autor ressalta a importância de uma melhor compreensão da prevalência e padrões do neurodesenvolvimento adversos em crianças extremamente prematuras, tornandose importante garantir um seguimento dos pacientes.

As crianças do presente estudo, em sua maioria, apresentaram o desempenho cognitivo, na média. Contudo, foi relevante a análise da amostra dividida pelo nível de prematuridade. Na comparação entre os grupos de crianças nascidas pré-termo extremo/ muito pré-termo e pré-termo moderado/pré-termo tardio, com relação aos indicadores de desenvolvimento cognitivo, não houve diferença estatisticamente significativa.

Focalizando a idade gestacional, os resultados do presente estudo são contrários ao estudo de meta-análise de Aarnoudse-Moens et al. (2011) que examinou o desempenho de habilidades acadêmicas em muito pré-termo, na faixa de 4 a 12 anos de idade. Os autores identificaram em uma amostra de crianças nascidas muito prematuras ( $<30$ semanas) déficit no desempenho cognitivo. Em um estudo anterior, do mesmo autor (Aarnoudse-Moens et al., 2009) foi observado maior risco para as crianças nascidas pré-termo extremos, além de apresentarem desempenho cognitivo menor em comparação aos seus pares nascidos a termo.

No estudo de Saur (2012) identificou em crianças nascidas prematuras tardia ( $<37$ semanas de idade gestacional), $34 \%$ de crianças com desempenho cognitivo 
classificado como intelectualmente na média e 49\% como intelectualmente superior e acima da média. A autora também identificou associação entre menor desempenho cognitivo e as variáveis prematuridade, baixo nível socioeconômico e menor escolaridade materna. Nossos achados apresentaram menores porcentagens do que as de Saur, o que pode estar relacionado com as características da amostra e o período de avaliação. No estudo de Saur as crianças tinham idade gestacional menor do que 37 semanas de idade gestacional e a amostra incluiu apenas 5,6\% de crianças com idade gestacional com menos de 34 semanas e 3,5\% com peso ao nascimento menor do que $1.500 \mathrm{~g}$. Desta forma o número pequeno de crianças em condição de risco neonatal graves podem ter favorecido os resultados mais positivos para o desfecho do desenvolvimento cognição.

Crianças nascidas muito pré-termo (<32 semanas de idade gestacional) em idade escolar apresentaram desempenho cognitivo na média, avaliados pelo WISCIII (Foulder-Hughes \& Cooke, 2003). Desempenho cognitivo na média, também foi encontrado no estudo realizado por Odd, Emond e Whitelaw (2012) com objetivo de avaliar a cognição de crianças nascidas pré-termo moderado e tardio (32 - 36 semanas de idade gestacional), em comparação a crianças nascidas a termo, na fase escolar. Os autores não identificaram relação ente o nível socioeconômico ou educacional materno, mas constatou-se que quanto menor a idade gestacional menor o nível intelectual.

Em um estudo recente de Harmon, Taylor, Minich, Wilson-Costello e Hack (2015), identificou-se riscos para o desempenho cognitivo e desempenho acadêmico mais baixos, no primeiro ano escolar, em crianças extremamente prematuras. Apesar de não ter sido identificada diferença significativa entre os grupos, foi encontrado que a maioria das crianças pré-termo extremo ainda precisam de apoio adicional na escola.

Com relação à adequação do peso para a idade gestacional, o estudo de Casey, Whiteside-Mansell, Barrett, Bradley, \& Gargus (2006), não verificou associação significativa com desempenho cognitivo. Contudo outros estudos, como o de Correia (2011) identificaram associação significativa entre ser pequeno para idade gestacional (PIG) e pior desempenho cognitivo.

Ao analisar os fatores preditores dos indicadores cognitivos, na fase préescolar, identificou-se no presente estudo a influência das variáveis ambientais e dos 
indicadores temperamento, atenção e inteligência verbal das crianças. Verificou-se que menor escolaridade materna e menor desempenho da criança na escala de inteligência verbal foram preditores do menor escore de inteligência global. Os achados são semelhantes aos de Chaudhari et al. (2005) que identificou que a melhor escolaridade da mãe contribuiu em $25 \%$ para o bom desempenho da criança na escala total do WISC-III.

No mesmo sentido que o presente estudo, porém incluindo uma amostra de crianças nascidas a termo, Andrade, Santos, Bastos, Pedromônico, Almeida-Filho, \& Barreto (2005) observaram associação entre nível cognitivo na fase de 17 e 42 meses e nível de escolaridade materna; quanto melhor a qualidade da estimulação ambiental disponível para a criança, melhor era o seu desempenho cognitivo. A escolaridade materna é um relevante fator de proteção para o desenvolvimento da criança, com destaque para o nível intelectual (Aarnoudse-Moens et al., 2009).

Com relação à escala de inteligência verbal, identificou-se que dificuldades de atenção e temperamento com menor controle com esforço das crianças, associados com menor escolaridade materna, foram preditores de pior desempenho em Inteligência verbal. $O$ fator controle com esforço mostra ser um importante fator de autorregulação do desenvolvimento, este inclui a capacidade de gerenciar voluntariamente a atenção (regulação de atenção) e inibir (controle inibitório) ou ativar (controle ativador) o comportamento quando necessário se adaptar, em situações nas quais a criança não está inclinada a realizar (Eisenberg, Smith, \& Spinrad, 2011). Desde modo, mais dificuldade de atenção e baixo controle com esforço associam-se a baixo desempenho na área inteligência verbal, pois para desempenhar uma boa função nesta área são necessárias funções de planejamento, abstração, organização, compreensão e autorregulação.

No estudo de Chang e Burns (2005), melhor controle com esforço foi preditor de melhor desenvolvimento dos processos de atenção de crianças pré-escolares em condição de pobreza, ou seja, de maior acurácia nas redes executiva, de orientação e de vigilância da atenção.

Além disso, nossos achados são reforçados pelo estudo de revisão realizado por Milligan (2010) que evidenciou que o nível educacional dos pais mostrou-se associado a um melhor desempenho cognitivo das crianças. Nota-se, portanto que características maternas associadas a indicadores de atenção e do controle com 
esforço do temperamento das crianças têm um efeito importante no desenvolvimento cognitivo na área verbal.

Observou-se também que menor escore em atenção, menor escolaridade materna e baixo nível socioeconômico foram preditores de pior desempenho intelectual na escala de execução. Esses achados vão ao encontro do estudo realizado por Maggi, Magalhães, Campos e Bouzada (2014) que evidenciou que crianças prematuras de baixo nível socioeconômico são mais propensas a ter o desempenho cognitivo comprometido, aos quatro anos de idade. Nota-se ainda que a relação entre nível socioeconômico, escolaridade da mãe e desempenho cognitivo podem estar associados com a qualidade e quantidade de estímulo que as famílias oferecerem as crianças em casa e em outros contextos. As condições ambientais também podem agir como um fator decisivo a até agravar o risco biológico no desenvolvimento das crianças (Seitz, Jenni, Molinari, Caflisch, Largo, \& Latal, 2006). Os achados do presente estudo vão ao encontro do estudo de Rodrigues et al. (2011), na medida em que encontraram que as variáveis distais das características socioeconômicas também influenciam o desenvolvimento cognitivo das crianças.

Ressaltam-se dois aspectos importantes nos resultados do presente estudo com relação ao desfecho do desenvolvimento cognitivo. Primeiramente, a variável escolaridade materna foi preditora nos três desfechos QI Total, Verbal e Execução. Em segundo lugar, o indicador atenção foi preditor de dois dos três desfechos cognitivos (QI Verbal e Execução). Portanto, nota-se que o desempenho cognitivo associou-se tanto a variável educacional materna quanto a atenção da criança.

\section{3 Indicadores de atenção das crianças nascidas pré-termo}

No presente estudo, além do desempenho cognitivo global, foram analisados os indicadores específicos da atenção, das crianças. O comprometimento da atenção entre os prematuros afeta uma gama de domínios desta função, incluindo atenção seletiva, atenção sustentada, focalização e transferência da atenção (Anderson et al.,2011; Mulder et al., 2009). Alguns estudos relatam uma associação entre a prematuridade extrema e problemas de atenção (Corte et al., 2009; Johnson et al., 2010; Johnson \& Marlow, 2011). 
No entanto, no presente estudo, verificou-se que as crianças nascidas prematuras apresentaram escores na média na avaliação da atenção realizada na fase pré-escolar. Com relação aos achados específicos sobre atenção foi constatado que, tanto no escore total quanto nos escores de atenção do tipo seletiva ou alternada, a maior parte das crianças apresentou resultados na média. Verificou-se que $26 \%$ das crianças situaram-se abaixo da média, em relação à pontuação total. Além disso, tanto na fase de atenção seletiva quanto alternada, os achados mostraram que de 14 a $26 \%$ das crianças nascidas pré-termo apresentaram dificuldades de atenção. As crianças prematuras apresentam algum "catch up" no desenvolvimento da atenção seletiva, de modo que a diferença entre essas crianças nascidas a termo vão diminuindo com o aumento da idade (Mulder et al., 2009).

A atenção seletiva implica em atender a alguma atividade mental em detrimento de outras (Butler \& Behrman, 2007). Neste caso um ou mais estímulos produzem informações relevantes, como em tarefas com mensagens competitivas, em que o indivíduo é solicitado a ouvir uma informação e ignorar as demais, deverá focar sua atenção no estímulo solicitado e, portanto, deverá recuperar somente uma das informações (Garcia, Pereira, \& Fukuda, 2007). Desta maneira, falhas nesta área podem interferir na vida diária das crianças, tanto em casa quanto na escola, em especial em situações que exigem concentração contínua durante um longo período de tempo (De Kieviet, Zoetebier, Van Elburg, Vermeulen, \& Oosterlaan, 2012).

Sendo assim, o estudo longitudinal de Bul \& Baar (2012) teve como objetivo avaliar a atenção seletiva sustentada na relação entre nascimento prematuro moderado (32-36 semanas) e os problemas de comportamento de crianças aos oitos anos de idade avaliados pelos pais e professores. A prematuridade teve um efeito direto principal nos problemas de comportamento, sendo que as crianças nascidas moderadamente prematuras apresentaram mais problemas de comportamento e problemas de atenção seletiva sustentada, em comparação às crianças nascidas a termo. Destaca-se que $47 \%$ das crianças prematuras apresentaram problemas de atenção.

A atenção alternada, por sua vez, refere-se à capacidade de alternar o foco atencional entre um estímulo e outro no cumprimento de uma tarefa. Sendo assim, 
na tarefa de atenção alternada requisita-se que seja procurado ora um alvo, ora outro, alternadamente (Rueda, 2010; Wagner, 2003).

Os achados do presente estudo foram otimistas em relação à atenção, pois a maior parte das crianças apresentaram escores médios. Estudos anteriores mostram o inverso, revelando que desde cedo as crianças prematuras podem apresentam prejuízos para a regulação de seus comportamentos e atenção (Anderson et al., 2011; Lejeune, Tolsa, Graz, Hüppi, \& Barisnikov, 2015). O recente estudo realizado por Verkerk et al. (2015) identificou que as crianças com muito baixo peso, aos três anos e oito meses de idade corrigida, apresentaram dificuldades de atenção. 0 estudo de revisão de Van de Weijer-Bergsma et al. (2008), que aborda os primeiros quatro anos de idade da criança, mostrou que houve dificuldades no desenvolvimento da atenção em crianças nascidos pré-termo, as quais poderiam acentuar-se no decorrer do desenvolvimento.

Em um estudo realizado com crianças muito prematuras (<29 semanas de gestação) aos 24 meses de idade, foram identificadas dificuldades em manter controle inibitório e exibiram um padrão de atenção distinto em relação ao grupo de crianças nascidas a termo (Lejeune et al., 2015). Ainda no primeiro ano de vida, as crianças nascidas prematuras mostram algumas dificuldades na regulação das respostas de excitação emocional, na alocação e sustentação da sua atenção (Landry, Garner, Swank, \& Baldwin, 1996). Nota-se também que, as crianças nascidas prematuras aos 18-36 meses, quando comparadas aos seus pares a termo, foram identificadas pelas suas mães com mais problemas de atenção (Cosentino-Rocha et al., 2014).

No presente estudo, na análise de comparação no que se refere a atenção entre os grupos estratificados pela nível de prematuridade, verificou-se que a atenção do tipo alternada foi o único indicador que apresentou diferença estatisticamente significativa entre os grupos. Portanto, as crianças nascidas prematuras extremas ou muito prematuras tiveram mais dificuldades neste tipo de atenção, em comparação com as nascidas pré-termo moderado ou tardio.

Diferentemente dos nossos achados, considerando-se o indicador atenção, o estudo de Griffiths et al. (2013) identificou que as crianças pré-termo extremo tiveram menores escores na atenção seletiva quando comparadas com crianças a 
termo. Nota-se que a imaturidade maior dos nascidos prematuros extremos ou muito prematuros afeta mais a área da atenção.

As crianças com nascimento prematuro apresentam algumas alterações no volume da substância branca e da substância cinzenta e desenvolvimento atrasado dos giros cerebrais (Kapellou et al., 2006). A atenção está relacionada com o controle do impulso, que vai melhorando com a idade na faixa de sete a 10 anos (Aarnoudse-Moens, Weisglas-Kuperus, Duivenvoorden, Goudoever, \& Oosterlaan, 2013; Garcia et al., 2007).

Os problemas relacionados à área da atenção podem afetar diferentes funções e desempenhos, pois têm impacto negativo no desempenho escolar (Anderson et al., 2003; Bhutta et al., 2002), podendo levar a dificuldades de aprendizagem (Pitcher et al., 2012), problemas cognitivos e de comportamento (Van de WeijerBergsma et al., 2008) e problemas de autorregulação (Klein et al., 2011; Rueda et al., 2004).

Considerando-se estudos de comparação entre crianças pré-termo e a termo também foram identificados pior desempenho para atenção, nas crianças pré-termo. Nota-se no estudo prospectivo de coorte, Delobel-Ayoub et al. (2009) que as crianças nascidas pré-termo extremo a moderado (22 - 32 semanas de idade gestacional) aos cinco anos de idade apresentavam mais problemas de comportamento e com uma prevalência duas vezes maior para hiperatividade/déficit de atenção, em comparação com as crianças a termo. Assim como identificado no estudo de Hack, Taylor, Schluchter, Andreias, Drotar, \& Klein (2009) prejuízos para a atenção em crianças nascidas pré-termo extreme $(<1.000 \mathrm{~g}$; média de 26 semanas IG) indicando mais sinais de desatenção e hiperativas em comparação as crianças a termo em idade escolar. Os autores concluíram ainda que, o tipo desatenção é prevalente entre as crianças de extremo baixo peso.

\subsection{Indicadores do temperamento das crianças nascidas pré-termo}

Com relação ao temperamento das crianças nascidas pré-termo do estudo, verificou-se escores moderados nos três fatores: afeto negativo, extroversão e controle com esforço. Notou-se escores em torno de quatro, em uma escala de sete, com indicadores mais altos para as dimensões: aproximação/ antecipação e riso / 
sorriso (afeto negativo); nível de atividade e impulsividade (extroversão) e prazer de baixa intensidade e sensibilidade perceptual (controle com esforço).

No que se refere ao fator extroversão, o estudo de Kerestes (2005) identificou em crianças nascidas prematuras apresentaram maior nível de atividade (Extroversão), em comparação com crianças a termo, aos seis e 12 meses de idade. Maior extroversão associou-se a mais problemas de comportamento do tipo externalizante em crianças nascidas pré-termo em idade pré-escolar (Klein, 2009). 0 temperamento de crianças nascidas pré-termo com baixo controle inibitório, alto nível de raiva e impulsividade, foi preditor de problemas de comportamento do tipo externalizante, em idade pré-escolar (Eisenberg et al., 2009).

Em contrapartida, o fator controle com esforço é um regulador dos altos níveis dos escores do fator extroversão, pois inibi uma reposta dominante e dá início a uma resposta subdominante a partir das diferentes exigências das tarefas (Rothbart, 1989). O controle com esforço é considerado um fator importante do temperamento, de acordo com Rothbart (2004), pois na fase pré-escolar atua na regulação do comportamento, especialmente modulando a extroversão e os afetos negativos. $O$ controle com esforço envolve estratégias cognitivas e de atenção que regulam o comportamento e emoções a partir de inibição voluntária, modulação de respostas e auto-monitoramento (Henderson \& Wachs, 2007). Consiste na habilidade de bloquear uma resposta dominante, para realizar uma resposta subdominante, detectar erros, planejar o futuro e capacitar a criança a escolher um curso de ação em condições de desordem (Rothbart, 1986, 2001; Rothbart \& Bates, 1998).

Portanto, no temperamento das crianças do presente estudo detectou-se um fator de proteção por meio do traço disposicional do controle com esforço, que pode modular a maior extroversão. Assim como no presente estudo, Gracioli (2013 identificou altos escores no controle com esforço em uma amostra de crianças prematuras na faixa de 18 a 36 meses, indicando bons aspectos reguladores do comportamento. Os altos escores em controle com esforço são preditores de melhor autorregulação comportamental em crianças pré-escolares, expressa por meio da capacidade de demonstração de afeto positivo em situações em que estas receberam presentes desejados, como um brinquedo, e presentes indesejados (Kieras, Tobin, Graziano, \& Rothbart, 2005). 
No entanto, observa-se que quando as crianças prematuras são comparadas aos seus pares a termo identificam-se diferenças no seu funcionamento com relação ao controle com esforço, como foi observado no estudo recente realizado por Lejeune et al. (2015). Ao avaliar e comparar o controle com esforço entre as crianças nascidas muito prematuros (<29 semanas de gestação) e crianças a termo aos 24 meses de idade, na visão dos pais, as crianças mostraram maiores dificuldades na manutenção do controle com esforço em comparação com crianças nascidas a termo. Da mesma forma, Voigt, Pietz, Pauen, Kliegel e Reuner (2012) relataram menor controle com esforço aos 24 meses de idade, em crianças muito prematuras.

Com relação ao afeto negativo, este é um dos primeiros aspectos que aparecem no temperamento. Inicialmente, caracteriza-se por formas primitivas de irritação e angústia seguidas por estados mais organizados relacionados à frustração e ao medo (Rothbart, 2004). No presente estudo os escores de afeto negativo foram moderados. No mesmo sentido, os achados de Klein (2009) identificaram escores mais baixos para o fator afeto negativo, quando comparado com os demais fatores. Segundo Calkins e Fox (2002), as crianças que apresentam dificuldades em modular seu afeto negativo, sinalizam falhas na autorregulação adquiridas na fase inicial do desenvolvimento, e podem apresentar dificuldades em desenvolver habilidades sociais podendo aumentar o risco para problemas de comportamento.

Observando-se a amostra do estudo, com relação ao temperamento das crianças nascidas pré-termo, divididas pelos níveis de prematuridade, verificou-se que não houve diferença significativa entre os grupos de crianças nascidas prétermo extremo/ muito pré-termo e crianças pré-termo moderado/ tardio. Nesse sentido, o perfil de temperamento das crianças apresentou, com relação aos três fatores, maior escore no fator extroversão, seguido pelo controle com esforço e menor escore no fator afeto negativo.

Nota-se na literatura que são poucos os estudos que avaliam o temperamento de grupo de crianças nascidas pré-termo de muito baixo peso, estratificada pelo nível de prematuridade. Contudo em um estudo realizado, no mesmo grupo de pesquisa, identificou na comparação de grupos entre crianças nascidas pré-termo extremo ( $\leq 30$ semanas de idade gestacional) e pré-termo moderado ( $\geq 32$ semanas de idade gestacional) também não identificou diferenças estatisticamente 
significativas para o temperamento, na faixa de 18 aos 36 meses, mas o fator extroversão, foi o que apresentou maior escores (Gracioli, 2013).

\subsection{Indicadores do comportamento das crianças nascidas pré-termo}

Com relação ao comportamento, avaliado pelo SDQ, as crianças nascidas pré-termo da amostra do estudo apresentaram alta prevalência de indicadores de problemas de comportamento (44\%), sendo 32\% com problemas identificados no nível clínico e 12\% em risco (limítrofe). Esses achados confirmam a associação entre a prematuridade e problemas comportamentais referidos no estudo de metaanálise de Bhutta et al. (2002). Esses achados são reforçados, por uma recente revisão realizada por Moreira et al. (2014) que confirmaram que a maioria dos estudos analisados quanto menor a idade gestacional e o peso ao nascimento maior o risco da criança apresentar problemas de comportamento.

Em consonância com o nosso estudo, os estudos de Kleine et al. (2003) e Scott et al. (2012) também identificaram alta prevalência de problemas comportamentais em crianças nascidas pré-termo e muito baixo peso. Os achados do presente estudo seguem o mesmo sentido de estudos sobre prematuros, que descrevem um alto índice de problemas de comportamento em crianças com menor idade gestacional, na fase pré-escolar (Delobel-Ayoub et al., 2009; Larroque et al., 2008; Woodward et al., 2009).

No entanto, quando os achados do presente estudo são comparados com um estudo de coorte de 677 crianças escolares da população de Ribeirão Preto, podese verificar um índice semelhantes de problemas de comportamentos, avaliados pelo SDQ, em 154 crianças nascidas pré-termo, de 39,6\% (Saur \& Loureiro, 2015). No entanto, focalizando-se as 24 crianças nascidas muito baixo peso, do estudo, este índice sobe para 50\% na fase escolar. Portanto, neste caso a prevalência de total de problemas de comportamento encontrada no presente estudo de 32\% é menor em comparação aos achados de Saur e Loureiro (2015) com crianças em idade escolar.

Em outro estudo também realizado em Ribeirão Preto, com crianças de 8 a 11 anos de idade, alunos de escola pública identificou-se menor prevalência de problemas de comportamento na subescala sintomas emocionas (30,8\%) (Cury \& Golfeto, 2003). Destaca-se que este estudo foi realizado há mais de 10 anos e com 
crianças da população geral, o que pode contribuir para esse índice menor do que os encontrados no presente estudo.

Os índices de prevalência dos problemas de comportamento são até quatro vezes maior, em crianças de extremo baixo peso do que em seus pares, que nasceram a termo (Hack et al., 2009; Johnson \& Marlow, 2011). No estudo de Johnson e Marlow (2011), os autores identificaram em suas análises que há um "fenótipo comportamental prematuro" caracteriza-se por um aumento do risco para os sintomas e patologias associadas com a falta de atenção, ansiedade e dificuldades sociais. Relacionado a esse estudo, outros autores reforçaram esta ideia e identificaram que os problemas mais frequentemente relatados, pelas mães são déficits de atenção, sintomas internalizantes (ansiedade, depressão, retirada, somáticas queixas) e dificuldades no funcionamento social (Conrad et al., 2010; Farooqi et al., 2007).

Nossos achados apontaram uma prevalência de $44 \%$ de problemas de comportamento, semelhante a outro estudo com crianças nascidas pré-termo. $\mathrm{O}$ estudo identificou em crianças de cinco anos, com idade gestacional menor do que 30 semanas e peso menor do que $1.250 \mathrm{~g} \mathrm{44 \%} \mathrm{problemas} \mathrm{de} \mathrm{comportamento} \mathrm{total}$ (Roberts, Lim, Doyle, \& Anderson, 2011). Em um outro estudo com prematuros extremos foi encontrada uma prevalência menor $26 \%$ de problemas de comportamento, avaliados pelo SDQ, aos cinco anos de idade (Potharst et al., 2011).

Adicionalmente, o estudo de Farooqi et al. (2007) mostrou resultados semelhantes aos nossos achados quanto aos aspectos comportamentais em uma coorte de crianças extremamente prematuras (<26 semanas de idade gestacional), utilizando o CBCL, aos 11 anos de idade. Foi verificada uma prevalência de problemas de comportamento em torno de $29 \%$.

Considerando-se as subescalas do SDQ, nas crianças do presente estudo, identificou-se que o comportamento pró-social e problemas de relacionamento com os amigos situaram-se na faixa de normalidade em $97 \%$ e $76 \%$, respectivamente. Os achados do presente estudo estão em consonância com os de Saur (2012), que identificou prevalência de $93,5 \%$ para comportamento pró-social e $74,7 \%$ para problemas de relacionamento com os amigos, para faixa da normalidade. 
Por outro lado, os sintomas emocionais, problemas de conduta e hiperatividade, em nível clínico, apresentaram altas prevalências nas crianças da amostra estudada; sendo 64\%,56\% e 50\%, respectivamente. De acordo com Delobel-Ayoub et al. (2009), crianças prematuras mostraram uma prevalência duas vezes maior em hiperatividade, sintomas emocionais e problemas de pares em relação as crianças a termo, sugerindo grupo de risco para problemas de comportamento, assim como identificado no estudo de Santos, Petresco, Morais, Manzolli, Mota e Santos (2014). Destaca-se ainda que os problemas de comportamento são potencializados quando relacionados com variáveis biológicas e ambientais

Semelhante ao nosso estudo, Santos et al. (2014) avaliaram o comportamento de crianças pré-termo, utilizando o SDQ. Observaram que as crianças prematuras possuem maior prevalência de sintomas emocionais, de hiperatividade e de problemas de conduta, entre cinco e 11 anos de idade.

No estudo de Saur e Loureiro (2015) os achados na subescala sintomas emocionais (51,9\%) são próximos aos achados do presente estudo, contudo os escores foram menores do que os nossos achados, nas subescalas de problemas de conduta $(27,3 \%)$ e hiperatividade $(28,6 \%)$, nas crianças nascidas prematuras na fase escolar. O fato de Saur e Loureiro (2015) não terem encontrado maiores prevalências de problemas de comportamento podem estar relacionado com dois aspectos metodológicos que devem ser considerados. O primeiro deles é que o relaciona-se com as características das crianças da amostra, apenas 5,6\% havia nascido com idade gestacional abaixo de 34 semanas e o segundo aspecto a ser destacado é que crianças foram avaliadas entre 10 e 11 anos de idade.

Portanto, considerando-se apenas as crianças nascidas muito baixo peso, do estudo de Saur e Loureiro (2015), nota-se uma porcentagem de 50\% de crianças com problemas de hiperatividade. Neste grupo, 92\% das crianças eram prematuras e 54\% pequenas para idade gestacional; neste caso os nossos índices passam a ser menores do que os encontrados pelas autoras. As diferenças entre os resultados podem estar relacionadas à amostra do estudo de Saur e Loureiro (2015), que foi composta, em sua maioria de crianças PIG e no presente estudo, a amostra foi comporta por $64 \%$ de crianças AIG. Nota-se então que nascer pequeno para idade gestacional pode ser uma condição de risco para problemas de comportamento. 
Corroborando os achados do presente estudo, na metanálise realizada por Bhutta et al. (2002) identificaram maior prevalência de hiperatividade em crianças nascidas pré-termo em comparação aos seus pares a termo. Da mesma maneira no estudo de revisão de Johnson (2007) as crianças nascidas prematuras encontravamse em risco para problemas comportamentais em especial déficits de atenção e hiperatividade, e Rodrigues et al. (2006) verificaram em um estudo de revisão que em $80 \%$ dos artigos analisados foram observados maiores índices de hiperatividade no grupo de crianças prematuras.

No entanto, de forma positiva, as prevalências nas subescalas do SDQ observadas no presente estudo foram menores do que as encontradas em uma amostra de crianças com queixa escolar e com nível socioeconômico semelhante ao do presente estudo, em que ocorreram $67 \%$ na subescala de hiperatividade e $64 \%$ em sintomas emocionais do SDQ (D’Abreu \& Marturano, 2011). As diferenças nos resultados das amostras podem estar relacionadas com 0 fato de as crianças nascidas prematuras do presente estudo estarem sendo seguidas por um programa de acompanhamento interdisciplinar desde a alta hospitalar e seus pais receberem orientações sobre seu desenvolvimento. Além disso, a amostra de D`Abreu e Marturano (2011) era referida para atendimento clínico, pois apresentava queixas de dificuldades de aprendizagem.

As médias dos escores de problemas de comportamento dos participantes do presente estudo situaram-se dentro da faixa de normalidade, indicando que, crianças frequentadoras de serviços de follow-up podem ter mais acesso a tratamentos especializados e orientações familiares que minimizem as possíveis repercussões negativas sobre seu desenvolvimento, como no caso da presente amostra. Os escores estão dentro dos parâmetros encontrados para a população normativa brasileira.

Quando a amostra do presente estudo foi dividida levando-se em consideração a idade gestacional, não foram encontradas diferenças significativas para os problemas de comportamento, sendo que em ambos os grupos de crianças prétermo extremo/muito pré-termo e de crianças pré-termo moderado/tardio foram encontrados baixos escores para problemas de comportamento. Consonantes aos nossos achados, Graciolli (2013) realizou uma comparação entre grupos de crianças nascidas pré-termo extremo e moderado, na fase anterior de 18 a 36 meses, 
identificando baixos escores para problemas de comportamento em ambos os grupos e também não encontrou diferenças significativas entre os grupos.

Uma hipótese explicativa para esses achados pode se basear na teoria de suscetibilidade diferencial. De acordo com esta teoria (Belsky, Vandell, Burchinal, Stewart, \& Cartney, 2007) cuidados no início da vida, em especial, aqueles que acontecem por um longo período de tempo, podem influenciar o funcionamento sócio-emocional, incluindo problemas de comportamento. Algumas crianças são mais afetadas, tanto positivamente quanto negativamente, por suas experiências do que outras. Nota-se que os aspectos genéticos e ou ambientais podem influenciar este processo. As crianças nascidas prematuras desde as extremo às tardio podem necessitar dos tratamentos oferecidos pela UTIN, ficando por algum período internadas. Contudo, verifica-se que as crianças nascidas pré-termo extremo precisam mais deste acompanhamento, pela imaturidade orgânica, ficando mais tempo internadas e, assim, recebendo mais cuidados no período inicial de suas vidas. Ressalta-se que, na UTIN na qual as crianças do presente estudo foram internadas, encontram-se alguns fatores de proteção importantes para o neurodesenvolvimento dos recém-nascidos pré-termo, tais como diminuição da luminosidade durante a madrugada, preferência pela luz natural à artificial durante o dia e proteção das incubadoras com cueiros para evitar a luz direta no recémnascido, rolinhos para contenção do recém-nascido, manipulação mínima dos prematuros extremos, apoio psicológico às famílias, visita dos pais liberada durante o período de internação na UTIN. São realizadas também, visitas da família ampliada e dos irmãos, sendo que esta última é acompanha e monitorada pela psicóloga do serviço. Pode-se supor que esses aspectos atuam como fatores protetores para o desenvolvimento das crianças mais vulneráveis.

Ao analisar o efeito das variáveis preditoras sobre os indicadores do comportamento identificou-se que tanto as variáveis ambientais quanto os indicadores da criança de temperamento, atenção e cognição tiveram influência nos desfechos do comportamento. Observou-se fatores preditores sobre o problema de comportamento total, em que, maior afeto negativo e extroversão, e menor controle com esforço e atenção associaram-se com mais problemas de comportamento nas crianças. Os resultados do presente estudo vão ao encontro dos achados dos estudos de Burnson, Poehlmann e Schwichtenberg (2013) e Edgar et al. (2008) na 
medida em que identificaram relações entre mais afeto negativo e problemas de comportamento. Considerando a relação entre o fator extroversão e problemas de comportamento, achados do estudo de Gracioli (2013) também mostraram que altos escores de extroversão associaram-se aos problemas de comportamento, em crianças nascidas pré-termo indicando, portanto, problemas de autorregulação e adaptação. Paralelamente, baixos níveis de controle com esforço foram preditores de maiores problemas de comportamento do tipo externalizantes (Prior et al., 2008).

Levando em consideração o efeito dos fatores preditores sobre a hiperatividade encontrada nas crianças nota-se que mais afeto negativo e menor controle com esforço e atenção associaram-se a mais hiperatividade. Consonante aos nossos achados, Burnson et al (2013) verificaram que mais controle com esforço nas crianças nascidas pré-termo esteve associado a menos problemas de comportamento, hiperatividade e sintomas emocionais. Este controle voluntário pode ser identificado em c omportamentos autorreguladores.

Considerando o efeito dos fatores preditores dos problemas de conduta, identificou-se que mais afeto negativo, sexo masculino e menor nível intelectual verbal estavam associados a mais problemas de conduta nas crianças. Os achados do presente estudo vão no mesmo sentido dos estudos de Cosentino-Rocha et al. (2015) e Saur e Loureiro (2015) que identificaram que os meninos apresentaram maiores escores para problemas de comportamento, em diferentes faixas etárias. Além disso, o sexo masculino é considerado uma variável preditora para doença neonatal mais grave após o nascimento pré-termo, assim como está associado com problemas de comportamento, entre crianças de extremo baixo peso ao nascer (Corte et al.,2009). O fato de ser menino aumenta a vulnerabilidade no desenvolvimento e quando associado a traços de afeto negativo e mais dificuldades de inteligência de natureza verbal abstrata aumenta a chance de problemas de conduta. $\mathrm{O}$ aspecto verbal é relevante para o pensamento verbalizado, que envolve processos de antecipação, planejamento, que favorecem os processos regulatórios do comportamento, sendo que estes envolvem processos que permitem a autorregulação, a partir da mediação e da corregulação do cuidador, que é quem vai auxiliar e promover e proteger o desenvolvimento das crianças (Linhares \& Martisn, 2015). Considerando-se Vygotsky, a linguagem é entendida como um instrumento de pensamento, sendo a fala o primeiro sinal do desenvolvimento 
cognitivo. A linguagem não é apenas uma expressão do conhecimento adquirido pela criança, pois existe uma interrelação entre pensamento e linguagem, um proporcionando recursos ao outro. Sendo assim, a linguagem tem um papel essencial na formação do pensamento e do caráter do indivíduo (Bezerra, 2001). Nos problemas de conduta há grande dificuldade nesses aspectos de regulação comportamental e impulsividade para ação.

Considerando-se o efeito das variáveis preditoras sobre problemas de relacionamento com os colegas identificou-se que mais extroversão, baixa escolaridade materna, alta escolaridade paterna e menor desempenho em execução foram preditoras para problemas de relacionamento com os colegas. No presente estudo, foi identificado que baixo nível de escolaridade materna foi um fator de risco para problemas de comportamento, assim como no estudo de Delobel-Ayoub et al. (2006). De acordo com Andrade et al. (2005), a escolaridade materna pode ter influência sobre o desenvolvimento do indivíduo, tanto no global quanto no específico.

Diferentemente do encontrado com relação à escolaridade materna, no presente estudo alta escolaridade paterna foi preditora de mais problemas de relacionamento com os colegas. Esta é uma relação inesperada e que precisa ser melhor investigada. Uma hipótese explicativa pode ser que a alta escolaridade paterna pode estar relacionada com o fato de o pai estar fora de casa, por longos períodos devido a sua atividade profissional. Neste sentido, quando pai está fora de casa pode deixar de exercer sua função de corregulador dos comportamentos das crianças. Mesmo o pai exercendo mais suas funções em casa e mais engajado nas atividades do cotidiano familiar (Bossardi, 2011), o pai é o provedor principal (Crepaldi, Andreani, Hammes, Ristof, \& Abreu, 2006). Neste sentido, existem condições no trabalho que podem dificultar a relação adequada entre o pai e seu filho (Brandth \& Kvande, 2002). Outras hipóteses explicativas podem ser pertinentes para compreensão desta relação entre alta escolaridade e problemas de relacionamento com os colegas, como por exemplo, crenças e valores sobre como ensinar as crianças relacionamentos interpessoais.

Levando-se em consideração os sintomas emocionais nota-se que, menor idade gestacional, melhor nível sócio econômico, mais afeto negativo e extroversão, e menos controle com esforço foram preditores de alto escore destes sintomas nas 
crianças. De forma inesperada o alto nível socioeconômico neste modelo de predição, foi um fator de risco para sintomas emocionais nas crianças, diferentemente do encontrado na literatura, como por exemplo, nos estudos Gray et al. (2004) que identificou alta correlação entre risco psicossocial e problemas comportamentais. Da mesma maneira Potijk, Winter, Bos, Kerstjens e Reijneveld (2015) identificou que crianças prematuras aos quatro anos de idade com baixo nível socioeconômico tiveram significativamente mais de problemas de comportamento do que aquelas com alto nível socioeconômico.

Os estudos de Msall, Sullivan e Park (2010) e Treyvaud et al. (2012) mostraram que o nível socioeconômico mais alto oferece fatores de proteção às crianças, tais como: a assistência médica, educação de qualidade e cuidados parentais positivos, minimizando os riscos de problemas de comportamento em crianças nascidas prematuras. Os resultados do estudo de Saur e Loureiro (2015) também são diferentes aos achados do presente estudo, pois identificaram que menor classificação socioeconômica foi preditora de mais sintomas emocionais, nas crianças.

O fator nível socioeconômico mais alto associa-se com nível escolar do pai também alto. Portanto, as possíveis explicações da relação entre esses fatores e sintomas emocionais e transtorno de conduta pode vincular-se a maior atividade profissional fora do lar, menos contato com a criança e menos disponibilidade de tempo para suporte afetivo das crianças. Além disso, o maior nível socioeconômico não necessariamente assegura o papel regulador dos pais no comportamento dos filhos. Essas possíveis explicações levantadas para essas relações que precisam ser melhor investigadas. 


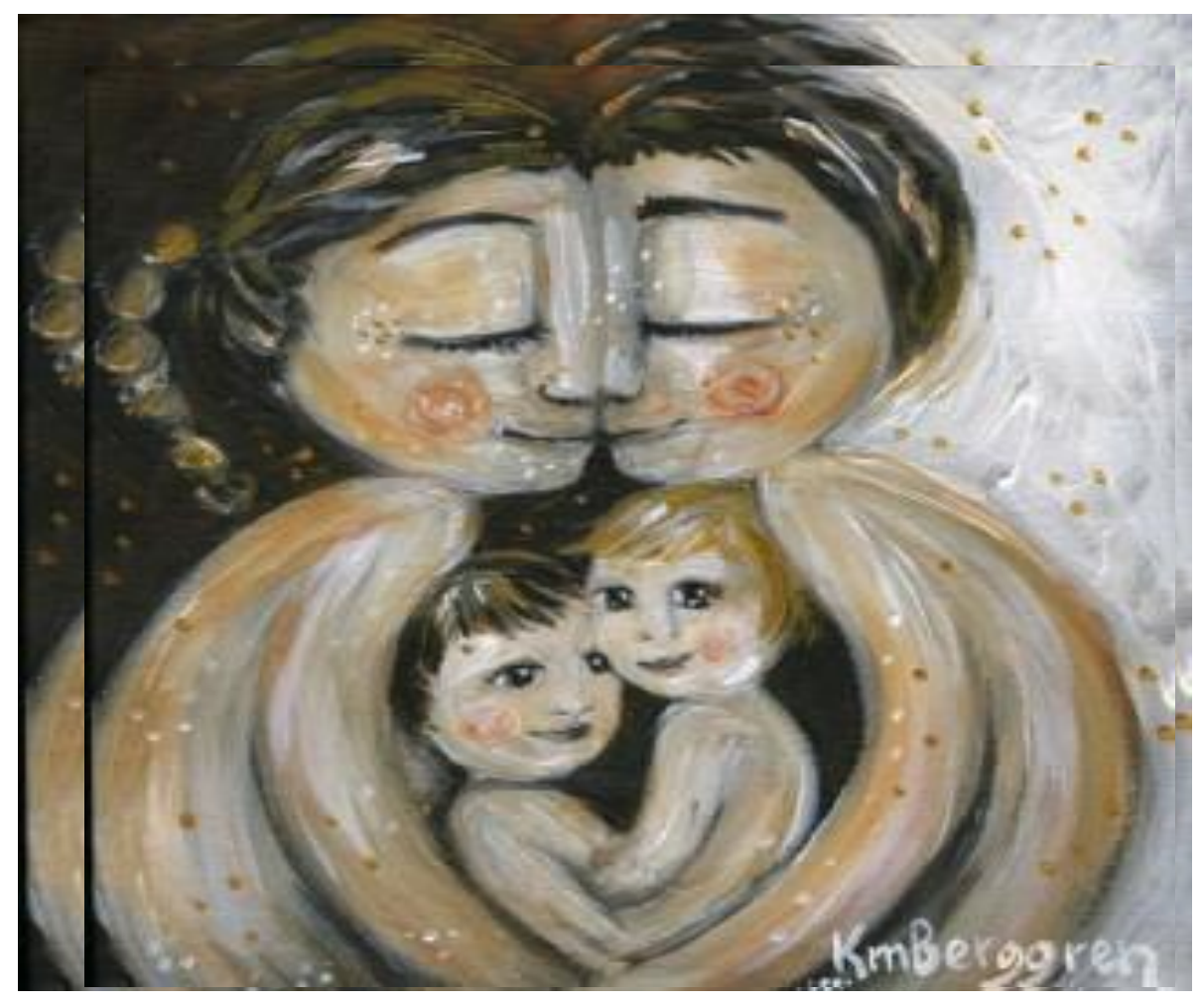

Artigo VI - Nenhum prematuro será submetido à tortura, nem a tratamento ou castigo cruel, desumano ou degradante. Sua dor deverá ser sempre considerada, prevenida e tratada através dos processos disponibilizados pela ciência atual. Nenhum novo procedimento doloroso poderá ser iniciado até que o bebê se reorganize e se restabeleça da intervenção anterior. Negar-lhe esse direito é crime de tortura contra a vida humana (Tavares, 2009). 


\subsection{Considerações Metodológicas}

Ao finalizar o presente estudo, algumas considerações devem ser feitas com relação a aspectos metodológicos e contribuições do estudo, limitações e questões futuras para novos estudos e desdobramentos para a prática.

Quanto aos aspectos metodológicos primeiramente, destaca-se que no presente estudo houve pouca perda amostral, pois, as crianças foram avaliadas nos retornos médicos, dos ambulatórios de prematuros do HCFMRP-USP. Notou-se grande adesão ao estudo, o que permitiu uma amostra sem perdas e viéses na sua formação.

Em segundo, com relação aos instrumentos, a avaliação da atenção das crianças foi realizada pelo Teste de Atenção por Cancelamento (TAC). Nota-se na literatura poucos estudos nacionais e internacionais usando este instrumento para avaliar atenção em crianças prematuras. O Questionário de capacidades e dificuldades (SDQ), instrumento de avaliação do comportamento, conta com adaptação e padronização para a população brasileira, o que torna os dados mais precisos para avaliar os níveis clínicos.

$\mathrm{Na}$ avaliação do temperamento, por sua vez, foi utilizado o The Child Behavior Questionnaire (CBQ). Trata-se de um instrumento pouco utilizado ainda no Brasil, a maior parte dos estudos são com crianças nascidas pré-termo o que facilita as comparações com a presente amostra de estudo. O CBQ apresenta grande vantagem de ter fatores e dimensões que representam os traços disposicionais do temperamento da criança com forte associação com seu comportamento. O CBQ segue a abordagem "desenvolvimental" o que contribui para integrar os indicadores avaliados no presente estudo de cognição, atenção e comportamento. Consequentemente, no presente estudo foi possível analisar a relação entre os indicadores de temperamento e comportamento em crianças nascidas pré-termo na fase pré-escolar.

Quanto às limitações do presente estudo pode-se destacar os aspectos a seguir. Primeiramente, este estudo teve por foco características individuais da criança nascida pré-termo e muito baixo peso e indicadores distais do ambiente familiar. Sabe-se, no entanto, da importância de analisar indicadores proximais do desenvolvimento familiar que têm forte influência no desenvolvimento das crianças, tais como interações mãe-criança e interações entre seus pares. Em segundo lugar, 
o temperamento e o comportamento foram avaliados por um único informante, o cuidador principal. Neste aspecto, no entanto, devem-se levar em conta que os pais são os melhores informantes para avaliações de crianças até seis anos, porém ter múltiplos informantes diminuiria possíveis vieses nas informações obtidas. Em terceiro lugar, a amostra foi de conveniência, pois a grande maioria das crianças foram avaliadas nos dias dos retornos médicos. Sendo assim as crianças foram inseridas na pesquisa de acordo com a disponibilidade e interesse em participar, naquele dia de consulta. No entanto, as características da amostra de estudo refletem o perfil de crianças atendidas nesse contexto do estudo.

Um aspecto importante de se considerar é que as crianças do presente estudo estavam sendo seguidas em Ambulatórios de prematuros por equipe multidisciplinar de profissionais da saúde (médicos, psicólogos, assistente social, fisioterapeuta e terapeuta ocupacional). Dessa maneira, deve-se ter cuidado na generalização dos achados da presente pesquisa para outras amostras de crianças que não estão acompanhadas em programas de follow- up de prematuros, pois estas podem apresentar índices de riscos mais altos em relação às crianças estudadas. Não se trata de uma limitação do estudo, mas este contexto pode ajudar a entender os resultados mais positivos encontrados na amostra avaliada.

Deve-se salientar que cinco em 67 crianças $(7 \%)$ não foram incluídas no estudo. Os critérios de exclusão deixaram de fora da amostra as crianças com graves comprometimentos neonatais, além das condições de prematuridade. Isso foi necessário para a viabilidade do uso dos instrumentos de avaliação utilizados. No entanto, deve-se levar em consideração essas exclusões no momento da generalização dos resultados sobre aspectos do desenvolvimento na fase préescolar, para a população de crianças nascidas prematuras.

Como sugestão de novos estudos e questões de pesquisa sugere-se a realização de estudos longitudinais, que podem ser realizados para investigar as consequências e sequelas a curto, médio e longo prazo, dos indicadores cognitivos, de atenção, temperamento e comportamento no desenvolvimento das crianças. Além disso, novos estudos podem adequar avaliações para analisar o desenvolvimento das crianças prematuras com características de comprometimento neonatal grave. 
Os achados alertam ainda para a necessidade de avaliações específicas em crianças nascidas prematuras, na fase pré-escolar, com objetivo de identificar possíveis dificuldades que possam levar a prejuízos na trajetória de vidas, dessas crianças, especialmente no contexto escolar.

Novos estudos também podem inserir a análise de variáveis proximais, tais como interações com o ambiente familiar, para melhor compreensão dos riscos e proteção do desenvolvimento dessas crianças vulneráveis biologicamente devido à prematuridade.

\subsection{Desdobramentos práticos}

Desta forma, faz-se necessário maior investimento em estratégias que facilitem o acesso e a adesão das crianças nascidas pré-termo muito baixo peso a serviços de seguimento longitudinal, para acompanhamento do desenvolvimento infantil, pois nota-se a necessidade de ativar e estimular recursos da criança e dos contextos que está inserida. O presente estudo contribuiu para a prática profissional, revelando a importância da avaliação de indicadores e seguimento das crianças prematuras a fim de avaliar preventivamente o desenvolvimento de crianças egressas de UTIN, além de reforçar a importância da intervenção para melhorar o prognóstico e identificar redes de suporte emocionais e psicossociais.

Com relação às avaliações, estas devem incluir os principais indicadores do desenvolvimento, tais como: cognição, temperamento e comportamento, durante a trajetória do desenvolvimento até a fase escolar, além de orientações familiares sobre os marcos do desenvolvimento e práticas educativas parentais positivas e eficazes.

O presente estudo contribuiu para demostrar a relevância de caracterizar sistematicamente as crianças a partir da avaliação psicológica. Ao avaliar as crianças podem ser demonstrados recursos e aspectos positivos e não apenas as dificuldades e problemas. Do ponto de vista da prática clínica, este é um aspecto fundamental para análise de casos de prematuros de diferentes níveis de gravidade. Deve-se ter uma abordagem da psicopatologia do desenvolvimento que vise encontrar recursos na criança e na família, além das dificuldades e problemas. 


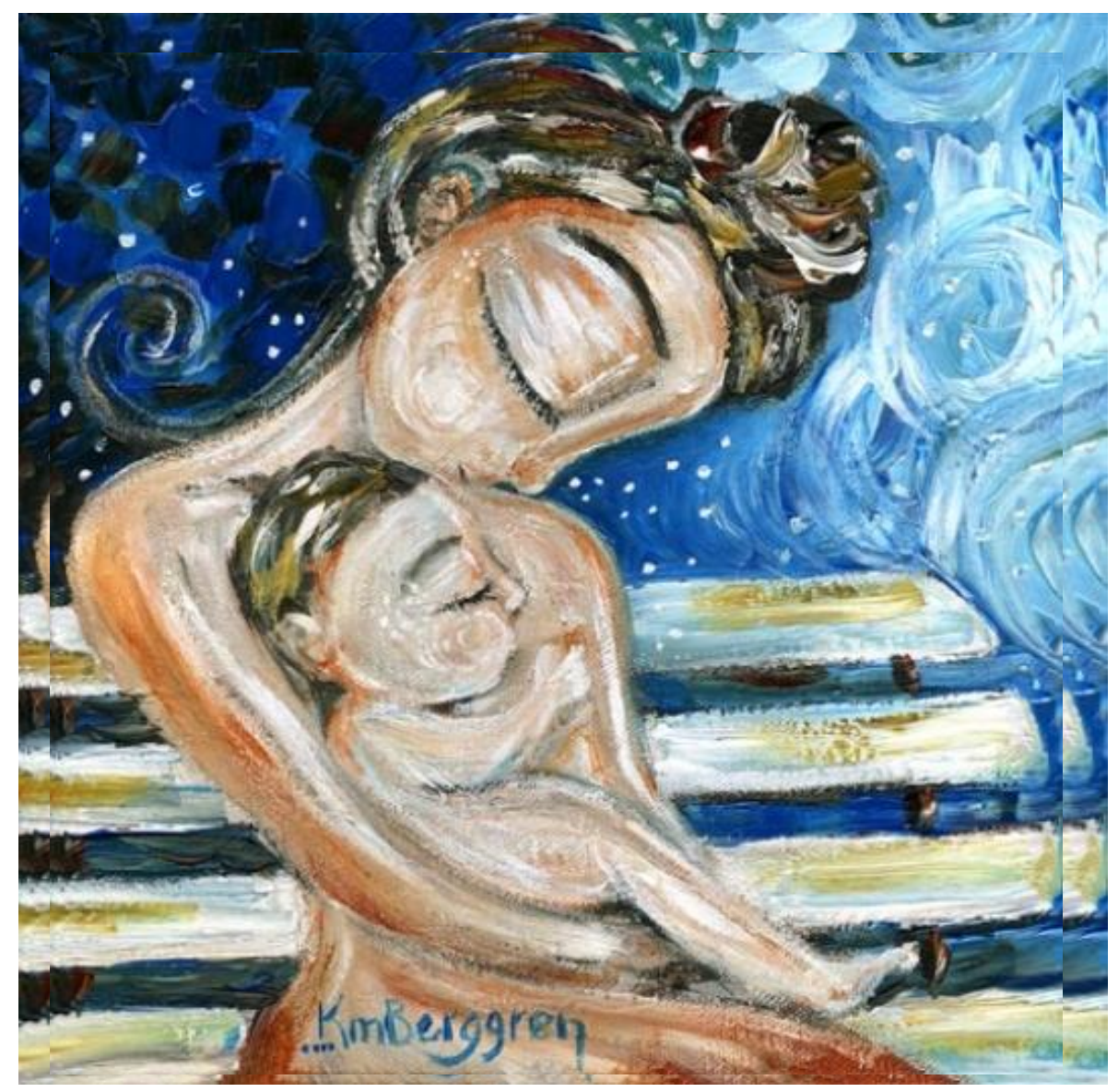

Artigo VII - Todo prematuro tem direito ao repouso, devendo por isso ter respeitados seus períodos de sono superficial e profundo que doravante serão tomados como essenciais para seu desenvolvimento psíquico adequado e sua regulação biológica. Interromper de forma aleatória e irresponsável sem motivo justificado o sono de um prematuro é indicativo de maus tratos (Tavares, 2009). 
A presente Tese de Doutorado focalizou a trajetória de desenvolvimento de crianças nascidas pré-termo e muito baixo peso, com ênfase nas relações entre as condições clínicas neonatais e os indicadores de cognição, atenção, temperamento e comportamento na fase pré-escolar.

Esta tese contribuiu para o avanço do conhecimento a respeito dos processos envolvidos nas trajetórias de desenvolvimento de crianças pré-termo, de modo a preencher lacunas na literatura científica. Sabe-se que o nascimento prematuro ainda é um importante foco de investigações em diferentes áreas do desenvolvimento, pois essas crianças podem apresentar sequelas no desenvolvimento.

O presente estudo mostrou que, nas crianças com vulnerabilidade biológica da prematuridade, houve um impacto destes aspectos na constituição da cognição, atenção, temperamento e comportamento do indivíduo. Contudo, a cognição avaliada pelo WISC III, foi à área que menos sofreu efeito direto da prematuridade, pois mostrou-se dentro da faixa de normalidade. Este mesmo padrão de desempenho foi identificado para a área da atenção (seletiva e alternada). Entretanto, quando avaliado o comportamento notou-se prejuízo em: sintomas emocionais, hiperatividade e problemas de conduta. Com relação ao temperamento as crianças mostraram traços disposicionais para afeto negativo e extroversão, porém com indicadores positivos de controle com esforço ou voluntário.

As crianças apresentaram recursos protetores relevantes tais como: desempenho cognitivo e de atenção dentro da normalidade, além de outras áreas do comportamento pró-social, bom relacionamento com os colegas e no comportamento global. $\mathrm{Na}$ percepção dos cuidadores essas áreas estavam preservadas.

O estudo avança no sentido de que avalia uma lacuna, identificada na literatura científica, em relação à avaliação de específicas de desenvolvimento de crianças prematuras como a atenção e associação entre temperamento e comportamento, em idade pré-escolar. Além disso, reforça a importância do seguimento longitudinal de crianças com risco biológico para a prevenção de problemas desenvolvimento. 


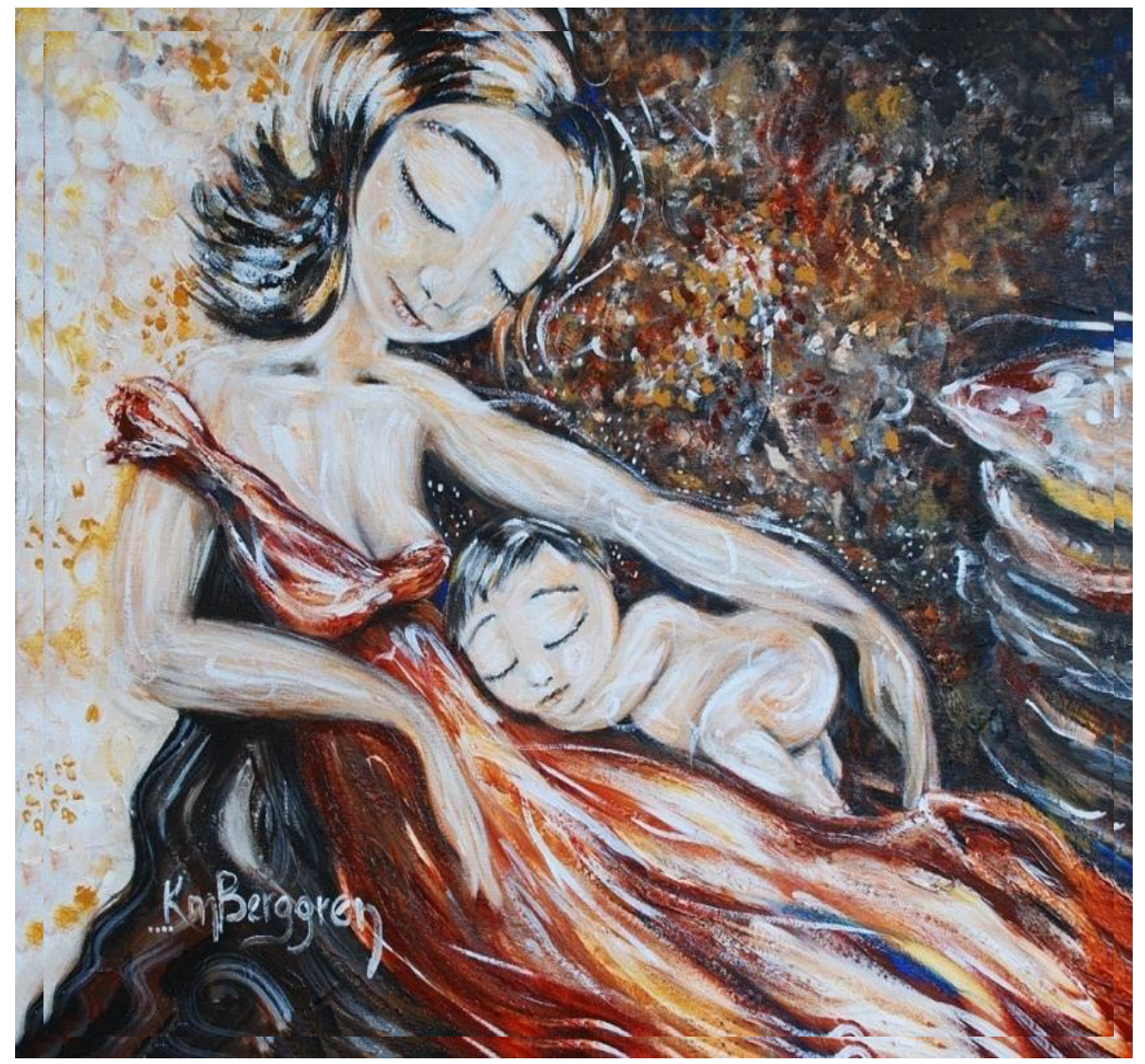

Artigo VIII- Todo prematuro tem o direito inalienável ao silêncio que o permita sentir-se o mais próximo possível do ambiente sonoro intra-uterino, em respeito a seus limiares e à sua sensibilidade. Qualquer fonte sonora que desrespeite esse direito será considerada criminosa, hedionda e repugnante (Tavares, 2009).

${ }^{2}$ De acordo com as Diretrizes para apresentação de dissertações e teses da USP: documento eletrônico e impresso Parte II (American Psychological Association - APA) 
Aarnoudse-Moens, C. S., Weisglas-Kuperus, N., Van Goudoever, J. B., \& Oosterlaan, J. (2009). Meta-analysis of neurobehavioral outcomes in very preterm and/or very low birth weight children. Pediatrics, 2, 717-728. doi:10.1542/peds.2008-2816

Aarnoudse-Moens, C. S., Smidts, D., Oosterlaan, J., Duivenvoorden, H., \& WeisglasKuperus, N. (2009). Executive function in very preterm children at early school age. Journal of Abnormal Child Psychology, 37, 981-993. doi:10.1007/s10802009-9327-z

Aarnoudse-Moens, C. S. H., Oosterlaan, J., Duivenvoorden, H. J., van Goudoever, J. B., \& Weisglas-Kuperus, N. (2011). Development of preschool and academic skills in children born very preterm. The Journal of pediatrics, 158(1), 51-56. doi: 10.1016 / j.jpeds.2010.06.052

Aarnoudse-Moens, C. S. H., Weisglas-Kuperus, N., Duivenvoorden, H. J., van Goudoever, J. B., \& Oosterlaan, J. (2013). Executive function and IQ predict mathematical and attention problems in very preterm children. Plos One, 8(2), e55994-7. doi: 10.1371/journal.pone.0055994

Achenbach, T. M. (1992). Developmental psychopathology. In M. H. Bornstein \& M. E. Lamb, Developmental psychology: An advance book (pp. 629-676). New York, NY: Lawrence Erlbaum.

Almeida, C. S., Paines, A. V., \& Balbão, C. (2008). Intervenção motora precoce ambulatorial para neonatos prematuros no controle postural. Revista Ciência \& Saúde, 1, 64-70.

Anderson, P., Doyle, L. W., \& Victorian Infant Collaborative Study Group. (2003). Neurobehavioral outcomes of school-age children born extremely low birth weight or very preterm in the 1990s. Journal of the American Medical Association, 289, 3264-3272. doi:10.1001/jama.289.24.3264

Anderson, P. J., De Luca, C. R., Hutchinson, E., Spencer-Smith, M. M., Roberts, G., Doyle, L. W., \& Victorian Infant Collaborative Study Group. (2011). Attention problems in a representative sample of extremely preterm/extremely low birth weight children. Developmental Neuropsychology, 36, 57-73. doi:10.1080/87565641.2011.540538

Anderson, P. J., Doyle, L. W., \& Victorian Infant Collaborative Study Group. (2004). Executive functioning in school-aged children who were born very preterm or with extremely low birth weight in the 1990s. Pediatrics, 114, 50-57. doi:10.1542/peds.114.1.50

Anderson, V., Spencer-Smith, M., \& Wood, A. (2011). Do children really recover better? Neurobehavioural plasticity after early brain insult. Brain, 134(Pt 8), 2197-2221. doi:10.1093/brain/awr103

Andrade, S. A., Santos, D. N., Bastos, A. C., Pedromônico, M. R. M., Almeida-Filho, N., \& Barreto, M. (2005). Ambiente familiar e desenvolvimento cognitivo 
infantil: uma abordagem epidemiológica. Revista de Saúde Pública, 39, 606611. doi:10.1590/S0034-89102005000400014

Andreani, G., Custódio, Z. A. O., \& Crepaldi, M. A. (2006). Tecendo as redes de apoio na prematuridade. Alethéia, (24), 115-126.

Associação Brasileira de Empresas de Pesquisa. (2012). Critério de Classificação Econômica Brasil. São Paulo, SP. Recuperado de http://www.abep.org/novo/CMS/Utils/FileGenerate.ashx?id=46

Aylward, G. P. (2002). Mental retardation and developmental disabilities. Research Reviews, 8, 234-240.

Aylward, G. P. (2005). Neurodevelopmental outcomes of infants born prematurely. Developmental and Behavioral Pediatrics, 26, 427-440. doi: 10.1097/01.DBP.0000452240.39511.d4

Balda, R. C., Guinsburg, R., Kopelman, B. I., Santos, A. M. N., Goulart, A. L., Almeida, M. F. B., ... \& Guinsburg, R. (2004). Avaliação da dor no período neonatal. Diagnóstico e tratamento em neonatologia. São Paulo: Atheneu, 57785.

Barbosa, V. C., Formiga, C. K. M. R., \& Linhares, M. B. M. (2007). Avaliação das variáveis clínicas e neurocomportamentais de recém-nascidos pré-termo. Revista Brasileira de Fisioterapia, 11, 275-281. doi: 10.1590/S141335552007000400006

Barros, R. G. A. (2012). Caracterização da adaptação escolar de um grupo de crianças nascidas prematuramente que iniciaram a escolaridade obrigatória (Dissertação de mestrado não publicada). Universidade Católica Portuguesa, Porto, Portugal.

Bayless, S., \& Stevenson, J. (2007). Executive functions in school age children born very prematurely. Early Human Development, 83, 247-254. doi:10.1016/j.earlhumdev.2006.05.021

Beani, L., Moscardini, A. C., Souza, A. S., Souza, A. S., Jr., Yamamoto, A. E., Croti, U. A., \& Braile, D. M. (2007). Avaliação tomográfica pulmonar tardia em prematuros com displasia broncopulmonar e persistência de canal arterial. Revista Brasileira de Cirurgia Cardiovascular, 22, 400-406. doi:10.1590/S0102-7638200700040000

Bear, L. M. (2004). Early identification of infants at risk for developmental disabilities. Pediatric Clinics of North America, 51, 685-701. doi:10.1016/j.pcl.2004.01.015

Belsky, J., Vandell, D. L., Burchinal, M., Clarke-Stewart, K. A., McCartney, K., \& Owen, M. T. (2007). Are There Long-Term Effects of Early Child Care?.Child development, 78(2), 681-701. doi: 10,1111 / j.1467-8624.2007.01021.x 
Berger, A. (2011). Self-regulation: Brain, cognition, and development. American Psychological Association. doi.org/10.1037/12327-000

Bohm, B., Smedler, A. C., \& Forssberg, H. (2004). Impulse control, working memory and other executive functions in preterm children when starting school. Acta Paediatrica, 93, 1363-1371. doi:10.1080/08035250410021379

Bordin, M. B. M., Linhares, M. B. M., \& Jorge, S. M. (2001). Aspectos cognitivos e comportamentais na média meninice de crianças nascidas pré-termo e com muito baixo peso. Psicologia: Teoria e Pesquisa, 17, 49-57. doi:10.1590/S010237722001000100008

Bossardi, C. N. (2011). Relação do engajamento parental e relacionamento conjugal no investimento com os filhos. Dissertação de mestrado - Centro de Filosofia e Ciências Humanas, Programa de Pós-Graduação em Psicologia, Florianópolis. Universidade Federal de Santa Catarina.

Buriol, V. C. D. S. (2014). Evolução temporal de fatores determinantes de saúde materno-infantil relacionados ao baixo peso ao nascer no Brasil.

Burnett, A. C., Scratch, S. E., \& Anderson, P. J. (2013). Executive function outcome in preterm adolescents. Early human development, 89(4), 215-220. doi: 10.1016 / j.earlhumdev.2013.01.013

Burnson, C., Poehlmann, J., \& Schwichtenberg, A. J. (2013). Effortful control, positive emotional expression, and behavior problems in children born preterm. Infant Behavior and Development, 36, 564-574. doi:10.1016 / j.infbeh.2013.04.003

Butler, A. S., \& Behrman, R. E. (Eds.). (2007). Preterm Birth: Causes, Consequences, and Prevention. National Academies Press.

Bhutta, A. T., Cleves, M. A., Casey, P. H., Cradock, M. M., \& Anand, K. J. (2002). Cognitive and behavioral outcomes of school-aged children who were born preterm: A meta-analysis. The Journal of the American Medical Association, 288, 728-737. doi:10.1001/jama.288.6.728

Brandth, B., \& Kvande, E. (2002). Reflexive fathers: Negotiating parental leave and working life. Gender, Work and Organization, 9, 186-203. doi:10.1111/1.4680.432 .00121

Bremmer, P., Byers, J. F., \& Kiehl, E. (2003). Noise and the premature infant: physiological effects and practice implications. Journal of Obstetric, Gynecologic, \& Neonatal Nursing, 32(4), 447-454. doi: 10,1177 / 0884217503255009

Breslau, N., Chilcoat, H., DelDotto, J., Andreski, P., \& Brown, G. (1996). Low birth weight and neurocognitive status at six years of age. Biological Psychiatry, 40, 389-397. doi:10.1016/0006-3223(95)00399-1 
Brown, L., Burns, Y. R., Watter, P., Gibbons, K. S., \& Gray, P. H. (2015). Motor performance, postural stability and behaviour of non-disabled extremely preterm or extremely low birth weight children at four to five years of age. Early Human Development, 91, 309-315. doi:10.1016 / j.earlhumdev.2015.03.003

Bühler, K. E., Bernardis, F., Custodio, F., M. A. E., \& Limongi, S. C. O. (2007). Construção da permanência do objeto em crianças nascidas pré-termo muito baixo peso. Revista CEFAC, 9, 300-307.

Bul, K. C., \& van Baar, A. L. (2012). Behavior problems in relation to sustained selective attention skills of moderately preterm children. Journal of developmental and physical disabilities, 24(2), 111-123. doi: 10,1007 / s10882011-9258-9

Calkins, S. D., \& Fox, N. A. (2002). Self-regulatory processes in early personality development: A multilevel approach to the study of childhood social withdrawal and aggression. Development and psychopathology, 14(03), 477-498. doi.org/10.1017/S095457940200305X

Calkins, S. (2009). Regulatory competence and early disruptive behavior problems: The role of physiological regulation. In S. L. Olson \& A. J. Sameroff (Eds.), Biopsychosocial regulatory processes in the development of childhood behavioral problems (pp. 86-107). New York: Cambridge University Press

Campos, C. M. C., Soares, M. M. A., \& Cattuzzo, M. T. (2013). O efeito da prematuridade em habilidades locomotoras e de controle de objetos de crianças de primeira infância. Motriz: Revista de Educação Física, 19, 22-33. doi:10.1590/S1980-65742013000100003.

Campos, A. F., Malloy-Diniz, L. F., Nascimento, J. D. A., \& Amorim, R. H. C. D. (2011). Neurological and neuropsychological aspects of children born preterm and with weight lower than 1,500 grams. Psicologia: Reflexão e Crítica, 24(4), 630-639. doi.org/10.1590/S0102-79722011000400002

Carneiro, J. A., Costa, F. M. D., Vieira, M. M., Reis, T. C., Carneiro, M. A., \& Caldeira, A. P. (2015). Characteristics of newborn of very low weight admitted to intensive neonatal care unit. Journal of Nursing UFPE on line [JNUOL/DOI: 10.5205/01012007], 9(4), 7207-7212.

Castro, E. C. M., \& Leite, A. J. M. (2007). Mortalidade hospitalar dos recém-nascidos com peso de nascimento menor ou igual a $1.500 \mathrm{~g}$ no município de Fortaleza. Jornal de Pediatria, 83, 27-32. doi:10.2223/JPED.1576

Castro, N. R., Rueda, F. J. M., \& Sisto, F. F. (2010). Evidências de validade para o Teste de Atenção Alternada - TEALT. Psicologia e Pesquisa, 4, 4-14.

Cassiano, R. G. M., \& Linhares, M. B. M. (2015). Temperamento, prematuridade e comportamento interativo mãe-criança. Psicologia: Reflexão e Crítica, 28, 416424. doi:10.1590/1678-7153.201528222 
Casey, P. H., Whiteside-Mansell, L., Barrett, K., Bradley, R. H., \& Gargus, R. (2006). Impact of prenatal and/or postnatal growth problems in low birth weight preterm infants on school-age outcomes: an 8-year longitudinal evaluation. Pediatrics, 118(3), 1078-1086. doi: 10,1542 / peds.2006-0361

Cecilio-Fernandes, D., \& Marín Rueda, F. J. (2007). Evidência de validade concorrente para o Teste de Atenção Concentrada (TEACO-FF). Psic: revista da Vetor Editora, 8(2), 167-174.

Celia, S. (1997). Grupos comunitários. In D. Zimerman \& L. C. Osorio, Como trabalhamos com grupos (pp. 101-105). Porto Alegre, RS: Artes Médicas.

Chabra, S. (2013). Subsets of preterm and term infants: call for consistency in terminology. Developmental Medicine and Child Neurology, 55(7), 673. doi:10.1111/dmcn.12126

Charpak, N., de Calume, Z. F., \& Hamel, A. (1999). O Método Mãe-Canguru: pais e familiares dos bebês prematuros podem substituir as incubadoras. McGrawHill.

Chang, F., \& Burns, B. M. (2005). Attention in preschoolers: Associations with effortful control and motivation. Child development, 76(1), 247-263. doi: 10,1111 / j.1467-8624.2005.00842.x

Chang, K. D., Blasey, C. M., Ketter, T. A., \& Steiner, H. (2003). Temperament characteristics of child and adolescent bipolar offspring. Journal of Affective Disorders, 77, 11-19. doi:10.1016/S0165-0327(02)00105-2

Chaudhari, S., Otiv, M., Khairnar, B., Pandit, A., Hoge, M., \& Sayyad, M. (2012). Pune low birth weight study-Growth from birth to adulthood. Indian pediatrics, 49(9), 727-732. doi: 10,1007 / s13312-013-0236-4

Chaves, R. G., Lamounier, J. A., \& César, C. C. (2007). Fatores associados com a duração do aleitamento materno. Jornal de Pediatria, 83, 241-246. doi:10.1590/S0021-75572007000400009

Clark, K. M., Castillo, M., Calatroni, A., Walter, T., Cayazzo, M., Pino, P., \& Lozoff, B. (2006). Breast-feeding, mental, and motor development at $5 \frac{1}{2}$ years. Ambulatory Pediatrics, 6, 65-71. doi:10.1016/j.ambp.2005.11.003

Conrad, A. L., Richman, L., Lindgren, S., \& Nopoulos, P. (2010). Biological and environmental predictors of behavioral sequelae in children born preterm. Pediatrics, 125, 83-89. doi:10.1542/peds.2009-0634

Cooke, R. W. I. (2005). Perinatal and postnatal factors in very preterm infants and subsequent cognitive and motor abilities. Archives of Disease in Childhood. Fetal Neonatal Edition, 90, 60-63. doi:10.1136/adc.2004.059188 
Cooke, R. W. I., \& Foulder-Hughes, L. (2003). Growth impairment in the very preterm and cognitive and motor performance at 7 years. Archives of Disease in Childhood, 88, 482-487. doi:10.1136/adc.88.6.482

Correia, L. L. (2009). Dor, temperamento e problemas de comportamento em crianças com queixa de dor de cabeça. Dissertação de Doutorado, Faculdade de Medicina de Ribeirão Preto-Universidade de São Paulo.

Correia, S. K., Bullamah, Saur, A. M., \& Loureiro, S. R. (2014). Comportamento de Escolares Estratificados cabelo Peso Ao Nascer e Idade Gestacional Psicologia: Teoria e Pesquisa , 30 (2), 179-188.

Consentino- Rocha (2012). Temperamento em crianças: efeito do nascimento prematuro e gênero. Dissertação de Mestrado, Faculdade de Medicina de Ribeirão Preto- Universidade de São Paulo.

Cosentino-Rocha, L., Klein, V. C., \& Linhares, M. B. M. (2014). Effects of preterm birth and gender on temperament and behavior in children. Infant Behavior \& Development, 37, 446-456. doi:10.1016/j.infbeh.2014.04.003

Couperus, J. W., \& Nelson, C. A. (2006). Early brain development and plasticity. In K. McCartney \& D. Phillips (Eds.), Blackwell handbook of early childhood development (pp. 85-105). Malden, MA: Blackwell.

Crepaldi, M. A., Andreani, G., Hammes, P. S., Ristof, C. D., \& Abreu, S. D. (2006). A participação do pai nos cuidados da criança, segundo a concepção de mães. Psicologia em Estudo, 11(3), 579-587.

Cury, C. R., \& Golfeto, J. H. (2003). Strengths and difficulties questionnaire (SDQ): a study of schoolchildren in Ribeirão Preto. Revista Brasileira de Psiquiatria, 25(3), 139-145. doi.org/10.1590/S1516-44462003000300005

D'Abreu, L. C. F., \& Marturano, E. M. (2010). Associação entre comportamentos externalizantes e baixo desempenho escolar: uma revisão de estudos prospectivos e longitudinais. Estudos de Psicologia, 15(1), 43-51.

Dahl, L. B., Kaaresen, P. I., Tunby, J., Handegard, B. H., Kvernmo, S., \& Ronning, J. A. (2006). Emotional, behavioral, social, and academic outcomes in adolescents born with very low birth weight. Pediatrics, 118, 449-459. doi:10.1542/peds.2005-3024

Dalgalarrondo, P. (2000). Psicopatologia e semiologia dos transtornos mentais. Porto Alegre, RS: Artmed.

Davidson, J., João, P. C., Rodrigues, R. O., \& Scavacini, A. S. (2011). Respostas cardiopulmonares durante o esforço em crianças e adolescentes nascidas prematuras. Revista Paulista de Pediatria, 29, 443-448. doi:10.1590/S010305822011000300021 
De Kleine, M. J. K., Den Ouden, A. L., Kollee, L. A. A., Nijhuis-Van der Sanden, M. W. G., Sondaar, M., van Kessel-Feddema, B. J. M., ... \& Verloove-Vanhorick, S. P. (2003). Development and evaluation of a follow up assessment of preterm infants at 5 years of age. Archives of disease in childhood, 88(10), 870-875. doi: 10.1136 / adc.88.10.870

De Kieviet, J. F., Zoetebier, L., Van Elburg, R. M., Vermeulen, R. J., \& Oosterlaan, J. (2012). Brain development of very preterm and very low-birthweight children in childhood and adolescence: a meta-analysis.Developmental Medicine \& Child Neurology, 54(4), 313-323.

Dee, D. L., Li, R., Lee, L., \& Grummer-Strawn, L. M. (2007). Associations between breastfeeding practices and young children's language and motor skill development. Pediatrics, 119 (Suppl. 1), 92-8. doi:10.1542/peds.2006-2089N

Deforge, H., Andre, M., Hascoet, J. M., Toniolo, A. M., Demange, V., \& Fresson, J. (2006). Cognitive development and attention performances at school age of "normal" prematurely born children. Archives de Pédiatrie: organe officiel de la Sociéte Francaise de Pédiatrie, 13, 1195-1201. doi:10.1016/j.arcped.2006.05.015

Delobel-Ayoub, M., Arnaud, C., White-Koning, M., Casper, C., Pierrat, V., Garel, M., ... Larroque, B. (2009). Behavioral problems and cognitive performance at 5 years of age after very preterm birth: The EPIPAGE Study. Pediatrics, 123, 1485-1492. doi:10.1542/peds.2008-1216

Delobel-Ayoub, M., Kaminski, M., Marret, S., Burguet, A., Marchand, L., N'Guyen, S., ... Larroque, B. (2006). Behavioral outcome at 3 years of age in very preterm infants: The EPIPAGE Study. Pediatrics, 117, 1996-2005. doi:10.1542/peds.2005-2310

Delgado, S. E., \& Halpern, R. (2005). Amamentação de prematuros com menos de 1500 gramas: funcionamento motor-oral e apego. Pró-Fono Revista de Atualização Científica, 17(2), 141-152.

Draper, E. S., Zeitlin, J., Fenton, A. C., Weber, T., Gerrits, J., Martens, G., ... Breart, G. (2009). Investigating the variations in survival rates for very preterm infants in 10 European regions: The MOSAIC birth cohort. Archives of Disease in Childhood. Fetal and Neonatal Edition, 94, 158-163. doi:10.1136/adc.2008.141531

Drotar, D., Hack, M., Taylor, G., Schluchter, M., Andreias, L., \& Klein, N. (2006). (2006). The impact of extremely low birth weight on the families of school-aged children. Pediatrics, 117, 6-13. doi:10.1542/peds.2005-2118

Duncan, G. J., Dowsett, C. J., Claessens, A., Magnuson, K., Huston, A. C., Klebanov, P.,\& Japel, C. (2007). School readiness and later achievement. Developmental Psychology, 43, 1428-1446. doi:10.1037/0012-1649. 43.6.1428 
Duvall, S.W., Erickson, S.J., MacLean, P., \& Lowe, J.R (2015). Perinatal Medical Variables Predict Executive Function Within a Sample of Preschoolers Born Very Low Birth Weight. Journal of child neurology, 30 (6), 735-740.

Eisenberg, N., Valiente, C., Spinrad, T.L., Cumberland, A., Liew, J.,Reiser, M., et al. (2009).Longitudinal relations of children's effortful control, impulsivity, and negative emotionality to their externalizing, internalizing, and co-occurring behavior problems. Developmental Psychology, 45(4), 988-1008. doi: 10,1037/ a0016213.

Eisenberg, N., Smith, C.L, \& Spinrad, T.L. (2011). Controle com esforço - Relations with Emotion Regulation, Adjustment, and Socialization in Childhood. In Handbook of self-regulation: Research, theory, and applications (2011): 263.

Elliott, R. (2003). Executive functions and their disorders Imaging in clinical neuroscience. British medical bulletin, 65(1), 49-59. doi: 10.1093 / BMB / 65.1 .49

Elgar, F.J., McGrath, P.J., Waschbusch, D.A., Stewart, S.H., \& Curtis, L.J. (2004). Mutual influences on maternal depression and child adjustment problems. Clinical Psychology Review, 24(4),441-59.

Elgen, I., Lundervold, A. J., \& Sommerfelt, K. (2004). Aspects of inattention in low birth weight children. Pediatric Neurology, 30, 92-98. doi:10.1016/S08878994(03)00402-8

Elgen, I., Sommerfelt, K., \& Markestad, T. (2002). Population based, controlled study of behavioural problems and psychiatric disorders in low birthweight children at 11 years of age. Archives of Disease in Childhood. Fetal and Neonatal Edition, 87, 128-132. doi:10.1136/fn.87.2.F128

Espírito Santo, J. L., Portuguez, M. W., \& Nunes, M. L. (2009). Status cognitivocomportamental de prematuros de baixo peso ao nascimento em idade préescolar que vivem em país em desenvolvimento. Jornal de Pediatria, 85, 35 41. doi:10.1590/S0021-75572009000100007

Espy, K. A., Fang, H., Charak, D., Minich, N., \& Taylor, H. G. (2009). Growth mixture modeling of academic achievement in children of varying birth weight risk. Neuropsychology, 23(4), 460- 474. doi:10.1037/a0015676

Farooqi, A., Hägglöf, B., Sedin, G., Gothefors, L., \& Serenius, F. (2007). Mental health and social competencies of 10- to 12-year-old children born at 23 to 25 weeks of gestation in the 1990s: A Swedish National Prospective Follow-up Study. Pediatrics, 120, 118-133. doi:10.1542/peds.2006-2988 
Feldman, R. (2009). The development of regulatory functions from birth to 5 years: Insights from premature infants. Child Development, 80, 544-561. doi:10.1111/j.1467-8624.2009.01278.x

Fernandes, L. V., Goulart, A. L., Santos, A. M. N., Barros, M. C. M., Guerra, C. C., \& Kopelman, B. I. (2012). Avaliação do neurodesenvolvimento de prematuros de muito baixo peso ao nascer entre 18 e 24 meses de idade corrigida pelas escalas Bayley III. Jornal de Pediatria, 88, 471-478. doi:10.1590/S002175572012000600005

Fleitlich, B., Cortázar, P. G., \& Goodman, R. (2000). Questionário de capacidades e dificuldades (SDQ). Infanto rev. neuropsiquiatr. infanc. adolesc, 8(1), 44-50.

Fonseca, L. M. M. Cuidados com o bebê prematuro: cartilha educativa para orientação materna. (2002). Dissertação de mestrado. Escola de Enfermagem de Ribeirão Preto, Universidade de São Paulo

Formiga, C. K., Martins, R., \& Linhares, M. B. M. (2009). Avaliação do desenvolvimento inicial de crianças nascidas pré-termo. Revista da Escola de Enfermagem da USP, 43(2), 472-480. doi.org/10.1590/S008062342009000200030

Foulder-Hughes, L., \& Cooke, R. W. I. (2003a). Do mainstream schoolchildren who were born preterm have motor problems? British Journal of Occupational Therapy, 66, 9-16. doi:10.1177/030802260306600103

Foulder-Hughes, L., \& Cooke, R. (2003b). Motor, cognitive, and behavioural disorders in children born very preterm. Developmental Medicine \& Child Neurology, 45, 97-103. doi:10.1017/S0012162203000197

Franck, L., \& Spencer, C. (2003). Parent visiting and participation in infant caregiving activities in a neonatal unit. Birth, 30,1.

Fraga, D. A., Linhares, M. B. M., Carvalho, A. E. V., \& Martinez, F. E. (2008). Desenvolvimento de bebês prematuros relacionado a variáveis neonatais e maternas. Psicologia em Estudo, 13(2), 335-344.

Frigo, J., de Azambuja Zocche, D. A., Palavro, G. L., Turatti, L. A., Neves, E. T., \& Schaefer, T. M. (2015). Percepções de pais de recém-nascidos prematuros em unidade de terapia intensiva neonatal. Revista de Enfermagem da UFSM, 5, 58-68. doi:10.5902/2179769212900

Fuentes, L. B., Serrano, R. H., Colmenarez, A. P. (1988). El abuso sexual en niños e jovenes. Caracas, Venezuela: Ediluc.

Gallahue, D. L., \& Ozmun, J. C. (2003). Compreendendo o desenvolvimento motor: Bebês, crianças, adolescentes e adultos. São Paulo, SP: Phorte. 
Garcia, I. (2001). Vulnerabilidade e resiliência. Adolescência Latinoamericana, 2, 128-130. doi:10.1590/S1413-85572010000100010

Garcia, V. L., Pereira, L. D., \& Fukuda, Y. (2007). Atenção seletiva: PSI em crianças com distúrbio de aprendizagem. Revista Brasileira de Otorrinolaringologia, 73, 404- 411. doi:10.1590/S0034-72992007000300017

Gaspardo, C. M., Martinez, F. E., \& Linhares, M. B. M. (2010). Cuidado ao desenvolvimento: Intervenções de proteção ao desenvolvimento inicial de recém-Nascidos pré-termo. Revista Paulista de Pediatria, 28, 77-85. doi:10.1590/S0103-05822010000100013

Gibelli, M. A. B. C. (2009). Fatores de risco para fungemia em recém-nascidos de muito baixo peso (Dissertação de mestrado). Recuperado de http://www.teses.usp.br/teses/disponiveis/5/5141/tde-08122009-174506/ptbr.php

Gillberg, C. (2003). Deficits in attention, motor control, and perception: a brief review. Archives of disease in childhood, 88(10), 904-910. doi: 10.1136 / adc.88.10.904

Glesse, S., Mantesso, A., Ramalho, S. A., Simoni, J. L., \& Saba-Chujfi, E. (2004). Influência de doença periodontal no trabalho de parto pré-termo. RGO (Porto Alegre), 52(5), 326-330.

Gluckman, P. D., Hanson, M. A., Bateson, P., Beedle, A. S., Law, C. M., Bhutta, Z. A., ... West-Eberhard, M. J. (2009). Towards a new developmental synthesis: Adaptive developmental plasticity and human disease. The Lancet, 373, 16541657. doi:10.1016/S0140-6736(09)60234-8

Goldfeld, S., O'Connor, M., Sayers, M., Moore, T., \& Oberklaid, F. (2012). Prevalence and correlates of special health care needs in a population cohort of Australian children at school entry. Journal of Developmental Behavioral Pediatrics, 33, 319-327. doi:10.1097/ DBP.0b013e31824a7b8e

Goodman, R. (1999). Questionário de Capacidades e Dificuldades (SDQ). Recuperado de http://www. sdqinfo.com

Gozzo, Y., Vohr, B., Lacadie, C., Hampson, M., Katz, K. H., Maller-Kesselman, J., ... \& Ment, L. R. (2009). Alterations in neural connectivity in preterm children at school age. Neuroimage, 48(2), 458-463. doi: 10.1016 / j.neuroimage.2009.06.046

Gracioli, S. M. A.(2013). Temperamento e comportamento de crianças nascidas prétermo extremo e moderado na fase de 18 a 36 meses. Dissertação de Mestrado- Universidade de São Paulo.

Gracioli, S. M. A., \& Linhares, M. B. M. (2014). Temperamento e sua relação com problemas emocionais e de comportamento em pré-escolares. Psicologia em Estudo, 19, 71-80. doi:10.1590/1413-7372213020007 
Grandi, C., Tapia, J. L., \& Cardoso, V. C. (2015). Impact of maternal diabetes mellitus on mortality and morbidity of very low birth weight infants: A multicenter Latin America study. Jornal de Pediatria, 91, 234-241. doi:10.1016/j.jpedp.2015.03.010

Gray, R. F., Indurkhya, A., \& McCormick, M. C. (2004). Prevalence, stability, and predictors of clinically significant behavior problems in low birth weight children at 3, 5, and 8 years of age. Pediatrics, 114, 736-743. doi:10.1542/peds.2003$1150-\mathrm{L}$

Griffiths, S. T., Aukland, S. M., Markestad, T., Eide, G. E., Elgen, I., Craven, A. R., \& Hugdahl, K. (2014). Association between brain activation (fmri), cognition and school performance in extremely preterm and term born children. Scandinavian Journal of Psychology, 55, 427-432. doi:10.1111/Sjop.12145

Griffiths, S. T., Elgen, I. B., Chong, W. K., Odberg, M. D., Markestad, T., Neto, E. Aukland, S. M. (2013). Cerebral magnetic resonance imaging findings in children born extremely preterm, very preterm, and at term. Pediatric Neurology, 49, 113-118. doi:10.1016/j.pediatrneurol.2013.03.006

Grunau, R. E. (2003). Self-regulation and behavior in preterm children: Effects of early pain. In P. J. Mcgrath \& A. Finley (Eds.), Pediatric pain: Biological and social context, progress in pain research and management (pp. 23-55). Seattle, WA: IASP Press.

Hack, M., Taylor, H. G., Schluchter, M., Andreias, L., Drotar, D., \& Klein, N. (2009). Behavioral outcomes of extremely low birth weight children at age 8 years. Journal of Develomental and Behavioral Pediatrics, 30, 122-130. doi:10.1097/DBP.0b013e31819e6a16

Halpern, R., \& Figueiras, A. C. M. (2004). Influências ambientais na saúde mental da criança. Jornal de Pediatria, 80, 104-110. doi:10.1590/S002175572004000300013

Halpern, R., Giugliani, E. R. J., Victora, C. G., Barros, F. C., \& Horta, B. L. (2002). Fatores de risco para suspeita de atraso no desenvolvimento neuropsicomotor aos 12 meses de vida. Revista Chilena de Pediatria, 73, 529-539. doi:10.4067/S0370-41062002000500016

Harmon, H. M., Taylor, H. G., Minich, N., Wilson-Costello, D., \& Hack, M. (2015). Early school outcomes for extremely preterm infants with transient neurological abnormalities. Developmental Medicine \& Child Neurology. doi:10.1111/dmcn.12811

Henderson, H. A., \& Wachs, T. D. (2007). Temperament theory and the study of cognition-emotion interactions across development. Developmental Review, 27(3), 396-427. doi: 10.1016 / j.dr.2007.06.004 
Heron, M. (2013). Deaths: leading causes for 2010. National vital statistics reports: from the Centers for Disease Control and Prevention, National Center for Health Statistics, National Vital Statistics System, 62(6), 1-96.

Hille, E. T. M., den Ouden, A. L., Saigal, S., Wolke, D., Lambert, M., Whitaker, A., ... Paneth, N. (2001). Behavioural problems in children who weigh $1000 \mathrm{~g}$ or less at birth in four countries. The Lancet, 357, 1641-1643. doi:10.1016/S0140$6736(00) 04818-2$

Howson, C. P., Kinney, M. V., Lawn, J. E. (Eds.). (2012). Born too soon: The global action report on preterm birth. Geneva, Switzerland: WHO. Recuperado de http://www.who.int/pmnch/media/news/2012/introduction.pdf

Huddy, C. L. J., Johnson, A., \& Hope, P. L. (2001). Educational and behavioural problems in babies of 32-35 weeks gestation. Archives of Disease in Childhood. Fetal and Neonatal Edition, 85, 23-28. doi:10.1136/fn.85.1.F23

Jaekel, J., Wolke, D., \& Bartmann, P. (2013). Poor attention rather than hyperactivity/impulsivity predicts academic achievement in very preterm and full-term adolescents. Psychological medicine, 43(01), 183-196. doi.org/10.1017/S0033291712001031

Jarjour T. I. (2015). Neurodevelopmental outcome after extreme prematurity: A review of the literature. Pediatric Neurology, 52, 143-52. doi:10.1016/j.pediatrneurol.2014.10.027

Johnson, S. (2007). Cognitive and behavioural outcomes following very preterm birth. In Seminars in Fetal and Neonatal Medicine (Vol. 12, No. 5, pp. 363-373. WB Saunders. doi: 10.1016 / j.siny.2007.05.004

Johnson, S., Fawke, J., Hennessy, E., Rowell, V., Thomas, S., Wolke, D., \& Marlow, N. (2009). Neurodevelopmental disability through 11 Years of age in children born before 26 weeks of gestation. Pediatrics, 124, e249-e257. doi:10.1542/peds.2008-3743

Johnson, S., Hollis, C., Kochhar, P., Hennessy, E., Wolke, D., \& Marlow, N. (2010). Psychiatric disorders in extremely preterm children: longitudinal finding at age 11 years in the EPICure study. Journal of the American Academy of Child \& Adolescent Psychiatry, 49(5), 453-463. doi: 10.1016 / j.jaac.2010.02.002

Johnson, S., \& Marlow, N. (2011). Preterm birth and childhood psychiatric disorders. Pediatric Research, 69, 11-18. doi:10.1203/PDR.0b013e318212faa0

Kallankari, H., Kaukola, T., Olsén, P., Ojaniemi, M., \& Hallman, M. (2015). Very preterm birth and foetal growth restriction are associated with specific cognitive deficits in children attending mainstream school. Acta Paediatrica, 104(1), 84-90. doi:10.1111/apa.12811 
Karatekin, C. (2001). Developmental disorders of attention. In C. A. Nelson \& M. Luciana (Eds.), Handbook of developmental cognitive neuroscience (pp. 561576). Cambridge, MA: MIT Press.

Kapellou, O., Counsell, S. J., Kennea, N., Dyet, L., Saeed, N., Stark, J., ... Edwards, A. D. (2006). Abnormal cortical development after premature birth shown by altered allometric scaling of brain growth. PLoS Medicine, 3, e265. doi:10.1371/journal.pmed.0030265

Katz-Salamon, M., Gerner, E. M., Jonsson, B., \& Lagercrantz, H. (2000). Early motor and mental development in very preterm infants with chronic lung disease. Archives of Disease in Childhood. Fetal and Neonatal Edition, 83, 1-6. doi:10.1136/fn.83.1.F1

Kerestes, G. (2005). Maternal ratings of temperamental characteristics of healthy premature infants are indistinguishable from those of full-term infants. Croatian medical journal, 46(1), 36-44.

Kerstjens, J. M., de Winter, A. F., Bocca-Tjeertes, I. F., Ten Vergert, E. M., Reijneveld, S. A., \& Bos, A. F. (2011). Developmental delay in moderately preterm-born children at school entry. The Journal of pediatrics, 159(1), 92-98. doi: 10.1016 / j.jpeds.2010.12.041

Kerestes, G. (2005). Maternal ratings of temperamental characteristics of healthy premature infants are indistinguishable from those of full-term infants. Croatian Medical Journal, 46, 36-44.

Khan, N. Z., Muslima, Parveen, M., Bhattacharya, M., Begum, N., Chowdhury, S., Jahan, M., \& Darmstadt, G. (2006). Neurodevelopmental outcomes of preterm infants in Bangladesh. Pediatrics, 118, 280-289. doi:10.1542/peds.2005-2014

Kieras, J. E., Tobin, R. M., Graziano, W. G., \& Rothbart, M. K. (2005). You can't always get what you want effortful control and children's responses to undesirable gifts. Psychological Science, 16(5), 391-396. doi: 10,1111 / j.09567976.2005.01546.x

Kramer, M. S., Aboud, F., Mironova, E., Vanilovich, I., Platt, R. W., Matush, L., ... Shapiro, S. (2008). Breastfeeding and child cognitive development: New evidence from a large randomized trial. Archives of General Psychiatry, 65, 578-584. doi:10.1001/archpsyc.65.5.578

Klein, V. C. (2009). Reatividade à dor, temperamento e comportamento na trajetória de desenvolvimento de neonatos pré-termo até a fase pré-escolar (Tese de doutorado não publicada). Universidade de São Paulo, Ribeirão Preto, SP.

Klein, V. C., Gaspardo, C. M., \& Linhares, M. B. M. (2011). Dor, auto-regulação e temperamento em recém-nascidos pré-termo com alto risco neonatal. Psicologia: Reflexão e Crítica, 24, 504-512. doi:10.1590/S010279722011000300011 
Klein, V. C., Gaspardo, C. M., Martinez, F. E., Grunau, R. E., \& Linhares, M. B. M. (2009). Pain and distress reactivity and recovery as early predictors of temperament in toddlers born preterm. Early Human Development, 85, 569576. doi:10.1016/j.earlhumdev.2009.06.001

Klein, V. C., \& Linhares, M. B. M. (2010). Temperamento e desenvolvimento: Revisão sistemática da literatura. Psicologia em Estudo, 15, 821-829. doi:10.1590/S1413-73722010000400018

Klein, V. C., Putnam, S. P., \& Linhares, M. B. M. (2009). Assessment of temperament in children: translation of instruments to Portuguese (Brazil) Language. Interamerican Journal of Psychology, 43(3), 442-447.

Klein, V. C., Rocha, L. C., Martinez, F. E., Putnam, S. P., \& Linhares, M. B. M. (2013). Temperament and behavior problems in toddlers born preterm and very low birth weight. The Spanish journal of psychology, 16, E18. doi.org/10.1017/sjp.2013.30

Kleine, M. J., Sanden, M. W., \& Ouden, A. L. (2006). Is paediatric assessment of motor development of very preterm and low-birthweight children appropriate?. Acta Paediatrica, 95(10), 1202-1208

Kobayashi, S., Wakusawa, K., Inui, T., Tanaka, S., Kobayashi, Y., Onuma, A., \& Haginoya, K. (2015). The neurological outcomes of cerebellar injury in premature infants. Brain and Development. doi:10.1016/j.braindev.2015.01.009

Koç, Ö., Kavuncuoğlu, S., Ramoğlu, M., Aldemir, E., Aktalay, A., \& Eras, Z. (2015). School performance and neurodevelopment of very low birth weight preterm infants: First report from Turkey. Journal of Child Neurology. doi:10.1177/ 0883073815587028

Kochanska, G., Murray, K. T., \& Harlan, E. T. (2000). Effortful control in early childhood: Continuity and change, antecedents, and implications for social development. Developmental Psychology, 36, 220-232. doi:10.1037/00121649.36.2.220

Kopp, C. B., \& Neufeld, S. J. (2003). Emotional development during infancy. In R. J. Davidson, K. R. Scherer, \& H. H. Goldsmith (Eds.), Handbook of affective sciences (pp. 347-374). New York, NY: Oxford University Press.

Lamônica, D. A. C., \& Picolini, M. M. (2009). Habilidades do desenvolvimento de prematuros. Revista CEFAC, 11, 145-153.

Landry, S. H., Garner, P. W., Swank, P. R., \& Baldwin, C. D. (1996). Effects of maternal scaffolding during joint toy play with preterm and full-term infants. Merrill-Palmer Quarterly, 42, 177-199.

Larroque, B., Ancel, P. Y., Marret, S., Marchand, L., André, M., Arnaud, C., ... EPIPAGE Study Group. (2008). Neurodevelopmental disabilities and special care of 5-year-old children born before 33 weeks of gestation (the EPIPAGE 
study): A longitudinal cohort study. The Lancet, 371, 813-820. doi:10.1016/S0140-6736(08)60380-3

Lejeune, F., Tolsa, C. B., Graz, M. B., Hüppi, P. S., \& Barisnikov, K. (2015). Emotion, attention, and effortful control in 24-month-old very preterm and full-term children. L'Année Psychologique, 115, 241-264. doi:10.4074/S0003503314000116

Leversen, K. T., Sommerfelt, K., Elgen, I. B., Eide, G. E., Irgens, L. M., Juliusson, P. B., \& Markestad, T. (2012). Prediction of outcome at 5 years from assessments at 2 years among extremely preterm children: A Norwegian national cohort study. Acta Paediatrica, 101, 264-270. doi:10.1111/j.1651-2227.2011.02504.x

Lezak, M. D., Howieson, D. B., \& Loring, D. W. (2004). Neuropsychological assessment (4th ed.). New York, NY: Oxford University Press.

Lee, E. S., Yeatman, J. D., Luna, B., \& Feldman, H. M. (2011). Specific language and reading skills in school-aged children and adolescents are associated with prematurity after controlling for IQ. Neuropsychologia, 49, 906-913. doi:10.1016/j.neuropsychologia.2010.12.038

Lemos, R. A., Frônio, J. S., Neves, L. A. T., \& Ribeiro, L. C. Estudo da prevalência de morbidades e complicações neonatais segundo o peso ao nascimento e a idade gestacional em lactentes de um serviço de follow-up. (2010). Revista APS, 13, 277-290.

Lima, E. V., Oliveira, D. M. P., Draque, C. M., Mori, H., Pinto, F. L. S., Saraiva, M. A., ... Amaro, E. R. (2006). Sobrevida de recém-nascidos de muito baixo peso em maternidade privada de nível terciário. Revista Paulista de Pediatria, 24, 155162.

Linhares, M. B. M. (2004). Estresse, resiliência e cuidados no desenvolvimento de neonatos de alto risco. In G. E. Mendes, M. A. Almeida, \& L. C. A. Williams (Eds.), Temas em educação especial (pp. 315-324). São Carlos, SP: Editora da Universidade Federal de São Carlos.

Linhares, M. B. M. (2009). Vulnerabilidade, risco e proteção no desenvolvimento de crianças nascidas pré-termo (Tese de livre-docência não publicada). Universidade de São Paulo, Ribeirão Preto, SP.

Linhares, M. B. M., Chimello, J. T., Bordin, M. B. M., Carvalho, A. E. V., \& Martinez, F. E. (2005). Desenvolvimento psicológico na fase escolar de crianças nascidas pré-termo em comparação com crianças nascidas a termo. Psicologia: Reflexão e Crítica, 18, 109-117. doi:10.1590/S0102-79722005000100015

Linhares, M. B. M., Carvalho, A. E. V., Correia, L. L., Gaspardo, C. M., Padovani, F. H. P., Crepaldi, M. A., ... \& Perosa, G. B. (2006). Psicologia pediátrica em neonatologia de alto risco: promoção precoce do desenvolvimento de bebês prematuros. Temas em Psicologia Pediátrica, 109-145. 
Linhares, M. B. M., \& Martins, C. B. S. (2015). O processo da autorregulação não desenvolvimento de crianças. Estudos de Psicologia (Campinas), 32, 281293. doi:10.1590/0103-166X2015000200012

Litt, J. S., Taylor, G., Margevicius, S., Schluchter, M., Andreias, L., \& Hack, M. (2012). Academic achievement of adolescents born with extremely low birth weight. Acta Paediatrica, 101, 1240-1245. doi:10.1111/j.16512227.2012.02790.x

Loe, I. M., Lee, E. S., \& Feldman, H. M. (2013). Attention and internalizing behaviors in relation to white matter in children born preterm. Journal of developmental and behavioral pediatrics, 34(3), 156. doi: 10.1080/08035250500525301

Lubchenco, L.O., Hansman, C., \& Boyd, E. Intrauterine growth in length and head circumference as estimated from live births at gestational ages from 26 to 42 weeks. Pediatrics, 47, 403-8.

Luu, T. M., Ment, L. R., Schneider, K. C., Katz, K. H., Allan, W. C., \& Vohr, B. R. (2009). Lasting effects of preterm birth and neonatal brain hemorrhage at 12 years of age. Pediatrics, 123, 1037-1044. doi:10.1542/peds.2008-1162

Maggi, E. F., Magalhães, L. C., Campos, A. F., \& Bouzada, M. C. F. (2014). Preterm children have unfavorable motor, cognitive, and functional performance when compared to term children of preschool age. Jornal de pediatria, 90(4), 377383. doi: 10.1016 / j.jped.2013.10.005

Mancini, M. C., Megale, L., Brandão, M. B., Melo, A. P. P., \& Sampaio, R. F. (2004). Efeito moderador do risco social na relação entre risco biológico e desempenho funcional infantil. Revista Brasileira de Saúde Materno Infantil, 4, 25-34.

Marlow, N., Hennessy, E. M., Bracewell, M. A., \& Wolke, D. (2007). Motor and executive function at 6 years of age after extremely preterm birth. Pediatrics, 120, 793-804. doi:10.1542/peds.2007-0440

Marlow, N., Wolke, D., Bracewell, M. A., Samara, M., \& EPICure Study Group. (2005). Neurologic and developmental disability at six years of age after extremely preterm birth. New England Journal of Medicine, 352, 9-19. doi:10.1056/NEJMoa041367

Martini, J. A. (2012). Qualidade de vida, avaliação cognitiva e comportamental de prematuros de muito baixo peso com idade entre cinco e oito anos.

Marque, F. C., Dias, I. M. V., \& Azevedo, L. (2006). A percepção da equipe de enfermagem sobre humanização do parto e nascimento. Escola Anna Nery Revista Enfermagem, 10, 439-447. doi:10.1590/S1414-81452006000300012

Martins, M. D. G., Santos, G. H. N. D., Sousa, M. D. S., Costa, J. E. F. B. D., \& Simões, V. M. F. (2011). Associação de gravidez na adolescência e prematuridade. Rev. bras. ginecol. obstet, 33(11), 354-360. 
Martins, I. M. B., Linhares, M. B. M., \& Martinez, F. E. (2005). Indicadores de desenvolvimento na fase pré-escolar de crianças nascidas prétermo. Psicologia em Estudo, 10, 235-243. doi:10.1590/S141373722005000200010

Matos, M. B. D., Cruz, A. C. N., Dumith, S. D. C., Dias, N. D. C., Carret, R. B. P., \& Quevedo, L. D. A. (2015). Stressor events in the family environment that are indicative of mental health problems in children of school age. Ciência \& Saúde Coletiva, 20(7), 2157-2163. doi.org/10.1590/1413-81232015207.17452014

Mazzocco, M. M. M., \& Kover, S. T. (2007). A longitudinal assessment of executive function skills and their association with math performance. Child Neuropsychology, 13, 18-45. doi:10.1080/09297040600611346

Meier, P. (2001). Breastfeeding in the special care nursery. Pediatric Clinics of North America, 48, 25-42. doi:10.1016/S0031-3955(08)70035-X

Méio, M. D. B. B., Lopes, C. S., \& Morsch, D. S. (2003). Fatores prognósticos para o desenvolvimento cognitivo de prematuros de muito baixo peso. Revista de Saúde Pública, 37, 311-318. doi:10.1590/S0034-89102003000300008

Mento, G., \& Bisiacchi, P. S. (2012). Neurocognitive development in preterm infants: insights from different approaches. Neuroscience \& Biobehavioral Reviews, 36(1), 536-555. doi: 10.1016 / j.neubiorev.2011.08.008

Milligan, D. W. (2010). Outcomes of children born very preterm in Europe. Archives of Disease in Childhood-Fetal and Neonatal Edition, 95(4), 234-240. doi: 10.1136 / adc.2008.143685

Ministério da Saúde. Secretaria de Atenção à Saúde. Departamento de Ações Programáticas Estratégicas. (2005). Agenda de compromissos para a saúde integral da criança e redução de mortalidade infantil. Brasília, DF: Ministério da Saúde. Recuperado de http://bvsms.saude.gov.br/ bvs/publicacoes/agenda_compro_crianca.pdf

Ministério da Saúde. (2013). Sistema de Informações sobre Nascidos Vivos SINASC.

http://tabnet.datasus.gov.br/cgi/tabcgi.exe?sinasc/cnv/nvuf.def

Montiel, M. J., \& Seabra, A. G. (2012). Teste de Atenção por Cancelamento. In A. G. Seabra \& N. M. Dias (Orgs.), Avaliação neuropsicológica cognitiva/atenção e função executiva (Vol. 1, pp. 57-66). São Paulo, SP: Memnon.

Moreira, R. S., Magalhães, L. C., \& Alves, C. R. (2014). Effect of preterm birth on motor development, behavior, and school performance of school-age children: A systematic review. Jornal de Pediatria, 90, 119-134. doi:10.1016/j.jped.2013.05.010

Morley, R., Fewtrell, M. S., Abbott, R. A., Stephenson, T., MacFadyen, U., \& Lucas, A. (2004). Neurodevelopment in children born small for gestational age: A 
randomized trial of nutrient-enriched versus standard formula and comparison with a reference breastfed group. Pediatrics, 113, 515-521.

Msall, M. E., \& Park, J. J. (2008).The spectrum of behavioural outcomes after extreme prematurity: Regulatory, attention, social and adaptative dimensions. Seminars in Perinatology, 32, 42-50. doi:10.1053/j.semperi.2007.12.006

Msall, M. E., Sullivan, M. C., \& Park, J. P. (2010). Pathways of risk and resilience after prematurity: role of socio-economic status. Neurodevelopmental outcomes of preterm birth from childhood to adult life, 224-236.

Mulder, H., Pitchford, N. J., Hagger, M. S., \& Marlow, N. (2009). Development of executive function and attention in preterm children: a systematic review. Developmental neuropsychology, 34(4), 393-421. doi:10,1080 / 87565640902964524

Mulder, H., Pitchford, N. J., \& Marlow, N. (2011). Inattentive behaviour is associated with poor working memory and slow processing speed in very pre-term children in middle childhood. British Journal of Educational Psychology,81(1), 147-160. doi: 10,1348 / $000709910 \times 505527$

Mustard, J. (2002). Early child development and the brain: The base for health, learning, and behavior throughout life. In M. Young (Ed.), From early child development to human development: Investing in our children's future (pp. 2361). Washington, DC: World Bank.

Nascimento, M. B. R., \& Issler, H. (2004). Aleitamento materno em prematuros: manejo clínico hospitalar. Jornal de Pediatria, 80(5), 163-72.

Nair, M. K. C., Chacko, M. K., Paul, K. M., Nair, L., George, B., \& Kumar, G. S. (2009). Low birthweight babies- outcome at 13 years. Indian Pediatrics, 46, 7174.

Nosarti, C., Giouroukou, E., Micali, N., Rifkin, L., Morris, R. G., \& Murray, R. M. (2007). Impaired executive functioning in young adults born very preterm. Journal of the International Neuropsychological Society, 13, 571-581. doi:10.1017/S1355617707070725

Nobre, F. D. A., Carvalho, A. E. V., Martinez, F. E., \& Linhares, M. B. M. (2009). Estudo longitudinal do desenvolvimento de crianças nascidas pré-termo no primeiro ano pós-natal. Psicologia: Reflexão e Crítica, 22, 362-369. doi:10.1590/S0102-79722009000300006

Nomura, Y., Wickramaratne, P. J., Pilowsky, D. J., Newcorn, J. H., Bruder-Costello, B., Davey, C., ... Weissman, M. M. (2007). Low birth weight and risk of affective disorders and selected medical illness in offspring at high and low risk for depression. Comprehensive Psychiatry, 48, 470-478. doi:10.1016/j.comppsych.2007.04.005 
Odd, D. E., Emond, A., \& Whitelaw, A. (2012). Long-term cognitive outcomes of infants born moderately and late preterm. Developmental Medicine \& Child Neurology, 54(8), 704-709. doi: 10,1111 / j.1469-8749.2012.04315.x

Olafsen, K. S., Kaaresen, P. I., Handegard, B. H., Ulvund, S. E., Dahl, L. B., \& Ronning, J. A. (2008). Maternal ratings of infant regulatory competence from 6 to 12 months: Influence of perceived stress, birth-weight, and intervention: A randomized controlled trial. Infant Behavior \& Development, 31, 408-421. doi:10.1016/j.infbeh.2007.12.005

Oliveira, G. E., Magalhães, L. C., \& Salmela, L. F. T. (2011). Relação entre muito baixo peso ao nascimento, fatores ambientais e o desenvolvimento motor e o cognitivo de crianças aos 5 e 6 anos. Revista Brasileira de Fisioterapia, 15, 138-145. doi:10.1590/S1413-35552011000200009

Oliveira, L. D., Flores, M. R., \& Souza, A. P. R. (2012). Fatores de risco psíquico ao desenvolvimento infantil: Implicações para a fonoaudiologia. Revista CEFAC, $14,333-342$.

Oliveira, R. G. (2011). Black book: Manual de referência de pediatria, medicamentos e rotinas médicas (4a ed.). Belo Horizonte, MG: Black Book.

Perra, O., McGowan, J. E., Grunau, R. E., Doran, J. B., Craig, S., Johnston, L., ... \& Alderdice, F. A. (2015). Parent ratings of child cognition and language compared with Bayley-III in preterm 3-year-olds. Early human development, 91(3), 211-216. doi.org/10.1016/j.earlhumdev.2015.01.009

Perricone, G., \& Morales, M. R. (2011). The temperament of preterm infant in preschool age. Ital. Journal of Pediatrics, 37, 1-7.

Phibbs, C. S., Baker, L. C., Caughey, A. B., Danielson, B., Schmitt, S. K., \& Phibbs, R. B. (2007). Level and volume of neonatal intensive care and mortality in verylow-birth-weight infants. The New England Journal of Medicine, 356, 21652175. doi:10.1056/NEJMsa065029

Pickler, R. H., Wetzel, P. A., Meinzen-Derr, J., Tubbs-Cooley, H. L., \& Moore, M. (2015). Patterned feeding experience for preterm infants: Study protocol for a randomized controlled trial. Trials, 16, 255. doi:10.1186/s13063-015-0781-3

Pinto, M., Silva, C., Munari, M., Almeida, C., \& Resende, T. (2008). Intervenção motora precoce em neonatos prematuros. Revista da Graduação, 1(2), 1-10.

Pitcher, J. B., Riley, A. M., Doeltgen, S. H., Kurylowicz, L., Rothwell, J. C., McAllister, S. M., ... Ridding, M. C. (2012). Physiological evidence consistent with reduced neuroplasticity in human adolescents born preterm. The Journal of Neuroscience, 32, 16410-16416. doi:10.1523/JNEUROSCI.3079-12.2012

Poehlmann, J., Schwichtenberg, A. J. M., Shlafer, R. J., Hahn, E., Bianchi, J. P., \& Warner, R. (2011). Emerging self-regulation in toddlers born preterm or low 
birth weight: Differential susceptibility to parenting? Development and Psychopathology, 23, 177-193. doi:10.1017/S0954579410000726

Posner, M. I. (1980). Orienting of attention. The 7th Sir F.C. Bartlett Lecture. Quarterly Journal of Experimental Psychology, 32, 3-25. doi:10.1080/00335558008248231

Posner, M. I., \& Fan, J. (2001). Attention as an organ system. Recuperado de http://www.sacklerinstitute.org/cornell/people/jin.fan/publicationspublications/AN T_AS_ORGAN_SYSTEM.pdf

Posner, M. I., \& Petersen, S. E. (1990). The attention system of the human brain. Annual Review of Neuroscience, 13, 25-42. doi:10.1146/annurev.ne.13.030190.000325

Posner, M. I., \& Rothbart, M. K. (2000). Developing mechanisms of self-regulation. Development and Psychopathology, 12, 427-441.

Posner, M. I., \& Rothbart, M. K. (1998). Attention, self-regulation, and consciousness. Philosophical Transactions of the Royal Society of London, 353, 1915-1927. doi:10.1098/rstb.1998.0344

Potharst, E. S., Van Wassenaer, A. G., Houtzager, B. A., Van Hus, J. W. P., Last, B. F., \& Kok, J. H. (2011). High Incidence of multi-domain disabilities in very preterm children at five years of age. Journal of Pediatrics, 159, 79-85. doi:10.1016/j.jpeds.2010.12.055

Potijk, M. R., Winter, A. F., Bos, A. F., Kerstjens, J. M., \& Reijneveld, S. A. (2015). Behavioural and emotional problems in moderately preterm children with low socioeconomic status: A population-based study. European Child \& Adolescent Psychiatry, 24, 787-795. doi:10.1007/s00787-014-0623-y

Putnam, S. P., Gartstein, M. A., \& Rothbart, M. K. (2006). Measurement of finegrained aspects of toddler temperament: The early childhood behavior questionnaire. Infant Behavior \& Development, 29, 386-401. doi:10.1016/j.infbeh.2006.01.004

Ramos, H. A. C., \& Cuman, R. K. N. (2009). Fatores de risco para prematuridade: Pesquisa documental. Escola Anna Nery Revista de Enfermagem, 13, 297-304. doi:10.1590/S1414-81452009000200009

Ranger, M., Zwicker, J. G., Chau, C, M. Y., Park, M. T. M., Chakravarthy, M. M., Poskitt, K., ... Grunau, R. E. (2015). Neonatal pain and infection relate to smaller cerebellum in very preterm children at school age. The Journal of Pediatrics. doi:10.1016/j.jpeds.2015.04.055

Reijneveld, S. A., de Kleine, M. J., van Baar, A. L., Kollee, L. A., Verhaak, C. M., Verhulst, F. C., \& Verloove-Vanhorick, S. P. (2006). Behavioural and emotional problems in very preterm and very low birthweight infants at age 5 years. 
Archives of Disease in Childhood. Fetal and Neonatal Edition, 91, 28. doi:10.1136/adc.2006.093674

Resegue, R., Puccini, R. F., \& Silva, E. M. K. (2007). Fatores de risco associados a alterações no desenvolvimento da criança. Pediatria, 29, 117-128.

Ribeiro, C. C., \& Lamônica, D. A. C. (2014). Habilidades comunicativas de crianças prematuras e prematuras extremas. Revista CEFAC, 16, 830-839. doi:10.1590/1982-021620143813

Roberts, G., Bellinger, D., \& McCormick, M. C. (2007). A cumulative risk factor model for early identification of academic difficulties in premature and low birth weight infants. Maternal and child health journal, 11(2), 161-172. doi: 10,1007/z s10995-006-0158

Roberts, G., Howard, K., Spittle, A. J., Brown, N. C., Anderson, P. J., \& Doyle, L. W. (2008). Rates of early intervention services in very preterm children with developmental disabilities at age 2 years. Journal of Paediatrics and Child Health, 44, 276-280. doi:10.1111/j.1440-1754.2007.01251.x

Roberts, G., Lim, J., Doyle, L. W., \& Anderson, P. J. (2011). High rates of school readiness difficulties at 5 years of age in very preterm infants compared with term controls. Journal Developmental and Behavioral Pediatrics, 32, 117-124. doi:10.1097/DBP.0b013e318206d5c9

Rodrigues, M. C. C., Mello, R. R., \& Fonseca, S. C. (2006). Dificuldade de aprendizagem em escolares de muito baixo peso ao nascer. Jornal de Pediatria, 82, 6-14. doi:10.1590/S0021-75572006000100004

Rodrigues, M. C. C., Mello, R. R., Silva, K. S., \& Carvalho, M. L. (2011). Desenvolvimento cognitivo de prematuros à idade escolar: Proposta de modelo hierarquizado parágrafo investigação dos fatores de risco. Cadernos de Saúde Pública, 27, 1154-1164. doi:10.1590/S0102-311X2011000600012

Rothbart, M. K. (1986). A psychobiological approach to the study of temperament. In G. A. Kohnstamm (Ed.), Temperament discussed - temperament and development in infancy and childhood (pp. 63-72). Lisse, Netherlands: Swets \& Zeitlinger.

Rothbart, M Temperament Laboratory. (2012). The instruments. Recuperado de http://wcalkinsw.bowdoin.edu/ sputnam/rothbart-temperament questionnaires/instrument-descriptions

Rothbart, M. K., Ahadi, S. A., Hershey, K. L., \& Fisher, P. (2001). Investigations of temperament at 3-7 years: The Children's Behavior Questionnaire. Child Development, 72, 1394-1408.

Rothbart, M. K., Posner, M. I., \& Kieras, J. (2006). Temperament, Attention, and the Development of Self-Regulation. 
Rothbart, M. K., \& Bates, J. E. (1998). Temperament. In W. Damon \& N. Eisenberg (Eds.), Handbook of child psychology (Vol. 3, 5a ed., pp. 105-176). New York, NY: Wiley.

Rothbart, M. K. (2004). Commentary: Differentiated measures of temperament and multiple pathways to childhood disorders. Journal of Clinical Child and Adolescence Psychology,33(1), 82-87. doi: 10,1207 / S15374424JCCP3301_8

Rothbart, M. K., Chew, K., \& Gartstein, M. A. (2001). Assessment of temperament in early development. In L. Singer \& P. S. Zeskind (Eds.), Biobehavioral assessment of the infant (pp. 190-208). New York, NY: Guilford.

Rothbart, M. K., \& Derryberry, D. (1981). Development of individual differences in temperament. In M. L. Lamb \& A. L. Brown (Eds.), Advances in developmental psychology (Vol. 1, pp. 37-86). New York, NY: Guilford.

Ruff, H. A., \& Rothbart, M. K. (2001). Attention in early development: Themes and variations. Oxford University Press.

Rueda, F. J. M. (2010). Teste de Atenção Dividida (TEADI) e Teste de Atenção Alternada (TEALT). São Paulo, SP: Casa do Psicólogo.

Rueda, M. R., Posner, M. I., \& Rothbart, M. K. (2004). Attentional control and selfregulation. In R. F. Baumeister \& K. D. Vohs (Eds.), Handbook of selfregulation: Research, theory, and applications (pp. 283-300). New York, NY: Guilford.

Rugolo, L. M. S. S. (2005). Crescimento e desenvolvimento a longo prazo do prematuro extremo. Jornal de Pediatria, 81, 101-110. doi:10.1590/S002175572005000200013

Rugolo, L. M. S. S. (2012). Importância da monitorização do desenvolvimento em recém-nascidos prematuros. Revista Paulista de Pediatria, 30, 460-461. doi:10.1590/S0103-05822012000400001

Saigal, S., Pinelli, J., Hoult, L., Kim, M. M., \& Boyle, M. (2003a). Psychopathology and social competencies of adolescents who were extremely low birth weight. Pediatrics, 111, 969-975.

Saigal, S., den Ouden, L., Wolke, D., Hoult, L., Paneth, N., Streiner, D. L., ... \& PintoMartin, J. (2003b). School-age outcomes in children who were extremely low birth weight from four international population-based cohorts. Pediatrics, 112(4), 943-950.

Salt, A., \& Redshaw, M. (2006). Neurodevelopmental follow-up after preterm birth: Follow up after two years. Early Human Development, 82, 185-197. doi:10.1016/j.earlhumdev.2005.12.015

Samara, M., Marlow, N., Wolke, D., \& the Epicure Study Group. (2008). Pervasive behavior problems at 6 years of age in a total-population sample of children 
born at $<25$ weeks of gestation. Pediatrics, 122, 562-573. doi:10.1542/peds.2007-3231

Sameroff, A. J. (2000). Developmental systems and psychopathology. Developmental and Psychopathology, 297-312. doi:10.1017/S0954579400003035

Sameroff, A. J. (2009). Conceptual issues in studying the development of selfregulation. In S. L. Olson \& A. J. Sameroff (Eds.), Biopsychosocial regulatory processes in the development of childhood behavioral problems (pp. 1-18). New York, NY: Cambridge University Press.

Sameroff, A. J., \& Rosenblum, K. L. (2006). Psychosocial constraints on the development of resilience. Annals of New York Academy of Sciences, 1094, 116-124. doi:10.1196/annals.1376.010

Santos, R. R. G., Petresco, S., de Morais, B. G., Manzolli, P. P., Mota, D. M., \& Santos, N. (2014). Achados comportamentais e cognitivos em crianças de 5 a 11 anos nascidas com baixo peso. Revista da AMRIGS,58(3), 203-208.

Santoro Júnior, W., \& Martinez, F.E. (2007). Impacto de Intervenção Uma próaleitamento NAS taxas de amamentação de recém-Nascidos de Muito Baixo Peso. J. Pediatr. (Rio J.) , 83 (6), 541-546.

Sansavini, A., Pentimonti, J., Justice, L., Guarini, A., Savini, S., Alessandroni, R., \& Faldella, G. (2014). Language, motor and cognitive development of extremely preterm children: Modeling individual growth trajectories over the first three years of life. Journal of communication disorders, 49, 55-68.

Sapienza, G., \& Pedromônico, M. R. M. (2005). Risco, proteção e resiliência no desenvolvimento da criança e do adolescente. Psicologia em Estudo, 10, 209216. doi:10.1590/S1413-73722005000200007

Saur, A. M. (2012). Riscos biológicos e aspectos cognitivos, comportamentais e emocionais de uma coorte de escolares (Dissertação de doutorado). Faculdade de Filosofia Ciências e Letras de Ribeirão Preto. Universidade de São Paulo.

Scratch, S. E., Anderson, P. J., Doyle, L. W., Thompson, D. K., Ahmadzai, Z. M., Greaves, R. F., ... Hunt, R. W. (2015). High postnatal growth hormone levels are related to cognitive deficits in a group of children born very preterm. Journal of Clinical Endocrinology \& Metabolism. doi:10.1210/jc.2014-4342

Shepherd, R. B. (2002). Paralisia cerebral. In Fisioterapia em pediatria (3a ed., pp. 110-144), São Paulo, SP: Santos Livraria Editora.

Shum, D., Neulinger, K., O'Callaghan, M., \& Mohay, H. (2008). Attentional problems in children born very preterm or with extremely low birth weight at 7-9 years. Archives of Clinical Neuropsychology, 23, 103-112. doi:10.1016/j.acn.2007.08.006 
Serenius, F., Källén, K., Blennow, M., Ewald, U., Fellman, V., Holmström, G., ... EXPRESS Group. (2013). Neurodevelopmental outcome in extremely preterm infants at 2.5 years after active perinatal care in Sweden. Journal of the American Medical Association, 309, 1810-1820. doi:10.1001/ jama.2013.3786

Seitz, J., Jenni, O. G., Molinari, L., Caflisch, J., Largo, R. H., \& Latal, H. B. (2006). Correlations between motor performance and cognitive functions in children born< $1250 \mathrm{~g}$ at school age. Neuropediatrics, 37(1), 6-12. doi: 10,1055 / s2006-923840

Silva, E. S., \& Nunes, M. L. (2005). The influence of gestational age and birth weight in the clinical assessment of the muscle tone of healthy term and preterm newborns. Arquivos de Neuropsiquiatria, 63, 956-962. doi:10.1590/S0004$282 \times 2005000600010$

Silva, W. F., \& Guedes, Z. C. F. (2013). Tempo de aleitamento materno exclusivo em recém-nascidos prematuros e a termo. Revista CEFAC, 15(1), 160-171.

Silva, L. G., Araújo, R. T., \& Teixeira, M. A. (2012). O cuidado de enfermagem ao neonato pré-termo em unidade neonatal: Perspectiva de profissionais de enfermagem. Revista Eletrônica de Enfermagem, 14, 634-643. doi:10.5216/ree.v14i3.12531

Silveira, M. F., Santos, I. S., Barros, A. L., Matijasevich, A., Barros, F. C., \& Victora, C. G. (2008). Aumento da prematuridade no Brasil: Revisão de estudos de base populacional. Revista de Saúde Pública, 42, 957-964. doi:10.1590/S0034-89102008000500023

Silk, J. S., Vanderbilt-Adriance, E., Shaw, D. S., Forbes, E. E., Whalen, D. J., Ryan, N. D., \& Dahl, R. E. (2007). Resilience among children and adolescents at risk for depression: Mediation and moderation across social and neurobiological contexts. Development and Psychopathology, 19, 841-865. doi:10.1017/S0954579407000417

Silveira, K. A., \& Enumo, S. R. F. (2012). Riscos biopsicossociais para o desenvolvimento de crianças prematuras e com baixo peso. Paidéia, 22(53), 335-345. doi: 10.1590/1982-43272253201305

Skranes, J., Evensen, K. I., Løhaugen, G. C., Martinussen, M., Kulseng, S., Myhr, G., ... \& Brubakk, A. M. (2008). Abnormal cerebral MRI findings and neuroimpairments in very low birth weight (VLBW) adolescents. European Journal of Paediatric Neurology, 12(4), 273-283. doi: 10.1016/ j.ejpn.2007.08.008

Scott, M. N., Taylor, H. G., Fristad, M. A., Klein, N., Espy, K. A., Minich, N., \& Hack, M. (2012). Behavior disorders in extremely preterm/extremely low birth weight children in kindergarten. Journal of Developmental and Behavioral Pediatrics, 33(3), 202. oi: 10,1097 / DBP.0b013e3182475287. 
Soria-Pastor, S., Padilla, N., Zubiaurre-Elorza, L., Ibarretxe-Bilbao, N., Botet, F., Costas-Moragas, C., ... Junque, C. (2009). Decreased regional brain volume and cognitive impairment in preterm children at low risk. Pediatrics, 124, 11611170. doi:10.1542/peds.2009-0244

Sousa, A. C. C. D., Galende, D. C. H., \& Botelho, N. M. (2012). Prebalência de parto pré-termo eletivo e suas principais repercussôes neonatais. Rev. para. med, 26(1).

Spittle, A., Orton, J., Anderson, P., Boyd, R., \& Doyle, L. W. (2012). Early developmental intervention programmes post-hospital discharge to prevent motor and cognitive impairments in preterm infants. Cochrane Database of Systematic Reviews, 12, CD005495. doi:10.1002/14651858.CD005495.pub3

Spittle, A. J., Boyd, R. N., Inder, T. E., \& Doyle, L. W. (2009). Predicting motor development in very preterm infants at 12 months' corrected age: The role of qualitative magnetic resonance imaging and general movements assessments. Pediatrics, 123, 512-517. doi:10.1542/peds.2008-0590

Stoelhorst, G. M. S. J., Martens, S. E., Rijken, M., van Zwieten, P. H. T., Zwinderman, A. H., Wit, J. M., \& Veen, S. (2003). Behaviour at 2 years of age in very preterm infants (gestational age $>32$ weeks). Acta Pædiatrica, 92, 595-601. doi:10.1111/j.1651-2227.2003.tb02513.x

Stoelhorst, G. M. S. J., Rijken, M., Martens, S. E., Brand, R., Ouden, A. L., Wit, J. M., \& Veen, S. (2005). Changes in neonatology: Comparison of two cohorts of very preterm infants (gestational age $<32$ weeks): The project on preterm and small for gestational age infants 1983 and the Leiden follow-up project on prematurity. Pediatrics, 115, 396-405. doi:10.1542/peds.2004-1497

Stoelhorst, G. M. S. J., Rijken, M., Martens, S. E., Van Zwieten, P. H., Feenstra, J., Zwinderman, A. H., ... Veen, S. (2003). Developmental outcome at 18 and 24 months of age in very preterm children: A cohort study from 1996 to 1997. Early Human Development, 72, 83-95. doi:10.1016/S0378-3782(03)00011-2

Sullivan, M. C., \& McGrath, M. M. (2003). Perinatal morbidity, mild motor delay, and later school outcomes. Developmental Medicine \& Child Neurology, 45, 104112. doi:10.1111 / j.1469-8749.2003.tb00913.x

Tavares J. (2001). A resiliência na sociedade emergente. In J. Tavares (Org.), Resiliência e educação (2a ed., pp. 43-75). São Paulo, SP: Cortez.

Tavares, L. A. M (2009). Declaração universal dos direitos do bebê prematuro. Recuperado http://www.psicnet.psc.br/v2/site/temas/temas_default.asp?ID=1841

Taylor, H. G., Klein, N., \& Hack, M. (2000). School-age consequences of birth weight less than 750g: A review and update. Developmental Neuropsychology, 17, 289-321. 
Taylor, H. G., Minich, N., Bangert, B., Filipek, P. A., \& Hack, M. (2004). Long-term neuropsychological outcomes of very low birth weight: associations with early risks for periventricular brain insults. Journal of the International Neuropsychological doi.org/10.1017/S1355617704107078

987-1004.

Taylor, HG, Margevicius, S., Schluchter, M., Andreias, L., \& Hack, M. (2015). Persistindo problemas de comportamento em Extremely Low Nascimento Adolescentes Peso. Journal of Developmental \& Behavioral Pediatrics, 36 (3), 178-187. doi: 10,1097 / DBP.0000000000000139

Treyvaud, K., Doyle, L. W., Lee, K. J., Roberts, G., Lim, J., Inder, T. E., \& Anderson, P. J. (2012). Social-emotional difficulties in very preterm and term 2 year olds predict specific social-emotional problems at the age of 5 years. Journal of pediatric psychology, jss042. doi: 10.1093 / jpepsy / jss042

Valeri, B. O., Holsti, L., \& Linhares, M. B. M. (2015). Neonatal pain and developmental outcomes in children born preterm: A systematic review. Clinical Journal of Pain, 31(4), 355-362. doi:10.1097/AJP.0000000000000114

Van de Weijer-Bergsma, E., Wijnroks, L., \& Jongmans, M. J. (2008). Attention development in infants and preschool children born preterm: A review. Infant Behavior and Development, 31, 333-351. doi:10.1016/j.infbeh.2007.12.003

Vanderbilt, D., \& Gleason, M. M. (2011). Mental health concerns of the premature infant through the lifespan. Pediatric Clinics of North America,58(4), 815-832. doi: 10.1016 / j.pcl.2011.06.012

Vederhus, B. J., Eide, G. E., Natvig, G. K., Markestad, T., Graue, M., \& Halvorsen, T. (2015). Health-related quality of life and emotional and behavioral difficulties after extreme preterm birth: developmental trajectories. PeerJ, 3, e738.

Verkerk, G., Jeukens-Visser, M., Houtzager, B., Wassenaer-Leemhuis, A. V., Koldewijn, K., Nollet, F., \& Kok, J. (2015). Attention in 3-Year-Old Children with VLBW and Relationships with Early School Outcomes. Physical \& occupational therapy in pediatrics. doi: 10,3109 / 01942638.2015.1012319

Vieira, M. E. B., \& Linhares, M. B. M. (2011). Desenvolvimento e qualidade de vida em crianças nascidas pré-termo em idades pré-escolar e escolar. Jornal de Pediatria, 87(4), 281-91. doi:10.2223/JPED.2096

Viberg, H., Pontén, E., Eriksson, P., Gordh, T., \& Fredriksson, A. (2008). Neonatal ketamine exposure results in changes in biochemical substrates of neuronal growth and synaptogenesis, and alters adult behavior irreversibly. Toxicology, 249(2), 153-159. doi: 10.1016 / j.tox.2008.04.019

Voigt, B., Pietz, J., Pauen, S., Kliegel, M., \& Reuner, G. (2012). Cognitive development in very vs. moderately to late preterm and full-term children: Can effortful control account for group differences in toddlerhood? Early Human Development, 88, 307-313. doi:10.1016 / j.earlhumdev.2011.09.001 
Volpe, J. J. (2009). Brain injury in premature infants: A complex amalgam of destructive and developmental disturbances. The Lancet Neurology, 8, 110124. doi:10.1016/S1474-4422(08)70294-1

Vygotsky, L. S. (2001). A construção do pensamento e da linguagem. Tradução Paulo Bezerra. São Paulo: Martins Fontes, 2001. (Psicologia e pedagogia).

Wachtel, E. V., Zaccario, M., \& Mally, P. (2015). Impact of Respiratory Morbidities on Neurodevelopmental Outcome of Late Preterm Infants.American journal of perinatology. doi: 10,1055 / s-0035-1551673

Wagner, C. J. P. (2003). Atenção visual em crianças e adolescentes: Um estudo a partir do paradigma do tempo de reação (Dissertação de mestrado não publicada). Universidade Federal do Rio Grande do Sul, Porto Alegre, RS.

Weiss, S. J., Jonn-Seed, M. S., \& Wilson, P. (2004). The temperament of pre-term, low birth weight infants and its potential biological substrates. Research in Nursing \& Health, 27, 392-402. doi:10.1002/nur.20038

Wechesler, D. (2002). Escala de Inteligência Wechesler para crianças: Manual (3a ed.). São Paulo, SP: Casa do Psicólogo.

Weindrich, D., Laucht, M., \& Schmidt, M. H. (2003). Late sequelae of low birth weight: mediators of poor school performance at 11 years. Developmental Medicine \& Child Neurology, 45(7), 463-469. doi: 10,1111 / j.14698749.2003.tb00941.x

Woerner, W., Fleitlich-Bilyk, B., Martinussen, R., Fletcher, J., Cucchiaro, G., Dalgalarrondo, P., ... \& Tannock, R. (2004). The Strengths and Difficulties Questionnaire overseas: evaluations and applications of the SDQ beyond Europe. European Child \& Adolescent Psychiatry, 13(2), ii47-ii54. doi: 10,1007 / s00787-004-2008-0

Woodward, L. J., Moor, S., Hood, K. M., Champion, P. R., Foster-Cohen, S., Inder, T. E., \& Austin, N. C. (2009). Very preterm children show impairments across multiple neurodevelopmental domains by age 4 years. Archives of Disease in Childhood. Fetal and Neonatal Edition, 94, e339-344.

World Health Organization. (2009). Global health risk: Mortality and burden of disease attributable to selected major risks. Recuperado de http://www.who.int/healthinfo/global_burden_diseae/GlobalHealthRisks_report_f ull.pdf

World Health Organization. (2012). Born too soon: The global action report on

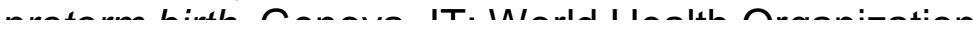

Yu, J. W., Buka, S. L., McCormick, M. C., Fitzmaurice, G. M., \& Indurkhya, A. (2006). Behavioral problems and the effects of early intervention on eight-year-old 
children with learning disabilities. Maternal and Child Health Journal, 10, 329338. doi:10.1007/s10995-005-0066-7

Yunes, M. A., \& Szymanski, H. (2001). Resiliência: Noção, conceitos afins e considerações críticas. In J. Tavares (Org.), Resiliência e educação (2a ed., pp. 13-42). São Paulo, SP: Cortez.

Zomignani, A. P., Zambelli, H. J. L., \& Antonio, M. A. R. G. M. (2009). Desenvolvimento cerebral em recém-nascidos prematuros. Revista Paulista de Pediatria, 27, 198-203. doi:10.1590/S0103-05822009000200013 


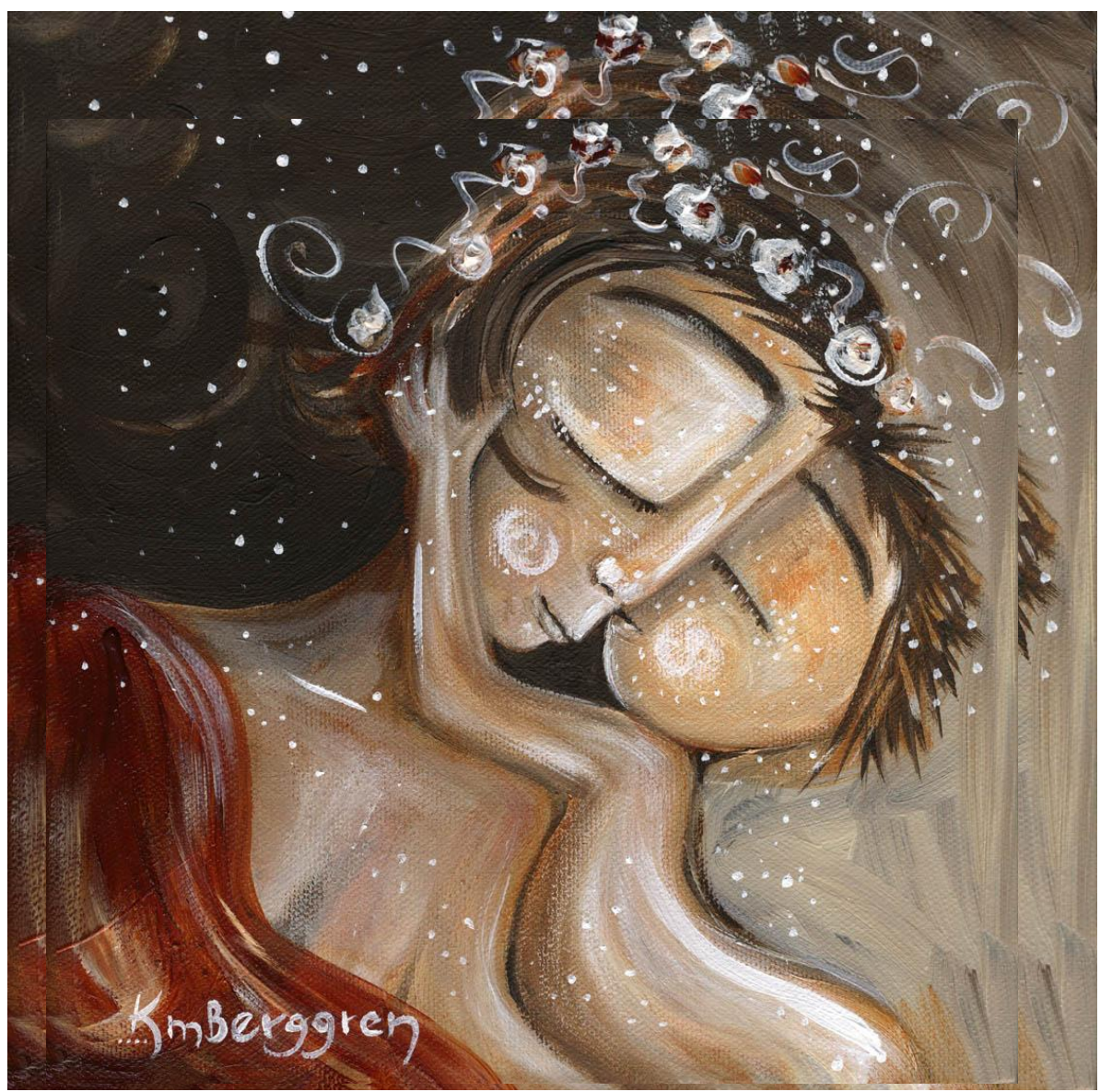

Artigo IX - Nenhum prematuro deverá, sob qualquer justificativa, ser submetido a procedimento estressante aplicado de forma displicente e injustificada pela Equipe de Saúde, sob pena da mesma ser considerada negligente, desumana e irresponsável (Tavares, 2009). 
APÊNDICE A - Termo de Consentimento Livre e Esclarecido

1. TíTULO DO PROJETO: "Comportamento, temperamento e sistema de atenção em crianças nascidas prematuras em idade escolar".

\section{OBJETIVOS}

O presente estudo tem por objetivo geral examinar a relação entre o comportamento, cognição, temperamento e o processo de atenção em 50 crianças nascidas prétermo $(\leq 37$ semanas) de muito baixo peso $(\leq 1.500 \mathrm{~g})$, em idade escolar.

\section{PROCEDIMENTOS}

Inicialmente será realizado contato com a mãe/ responsável será agendado um horário para avaliação. Primeiramente será realizada explicação sobre os objetivos da pesquisa, leitura do mesmo, assinatura do termo de consentimento livre e esclarecido e entrevista com a mãe. E em um segundo momento será realizada a avaliação da criança. Na $2^{\underline{a}}$ sessão será oferecida uma devolutiva, a fim de comunicar a mãe sobre os resultados das avaliações realizadas.

\section{DESCONFORTOS E RISCOS ESPERADOS}

Não haverá desconforto ou risco para os bebês nem para as mães durante o procedimento de avaliação.

\section{BENEFÍCIOS}

Os benefícios para as crianças e suas famílias serão decorrentes do nosso maior conhecimento sobre como fatores ambientais e fatores constitucionais atuam na trajetória de desenvolvimento psicológico da criança. Este conhecimento poderá subsidiar intervenções preventivas para o grupo de crianças nascidas pré-termo.

\section{GARANTIA DE ACESSO}

Em qualquer etapa do estudo, o responsável legal pelo paciente terá acesso aos profissionais responsáveis pela pesquisa, para esclarecimento de eventuais dúvidas. Os pesquisadores principais responsáveis pelo projeto são a psicóloga e Doutoranda Fabíola Dantas A. Nobre A. de Carvalho, do Departamento de Neurociências e Ciências do Comportamento e a psicóloga Profa ${ }^{\mathrm{a}}$. Dra. Maria Beatriz Martins Linhares, do Departamento de Neurociências e Ciências do Comportamento, que podem ser encontradas na Avenida Tenente Catão Roxo, 2650, telefone 36024610. Se houver alguma consideração ou dúvida sobre a ética da pesquisa, entre em contato com o Comitê de Ética do Hospital das Clínicas da Faculdade de Medicina de Ribeirão Preto - USP. 


\section{LIBERDADE DE RETIRAR O CONSENTIMENTO}

É garantida a liberdade da retirada de consentimento a qualquer momento, deixando de participar do estudo, sem prejuízo direto à continuidade de seu tratamento no hospital.

\section{DIREITO DE CONFIDENCIALIDADE}

As informações obtidas serão analisadas em conjunto com a de outros pacientes, não sendo divulgada a identificação de nenhum paciente, salvo os pesquisadores responsáveis envolvidos no projeto e seus colaboradores de pesquisa.

\section{COMPROMISSO DE ATUALIZAR A INFORMAÇÃO}

$O$ representante legal do paciente tem o direito de ser mantido atualizado sobre os resultados parciais da pesquisa.

\section{DESPESAS E COMPENSAÇÕES}

Não há despesas pessoais para os participantes, em qualquer fase do estudo. Os gastos adicionais relacionados à participação na pesquisa, como por exemplo, transporte e alimentação, serão ressarcidos. Também não há compensação financeira relacionada à sua participação. Se existir qualquer despesa adicional, ela será absorvida pelo orçamento da pesquisa.

\section{DANOS PESSOAIS}

Em caso de dano pessoal, diretamente causado pelos procedimentos ou tratamentos propostos neste estudo (nexo causal comprovado), o participante tem direito a tratamento médico na instituição HCFMRP-USP. Deve-se salientar que o estudo não inclui nenhum tratamento.

\section{COMPROMISSO DO PESQUISADOR}

O pesquisador se compromete a utilizar os dados e o material coletado apenas para esta pesquisa e divulgações acadêmicas científicas relacionadas.

Acredito ter sido suficientemente informado a respeito das informações que li ou que foram lidas para mim, descrevendo o estudo "Comportamento, temperamento e sistema de atenção em crianças nascidas prematuras em idade escolar".

Ficaram claros, para mim os propósitos do estudo, os procedimentos a serem realizados, seus desconfortos e riscos, as garantias de confidencialidade e de esclarecimentos permanentes.

Ficou claro também que minha participação é isenta de despesas e que tenho garantia de acesso a tratamento hospitalar se necessário.

Concordo, voluntariamente, em participar deste estudo, estando ciente de que poderei retirar meu consentimento a qualquer momento, antes ou durante o mesmo, 
sem penalidades, prejuízo ou perda de qualquer benefício que possa ter adquirido, ou no atendimento neste serviço.

Assinatura do representante legal do paciente

Data

Declaro que obtive de forma apropriada e voluntária o Consentimento Livre e Esclarecido desse representante legal, para participação nesse estudo.

Assinatura do representante legal do paciente

Assinatura do pesquisador do estudo

$\overline{\text { Data }}$

Data

\section{TERMO DE CONSENTIMENTO LIVRE E ESCLARECIDO}

$\mathrm{Eu}$, , responsável pelo menor declaro ter lido a carta de

informação a respeito do projeto "Comportamento, temperamento e sistema de atenção em crianças nascidas prematuras em idade escolar.

Estou esclarecido (a) a respeito do estudo proposto, sem dúvidas, e autorizo a realização do procedimento conforme descrito. Fui informado (a) que posso negarme a participar do estudo ou dele retirar-me quando julgar conveniente, sem que haja qualquer prejuízo.

Ribeirão Preto, de de 20

\section{Assinatura do responsável}

Parentesco com o paciente

$R G$ : 
APENDICE B- Ficha sobre a história da criança

\section{DADOS DE IDENTIFICAÇÃO}

Nome da Criança: RGHC:

Sexo:

Data de Nascimento:

Idade:

Nome da mãe:

Idade:__ Nível de escolaridade: Ocupação:

Nome do pai:

Idade:

Nível de escolaridade:

Ocupação:

Situação conjugal: ( ) solteiro ( ) casado ( ) união consensual ( ) divorciado ( ) separado ( ) viúvo

\section{CONCEPÇÃO DA CRIANÇA}

Foi planejada? ( ) sim ( ) Não Fez pré-natal ? ( ) sim ( ) Não № de consultas Número de gestações:

Número de parto:

Número

de abortos: Número de filhos nascidos vivos: Número de filhos natimortos: Número de filhos falecidos: Posição da criança quanto a ordem de nascimento:___Posição na ordem da gestações:

Tipo de parto: ( ) Normal ( ) Cesárea eletiva ( ) Cesárea não eletiva ( ) Fórceps

\section{CONDIÇÃO AMBIENTAL/ SOCIAL}

Tipo de moradia: ( ) própria ( ) alugada ( ) emprestada Condições de saneamento básico: ( ) luz ( ) água encanada ( ) esgoto ( ) asfalto NN. de cômodos da casa: Quarto Sala Cozinha Banheiro

Número de cômodos da casa: Número de pessoas residente na casa:

Endereço:

Fone: ( ) Cidade: Bairro: 
APENDICE C- Dados do prontuário do paciente no HCFMRP-USP

\section{DADOS DE IDENTIFICAÇÃO}

Nome da Criança: RGHC:

Sexo:

Data de Nascimento: Idade:

Nome da mãe:

Idade:

Nível de escolaridade:

Ocupação:

Nome do pai:

Idade: Nível de escolaridade:

Ocupação:

\section{VARIÁVEIS NEONATAIS}

peso ao nascimento (gramas): PIG ( ) AIG（） GIG（）

idade gestacional (semanas):__ Tempo de internação na UTIN:_ Tempo de internação total:

Alimentação:

Aleitamento materno ( ) Artificial ( ) Misto ( ) Período:

CRIB (Clinical Risk Index for Babies) (Cockburn et al, 1993): Apgar do $5^{\circ}$ minuto:

\section{HISTÓRIA DE SAÚdE EVOLUÇÃo CLÍNICA DO BEBÊ DURANTE A HOSPITALIZAÇÃO}

anemia ( ) anóxia ( ) apnéia de repetição ( ) cardiopatia ( ) convulsão ( ) displasia broncapulmonar ( ) desconforto reparatório precoce ( ) distúrbio de coagulação ( ) doença pulmonar crônica ( ) enterocolite negrotizante ( ) hemorragia intracraniana graus I ( ) II ( ) III ( ) IV ( ) outras hemorragias ( ) hiperbilirrubinemia ( ) hipertensão pulmonar ( ) hipoglicemia ( ) insuficiência respiratória aguda ( ) pneumotórax ( ) retinopatia da prematuriade ( ) septicemia ( ) síndrome da aspiração mecônica ( ) síndrome da membrana hialina ( )

\section{TRATAMENTOS}

Fototerapia ( ) transfusão de sangue ( ) nutrição parenteral ( ) antibióticoterapia ( ) surfactante ( ) ventilação mecânica ( ) corticoterapia ( ) cirurgia cardíaca ( ) cirurgia neurológica ( ) cirurgia gastro-intestinal ( ) 


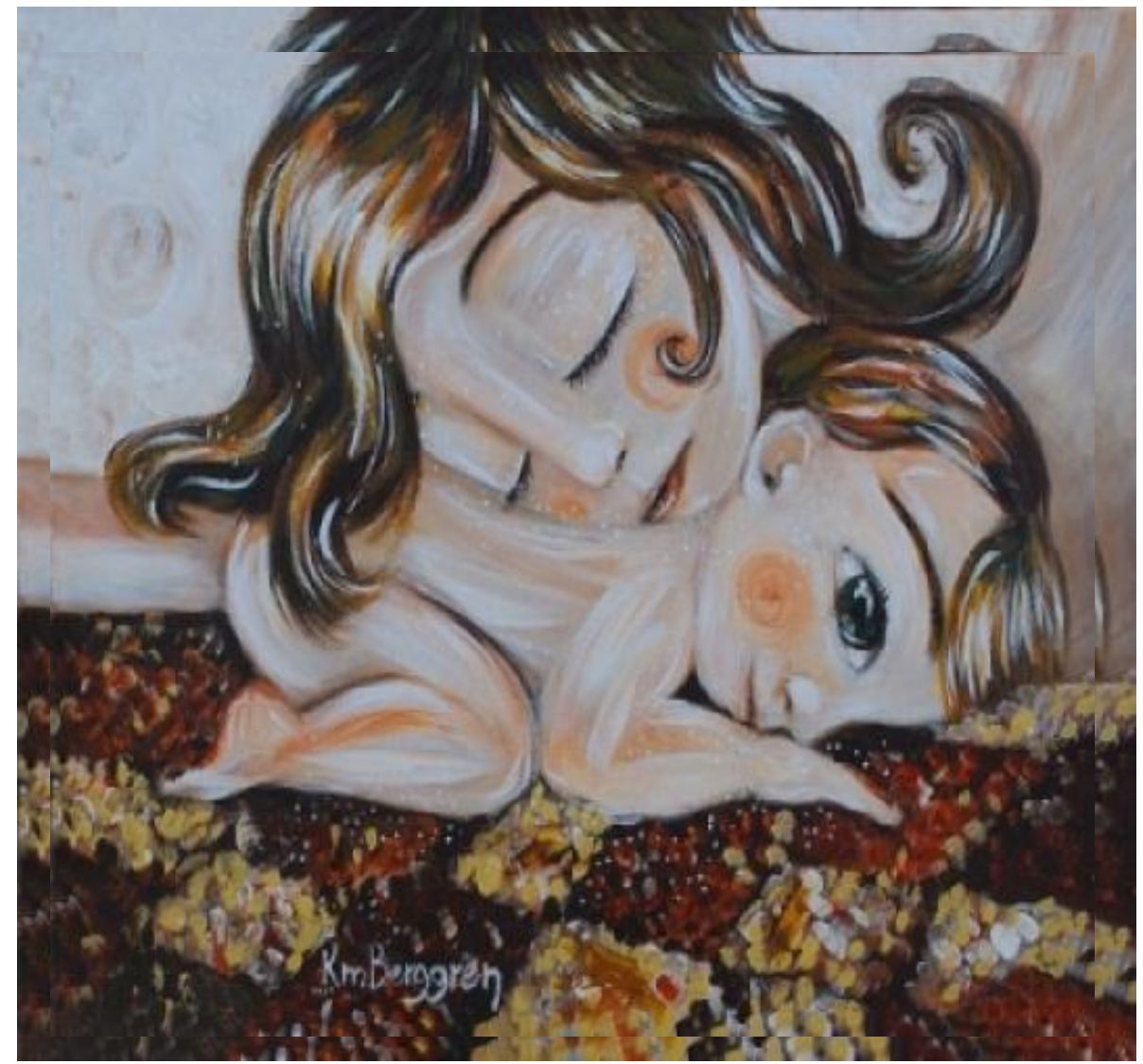

Artigo X - Todo prematuro tem direito a perceber a alternância entre a claridade e a penumbra, que passarão a representar para ele a noite e o dia. Nenhuma luz intensa permanecerá o tempo inteiro acesa e nenhuma sombra será impedida de existir sob a alegação de monitorização continua sem que os responsáveis por estes comportamentos deixem de ser considerados displicentes, agressores e de atitude dolosa (Tavares, 2009). 
ANEXO A- Aprovação do Comitê de Ética em Pesquisa do HC-FMRP-USP

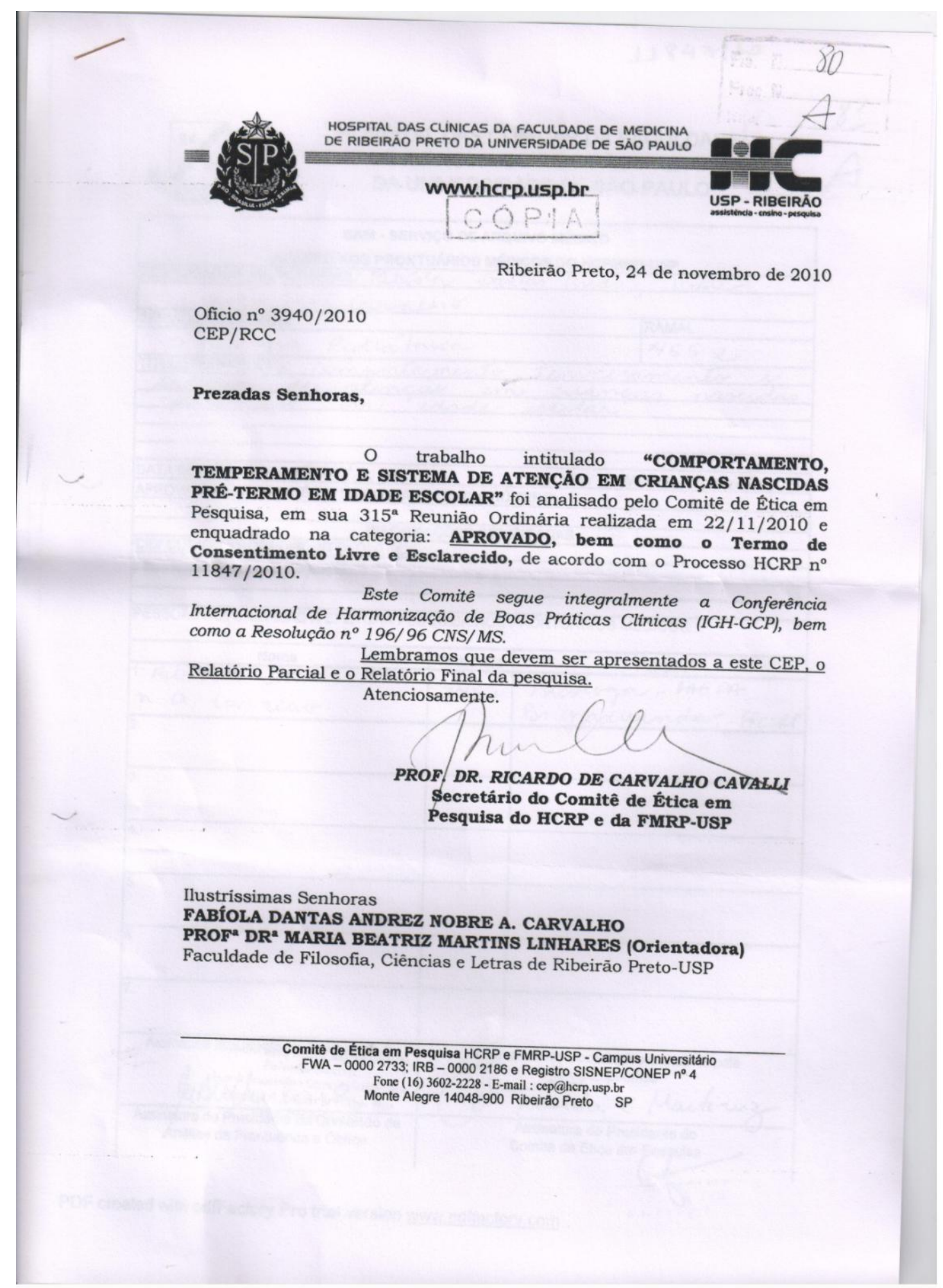


ANEXO B- Questionário de capacidades e dificuldades (SDQ)

Instruções: Por favor, em cada item marque com uma cruz o quadrado que melhor descreva a criança. Responda a todas as perguntas da melhor maneira possível, mesmo que você não tenha certeza absoluta ou se a pergunta lhe parecer estranha. Dê suas respostas com base no comportamento da criança nos últimos seis meses.

Nome criança:

Data nascimento:

Masc $\square$ Fem

Questionário preenchido por:

\begin{tabular}{|c|c|c|c|c|}
\hline Escala & Perguntas & Falso & \begin{tabular}{c|} 
Mais ou \\
menos \\
verdadeiro
\end{tabular} & Verdadeiro \\
\hline PS & $\begin{array}{l}\text { Tem consideração pelos sentimentos de outras } \\
\text { pessoas. }\end{array}$ & 0 & 1 & 2 \\
\hline $\mathrm{H}$ & $\begin{array}{l}\text { Não consegue parar sentado quando tem que fazer } \\
\text { a lição ou comer; mexe-se muito, esbarrando em } \\
\text { coisas, derrubando coisas. }\end{array}$ & 0 & 1 & 2 \\
\hline SE & $\begin{array}{l}\text { Muitas vezes se queixa de dor de cabeça, dor de } \\
\text { barriga ou enjoo. }\end{array}$ & 0 & 1 & 2 \\
\hline PS & $\begin{array}{l}\text { Tem boa vontade em compartilhar doces, } \\
\text { brinquedos, lápis... com outras crianças. }\end{array}$ & 0 & 1 & 2 \\
\hline PC & $\begin{array}{l}\text { Frequentemente tem acessos de raiva ou crises de } \\
\text { birra. }\end{array}$ & 0 & 1 & 2 \\
\hline $\mathrm{R}$ & É solitário, prefere brincar sozinho. & 0 & 1 & 2 \\
\hline PC & $\begin{array}{l}\text { Geralmente é obediente e faz normalmente o que } \\
\text { os adultos lhe pedem. }\end{array}$ & 2 & 1 & 0 \\
\hline SE & $\begin{array}{l}\text { Tem muitas preocupações, muitas vezes parece } \\
\text { preocupado com tudo. }\end{array}$ & 0 & 1 & 2 \\
\hline PS & $\begin{array}{l}\text { Tenta ser atencioso se alguém parece magoado, } \\
\text { aflito ou se sentindo mal. }\end{array}$ & 0 & 1 & 2 \\
\hline $\mathrm{H}$ & $\begin{array}{l}\text { Está sempre agitado, balançando as pernas ou } \\
\text { mexendo as mãos. }\end{array}$ & 0 & 1 & 2 \\
\hline $\mathrm{R}$ & Tem pelo menos um bom amigo ou amiga. & 2 & 1 & 0 \\
\hline PC & $\begin{array}{l}\text { Frequentemente briga com outras crianças ou as } \\
\text { amedronta. }\end{array}$ & 0 & 1 & 2 \\
\hline SE & $\begin{array}{l}\text { Frequentemente parece triste, desanimado ou } \\
\text { choroso. }\end{array}$ & 0 & 1 & 2 \\
\hline
\end{tabular}




\begin{tabular}{|c|l|c|c|c|}
\hline $\mathrm{R}$ & Em geral, é querido por outras crianças. & 2 & 1 & 0 \\
\hline $\mathrm{H}$ & Facilmente perde a concentração. & 0 & 1 & 2 \\
\hline $\mathrm{SE}$ & $\begin{array}{l}\text { Fica inseguro quanto tem que fazer alguma coisa } \\
\text { pela primeira vez, facilmente perde a confiança em } \\
\text { si mesmo. }\end{array}$ & 0 & 1 & 2 \\
\hline $\mathrm{PS}$ & É gentil com crianças mais novas. & 0 & 1 & 2 \\
\hline $\mathrm{PC}$ & Frequentemente engana ou mente. & 0 & 1 & 2 \\
\hline $\mathrm{R}$ & Outras crianças "pegam no pé" ou atormentam-no. & 0 & 1 & 2 \\
\hline $\mathrm{PS}$ & $\begin{array}{l}\text { Frequentemente se oferece para ajudar outras } \\
\text { pessoas (pais, professores, outras crianças). }\end{array}$ & 0 & 1 & 2 \\
\hline $\mathrm{H}$ & Pensa nas coisas antes de fazê-las. & 2 & 1 & 2 \\
\hline $\mathrm{PC}$ & $\begin{array}{l}\text { Rouba coisas de casa, da escola ou de outros } \\
\text { lugares. }\end{array}$ & 0 & 1 & 2 \\
\hline $\mathrm{R}$ & $\begin{array}{l}\text { Dá-se melhor com adultos do que com outras } \\
\text { crianças. }\end{array}$ & 0 & 1 & 2 \\
\hline SE & Tem muitos medos, assusta-se facilmente. & 0 & 1 & 0 \\
\hline H & $\begin{array}{l}\text { Completa as tarefas que começa, tem boa } \\
\text { concentração. }\end{array}$ & 2 & 1 & 2 \\
\hline
\end{tabular}

Você tem algum outro comentário ou preocupações? Descreva-os abaixo.

Pensando no que acabou de responder, você acha que seu filho/a tem alguma dificuldade? Pode ser uma dificuldade emocional, de comportamento, pouca concentração ou para se dar bem com outras pessoas.

Não $\square$ Sim: pequenas dificuldades $\square$ dificuldades bem definidas $\square$ dificuldades graves $\square$

Se você respondeu "sim", por favor, responda às seguintes questões sobre estas dificuldades:

Há quanto tempo estas dificuldades existem?

$$
\text { Menos de } 1 \text { mês } \square \quad 1-5 \text { meses } \square \quad 6 \text {-12 meses } \square \quad \text { Mais de } 1 \text { ano } \square
$$

Estas dificuldades incomodam ou aborrecem seu filho/a?

$$
\text { Nada } \square \quad \text { Um pouco } \square \quad \text { Muito } \square \quad \text { Mais que muito } \square
$$
abaixo?

Estas dificuldades atrapalham o dia-a-dia do seu filho/a em alguma das situações

\begin{tabular}{l|c|c|c|c}
\hline & Nada & Um pouco & Muito & Mais que muito \\
\hline Dia-a-dia em casa & $\square$ & $\square$ & $\square$ & $\square$ \\
\hline
\end{tabular}




\begin{tabular}{l|c|c|c|c}
\hline Amizades & $\square$ & $\square$ & $\square$ & $\square$ \\
\hline Aprendizado escolar & $\square$ & $\square$ & $\square$ & $\square$ \\
\hline $\begin{array}{l}\text { Atividades de lazer } \\
\text { (passeios, esportes, etc) }\end{array}$ & $\square$ & $\square$ & $\square$ & $\square$ \\
\hline
\end{tabular}

Estas dificuldades são um peso para você ou para a família como um todo?
( ) Nada $\square$
( ) Um pouco
Muito
Mais que muito

INTERPRETAÇÃO DOS RESULTADOS

\begin{tabular}{|c|l|c|c|c|c|}
\hline & \multicolumn{1}{|c|}{ ESCALAS } & TOTAL & $\begin{array}{c}\text { NORMA } \\
\text { L }\end{array}$ & LIMÍTROFE & ANORMAL \\
\hline PS & lomportamento pró-social & & $6-10$ & 5 & $0-4$ \\
\hline H & Hiperatividade & & $0-5$ & 6 & $7-10$ \\
\hline SE & Sintomas Emocionais & & $0-3$ & 4 & $5-10$ \\
\hline PC & Problemas de conduta & & $0-2$ & 3 & $4-10$ \\
\hline R & $\begin{array}{l}\text { Problemas de relacionamento com } \\
\text { colegas }\end{array}$ & $0-2$ & 3 & $4-10$ \\
\hline T & Pontuação Total da criança & & $0-13$ & $14-16$ & $17-40$ \\
\hline
\end{tabular}

PONTUAÇÃO DO SUPLEMENTO DE IMPACTO

\begin{tabular}{|l|c|c|c|c|}
\hline \multicolumn{1}{|c|}{ AVALIAÇÃO DOS PAIS } & Nada & Um pouco & Muito & $\begin{array}{c}\text { Mais que } \\
\text { muito }\end{array}$ \\
\hline Dificuldades incomodam ou aborrecem a criança & 0 & 0 & 1 & 2 \\
\hline Interferem no dia-a-dia em casa & 0 & 0 & 1 & 2 \\
\hline Interferem nas amizades & 0 & 0 & 1 & 2 \\
\hline Interferem no aprendizado escolar & 0 & 0 & 1 & 2 \\
\hline Interferem nas atividades de lazer & 0 & 0 & 1 & 2 \\
\hline
\end{tabular}

TOTAL

\begin{tabular}{|c|c|c|}
\hline NORMAL & LIMÍTROFE & ANORMAL \\
\hline 0 & 1 & 2 ou mais \\
\hline
\end{tabular}


ANEXO C - Critério de classificação econômica Brasil (ABEP, 2012)
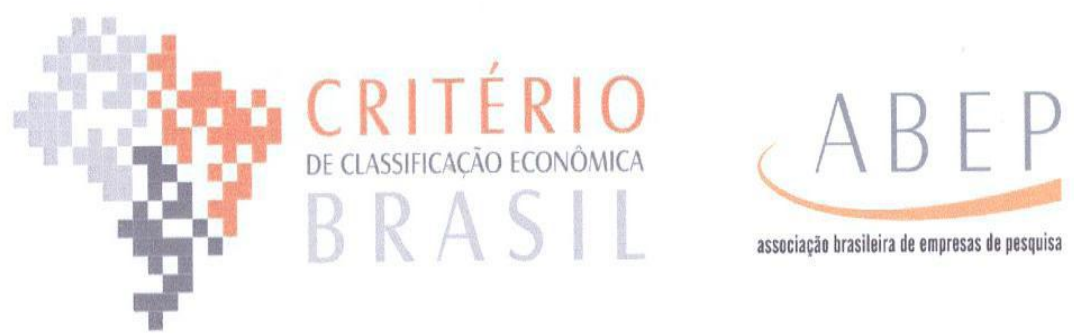

associaçăo brasileira de empresas ue pesquisa

O Critério de Classificação Econômica Brasil, enfatiza sua função de estimar o poder de compra das pessoas e famílias urbanas, abandonando a pretensão de classificar a população em termos de "classes sociais". A divisão de mercado definida abaixo é de classes econômicas.

\section{SISTEMA DE PONTOS}

\section{Posse de itens}

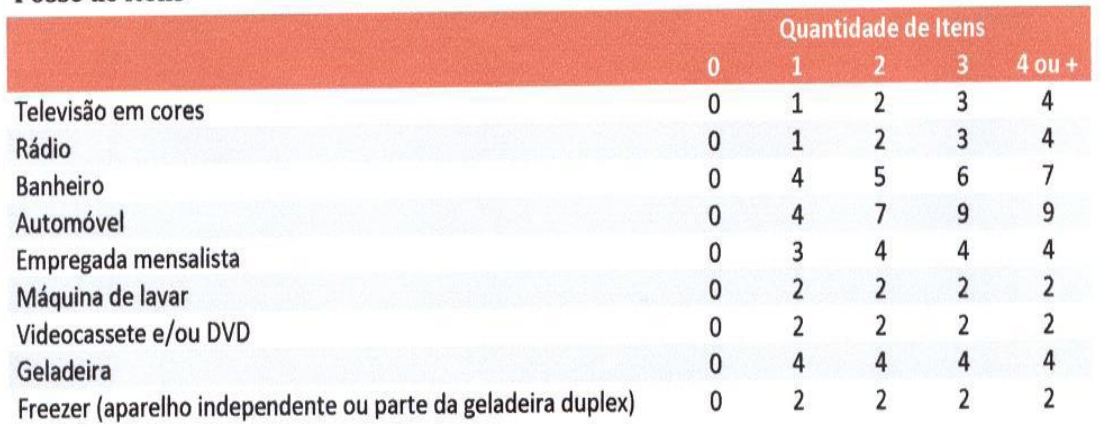

Grau de Instrução do chefe de família

Analfabeto / Primário incompleto

Primário completo / Ginasial incompleto

Ginasial completo / Colegial incompleto

Colegial completo / Superior incompleto

Superior completo
Analfabeto / Até $3^{\circ}$. Série Fundamental 0

Até $4^{2}$. Série Fundamental 1

Fundamental completo 2

Médio completo 4

Superior completo $\quad 8$

\section{CORTES DO CRITÉRIO BRASIL}

\begin{tabular}{|ll|}
\hline Classe & Pontos \\
\hline A1 & $42-46$ \\
A2 & $35-41$ \\
B1 & $29-34$ \\
B2 & $23-28$ \\
C1 & $18-22$ \\
C2 & $14-17$ \\
D & $8-13$ \\
E & $0-7$ \\
\hline
\end{tabular}

